\title{
GENERATIONAL STATUS, SOCIAL CAPITAL AND FAMILY ENGAGEMENT IN IMMIGRANT FAMILIES
}

A Dissertation presented to

the Faculty of the Graduate School

at the University of Missouri-Columbia

\begin{tabular}{l} 
In Partial Fulfillment \\
of the Requirements for \\
the Degree Doctor of Philosophy \\
\hline
\end{tabular}

by JINMYUNG CHOI

Dr. Lisa Dorner, Dissertation Supervisor

July 2021 
The undersigned, appointed by the dean of the Graduate School, have examined the dissertation entitled

\section{GENERATIONAL STATUS, SOCIAL CAPITAL AND FAMILY ENGAGEMENT}

\section{IN IMMIGRANT FAMILIES}

Presented by Jinmyung Choi,

A candidate for the degree of doctor of philosophy,

and hereby certify that, in their opinion, it is worthy of acceptance.

Professor Lisa Dorner, Advisor

Professor James Sebastian

Professor Emily Crawford-Rossi,

Professor Stephanie Potochnick 


\section{Dedication}

To my husband Jin Mun and dear daughter Yoonjin for your constant love and support. 


\section{Acknowledgments}

During my doctoral program, I have met wonderful people whose support and love made this journey possible. First of all, I would like to express my deepest appreciation to my advisor Dr. Lisa Dorner. Dr. Dorner has been an ideal teacher, mentor, and advisor. She gave me valuable guidance and advice. I am sure that they were of great help not only to my academic development, but also to my life. I am very proud of, and grateful for being with Dr. Dorner in this journey. I am also deeply indebted to Dr. James Sebastian. His expertise in methodology, structural equation modeling, helped me to conduct rigorous empirical tests in my dissertation. Learning a new statistical methodology was very challenging but having such an expert to guide me through the process certainly made it much easier. I would also like to extend my gratitude to Dr. Emily Crawford-Rossi who gave me insightful feedback for my dissertation as well as emotional support and encouragement during my doctoral program. I am also grateful to Dr. Stephanie Potochnick for her feedback and for conceptualizing my work into new avenues during my defense.

I also would like to give my special thanks to my ELPA friends: Ohm, JeongMi, Laura, Isabel, Dena, Luca, Jason, and Sujin who provided me with huge emotional support. I must extend a special thanks to Ohm, I am unbelievably fortunate to have you in this journey. Special thanks to Jeong-Mi for being a cheering and supportive dissertation writing buddy. I also would like to express my sincere thanks to Jan and Rob who met in Columbia. Jan, I will never forget your kindness and love.

Finally, I owe a great debt of gratitude to my family. Special thanks to my parents Bukjin Choi and Kyunghwa Son. Thank you for believing in me. Dad, you are the greatest teacher of my life. Mom, without your support and love, I could not have 
made it. My sister Jinhwa (and Hwon) and brother Kangbo, thank you for all of your love and encouragement. I also would like to express my deepest gratitude to parentsin-law for their support and love. Last, but most definitely not least, I would like to express my deepest love to my husband Jin Mun and daughter Yoonjin. Jin Mun, I am not sure what I would do without your amazing support. Thank you for being my best friend, and for being a caring and trustworthy partner, and for making me a better person through your presence in my life. 


\section{Table of Contents}

Acknowledgments....................................................

List of Figures.......................................................

List of Tables.............................................................. vii

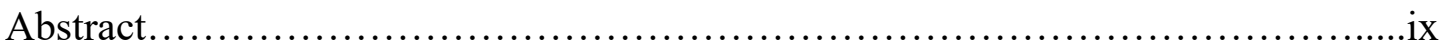

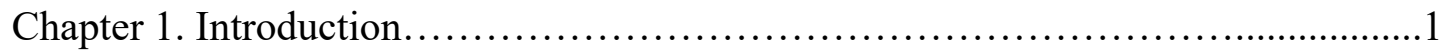

Statement of the Problem............................................. 2

Purpose of the Study...........................................6

Theoretical Framework: Social Capital.....................................

Research Question and Hypotheses.....................................8

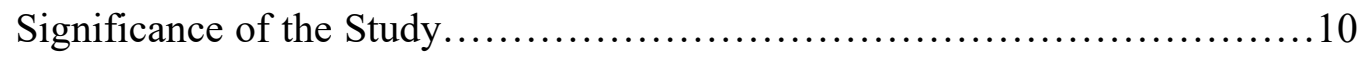

Definitions of Key terms........................................... 12

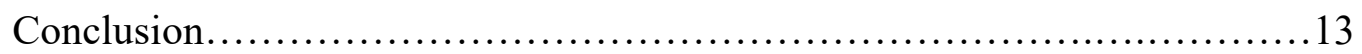

Chapter 2. Literature Review and Theoretical Framework.......................15

Family Engagement Research in General................................. 15

Frameworks for Family Engagement................................... 16

Policies to Encourage Family Engagement..............................20

Effects of Family Engagement on Children's Educational Success.............12

Immigrant Family Engagement......................................25

Family Engagement of Immigrants: An Introduction.......................25

Strengths and Barriers of Immigrant Families for Educational Engagement....29

Types of Immigrant Family Engagement..................................26

Generational Status................................................... 31

Theoretical Framework...............................................34

Social Capital....................................................... 35 
Social Capital Within Family/Household.....................................38

Social Capital Outside Family/Household...............................40

Other Determinants of Social Capital..................................41

Social Capital and Family Engagement.................................43

Conclusion........................................................45

Chapter 3. Methodology ................................................48

Data and Sample.................................................48

Data Rationale....................................................49

Data Limitations.......................................................50

Analytical Sample and Weight.......................................50

Hypotheses of the Study...........................................51

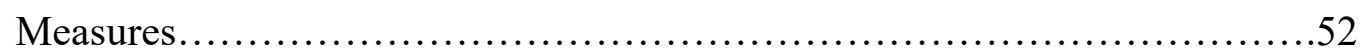

Outcome Variables ........................................52

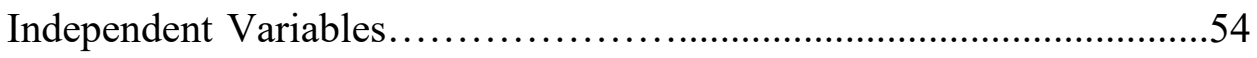

Mediated Variables ............................................54

Background Variables..........................................57

Analytical Methods................................................63

Confirmatory Factor Analysis..................................63

Model Goodness-of-Fit Statistics...............................67

Analysis....................................................67

Conclusion...........................................................69

Chapter 4 Results..................................................... 70

Results of Confirmatory Factor Analyses................................70

Descriptive Statistics.............................................. 74

Final SEM Model..................................................78 
Testing Direct Paths between Generational Status and Social Capital....78 Testing Direct Paths between Social Capital and Home- and School-Family Engagement............................................ 81

Testing Direct Paths between Generational Status and Home- and Schoolbased Family Engagement.....................................83

Indirect Relationships among Generational Status, Social Capital, and Home- and School-Based Family Engagement.......................83

Conclusion.............................................................

Chapter 5. Discussion.............................................. 87

Discussion of Research Findings......................................87

Generational Status and Social Capital..............................88

Generational Status and Family Engagement.........................90

Social Capital and Family Engagement............................91

Social Capita: Mediated factor...................................92

Limitations.................................................... 95

Future Research.....................................................97

Policy Implications...............................................98

Conclusion................................................... 101

References.......................................................... 103

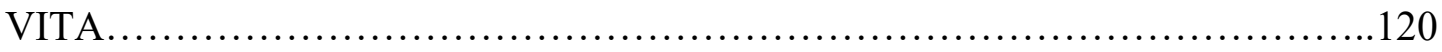




\section{List of Figures}

Figure 2.1 Conceptual Framework of Generational Status, Social Capital, and Immigrant Family Engagement. .46

Figure 3.1 Social Capital Measurement Model 1: First-order Factor Model. .65

Figure 3.2 Social Capital Measurement Model 2: Second-order Factor Model. .66

Figure 4.1 Relationship Among Generational Status, Social Capital, and Home-based Family Engagement. .79

Figure 4.2 Relationship Among Generational Status, Social Capital, and School-based Family Engagement. .81 


\section{List of Tables}

Table 2.1 Epstein's six types of parent involvement........................... 17

Table 2.2 Population by Generation Status between 1998 and 2013 in the US.........32

Table 3.1 Variable list of the Study ......................................... 58

Table 4.1 Social Capital Measurement Component Results.......................71

Table 4.2 Correlations Between the Four Dimensions of the Social Capital...........71

Table 4.3 Factor Loading for All Latent Variables................................ 72

Table 4.4 Family Engagement Measurement Component Results..................73

Table 4.5 Descriptive Statistics on Primary Study Measures Among First-, Secondand Third-Plus-Generation Students................................77

Table 4.6 Final SEM: Direct Relationships among Second-Generational Status, Social Capital, and Home-and School Family Engagement.....................82

Table 4.7 Final SEM: Indirect Relationships of Generational Status, Social Capital, and Home-Based Family Engagement.................................84

Table 4.8 Final SEM: Indirect Relationships of Generational Status, Social Capital, and School-Based Family Engagement.................................85 


\begin{abstract}
This study highlighted the importance of social capital in understanding the disparity in family engagement across immigrant generations. Using the national representative data, the ELS:2002, confirmatory factor analysis (CFA) and structural equation modeling (SEM) was used to examine the relationships among generational status, social capital, and home- and school-based family engagement. The results suggested that social capital played an important role in immigrant home- and schoolbased family engagement. The findings of specific pathways through social capital in and outside the family to home- and school-based family engagement might make a tangible contribution to understanding of family engagement and immigrant generations. Further, the present research suggested that immigrant families were not only constrained from participating in their children's education, but also had their own strengths for family engagement such as positive expectations for and extensive communications with their children.
\end{abstract}




\section{Chapter 1. Introduction}

The immigrant student population has grown steadily over the recent past in the United States. Indeed, it is the fastest-growing group among school-aged children (Portes \& Fernandez-Kelly, 2008). In 2019, students from immigrant families in the U.S. were 26 percent of the school-aged population, versus only 13.4 percent in 1990 (Batalova et al., 2021). This implies that a significant portion of parents in U.S. schools have immigrant backgrounds: almost one in four school-aged children has at least one immigrant parent (O’Hare, 2004). In general, immigrants refer to any foreign-born person or ones living in a country other than their birth country (Bolter, 2019). Meanwhile immigrant youth indicate children from birth to age seventeen with at least one foreign-born parent (Borjas, 2011; Tienda \& Haskins, 2011).

To ensure their children's educational success, immigrant parents continually develop and renew their educational approaches, establish new social networks, and put enormous efforts to acquire the new language (English, in the case of the U.S.) (Baum \& Flores, 2011; Carreón et al., 2005; Yu \& Singh, 2012). Being engaged in their children's school is a particular concern of immigrant parents; many moved here, in fact, for better educational opportunities for their families (Suárez-Orozco, 2009). Scholars have found that parents with immigrant backgrounds generally have optimistic attitudes towards their children's future and high educational aspirations, which leads to more active and frequent engagements in their children's education (Feliciano \& Lanuza, 2016; Kao \& Tienda, 1995; Sua'rez-Orozco et al., 2009; Zhou \& Kim, 2006). In turn, “family engagement” plays a crucial role for children's educational success. Research has found it is correlated with students' higher academic achievement, self-efficacy, lower drop-out rates, and higher college enrollment rates (Benner et al., 2016; Fan \& Williams, 2010; McNeal, 2001; Ryan \& 
Ream, 2016). Immigrant parents indeed are strongly motivated to engage in their children's education (Feliciano \& Rumbaut, 2005; Ogbu, 1978; Raleigh \& Kao, 2010; Suarez-Orozco et al., 2008).

The growing immigrant population in the U.S. coupled with this strong research base on the essential role of family engagement for educational success has led to extensive scholarly attention to the educational engagement of immigrant families in particular. Still, quite a few questions remain underexplored in this field (Kao \& Rutherford, 2007; Nguyen et al., 2009). Specifically, little is known about why immigrant parents choose specific types of family engagement, and what factors account for their choice. This study seeks to reveal the relationship between immigrant parents' backgrounds, specifically their generational status and social capital, with how they engage in their children's schooling. The next section presents problems in immigrant family engagement and emphasizes the need for this study.

\section{Statement of the Problem}

Family is the main context in which child development takes place (Bronfenbrenner, 1986), and thus, family engagement in education is one of the crucial determinants of successful child development (Carreón et al, 2005). Family engagement generally refers to the participation of parents in their children's education (Fan \& Williams, 2010; Fishel \& Ramirez, 2005; Hill \& Tyson, 2009; LaRocque et al., 2011; Sy et al., 2007; Jeynes, 2012). Parents engage in their children's education at home by monitoring and encouraging children, assisting with their homework, and so on (Pomerantz et al., 2009; Fan \& Williams, 2010). Parents also engage in schools by volunteering for in-school activities, attending school meetings, contacting teachers, and participating in school governance (Comer, 1995; Fan \& Williams, 2010; Pomerantz et al., 2009). A large body of scholarship suggested 
that family engagement is positively related to children's educational performance (Barnard, 2004; Fan \& Chen, 2001; Lee \& Bowen, 2006; Jeynes, 2003; McWayne et al., 2004). Also, recent research has focused on the mediating effects of poverty, race, and social inequality of parents on the association between family engagement and children's educational success (Eamon, 2002; Schreiber, 2002).

Family engagement is of great importance for immigrant students as well. For example, immigrant students may experience more difficulties in a wide range of schoolwork in host countries. Limited proficiency in host country languages and unfamiliarity with the new school system can be challenging for immigrant students (Bang et al., 2010; Suárez-Orozco et al. 2009). Effective family engagement, often facilitated by social connections, can tackle those difficulties and facilitate immigrant children to adapt to the new school system more quickly (Coleman, 1988). In sum, effective family engagement can significantly facilitate immigrant children's educational success (Jung \& Zhou, 2016; Rong \& Preissle, 2008).

The relationship between immigrant family engagement and immigrant children's accomplishments becomes more complex with the growing diversity in the immigrant population of the U.S. (Trevelyan et al., 2016). As such, the racial features of immigrants have become more diverse with the long history and growing immigrant populations in the U. S. The racial features can play an important role in shaping social capital and selecting family engagement types. This is because immigrant parents have different characteristics, experiences, or lifestyles depending on their racial features (Perna \& Titus, 2005).

For example, while approximately six out of ten adults (61\%) from Asia in recent years have at least a bachelor's degree, only 13\% of Hispanic adults have it. Median household income of immigrants shows the similar pattern: while Asian 
immigrant's median income was $\$ 60,000$ in 2010 , median household income of Hispanic immigrants was $\$ 13,000$ (Pew Research Center, 2012). The reason for immigration is also different across racial groups. Hispanic immigrants reported that the primary reason for immigration was economic opportunities, but the main impetus for Asian group's immigration is related with family issues and educational opportunities (Pew Research Center, 2012). Such different backgrounds may lead to shape different social capital and choose different types of family engagement in the U.S. Therefore, the racial features of immigrants warrant more profound scholarly attention.

Additionally, immigrant families have different family backgrounds that may shape their engagement in children's schooling, including their cultural heritage, English language proficiency, and socio-economic status; each of these are often correlated with their generational status (Hao \& Bonstead-Bruns, 1998; Turney \& Kao, 2009). In turn, generational status may play a key role in the selection of specific types of family engagement. For example, first-generation immigrant parents engage in their child's education more at home than at school because of their unfamiliarity to the US school system and limited English proficiency (Guo, 2006; Ruiz-deVelasco et al., 2000; Kao \& Rutherford, 2007; Wang, 2008). Thus, there is a burgeoning need to examine the dynamics of family engagement among immigrant families.

Social capital is also an essential factor for accounting for types of immigrant family engagement. In general, social capital refers to nontangible resources that are generated from the strength of social relationships (Bourdieu, 1986; Coleman, 1988). The size and the types of immigrant families' social capital may vary across their immigrant backgrounds (Bankston \& Zhou, 2002). For example, a parent's host 
country language proficiency can reinforce their social connections with U.S.-born parents or teachers, while parents with limited host language proficiency may hesitate to meet U.S.-born parents or teachers, which prevents them from building social capital outside of their immigrant group (Guo, 2006). Therefore, to better understand immigrant family engagement, researchers should investigate the social capital of immigrant families.

Under the circumstances of the fast-growing immigrant student population and the importance of family engagement, the US government has begun to take into account immigrants in family engagement policies. For example, throughout the Every Student Succeeds Act (ESSA) of 2015, the government articulated that school districts should provide notifications about students to all parents, and the notifications must be understandable and, to the extent practical, in a language the parent can understand (U.S Education, 2016). It is a noteworthy signal that the ESSA and the US government have attempted to embrace parents with limited English proficiency.

Yet, in spite of growing concerns of policy makers, scant research attention has been paid to the family engagement of immigrant families (Kao \& Rutherford, 2007; Nguyen et al., 2009). Most existing studies have centered on the relationship between students' educational success and the engagement of parents or caregivers from the perspective of non-immigrant families. Furthermore, even scholarly efforts interested in a generational influence of immigrant family on education (Kao \& Tienda, 1995; Peguero \& Bondy, 2011; Portes \& Zhou, 1993; Portes \& Rumbaut, 2001 Zhou, 1997) has paid little attention to its effect on the selection of family engagement types. In particular, the mechanism of how generational status affects family engagement is less clear. Among the multitude of unexplored questions to 
immigrant family engagement, this research focuses on how different characteristics of immigrant parents form their family engagement. In particular, I suggest that immigrant generational status and social capital might play key roles in how families become engaged. The following sections define these ideas and provide a brief rationale why these two factors are critical when thinking about family engagement.

\section{Purpose of the Study}

The purpose of the study is to examine the relationships among generational status, social capital, and family engagement. While there is a large body of scholarship on the association among social capital, family backgrounds, and family engagement in general (e.g., Furstenberg \& Hughes, 1995; Smith et al., 1992; Yan, 1999), scant research has explored these topics and immigrant parents. Particularly, little is known about whether and how immigrant parents' generational status is related to the ways that families are engaged, or what I call "family engagement types." Thus, this dissertation examines the relationship between immigrant generational status and families' types of family engagement. In addition, I test if social capital plays a mediating role between generational status and types of family engagement.

This study classifies the family engagement into home-based family engagement and school-based family engagement. Home-based family engagement is parent's assistance for school-related tasks, monitoring, and supervising of their children (Hill \& Tyson, 2007; Pomerantz et al., 2009). School-based engagement represents that parents are volunteering for in-school activities, attending school meetings, and participating in school governance (Comer, 1995; Fan \& Williams, 2010; Pomerantz et al., 2009). 
In the current study, I delve into the implication of generational status on family engagement based on social capital theory. I define social capital in more detail in the next section and Chapter 2, but in brief, social capital commonly refers to nontangible resources that are generated from the strength of social relationships (Bourdieu, 1986; Coleman, 1988). The positive effects of social capital on child development have been widely studied in the literature (Dika \& Singh, 2002), including its influence on family engagement (Carbonaro, 1996; Yan, 1999). Drawing from these studies, I explore the role that social capital plays in the formation of family engagement, particularly for immigrant parents.

Parents' generational status may also play a key role in shaping family engagement. Generational status is commonly categorized into three types: (a) firstgeneration refers to people who were foreign-born; (b) second-generation means that people who were born from first-generation immigrant parents; and (c) third-plus generation refers to people both of whose parents are native born (Rumbaut, 2004; Tienda \& Haskins, 2011; Trevelyan et al., 2016). Generational status adds another layer of difference in the characteristics and lifestyles of the US immigrant people (Bankston \& Zhou, 1995; Harker, 2001; Trevelyan et al., 2016). Unique attributes of immigrant parents in each generation may lead to diverging consequences to their family engagement. Therefore, I assume that generational status can contribute to the creation of family engagement.

Taken together, this study seeks to discover the encompassing relationship between immigrant generational status, social capital, and family engagement. The generational status of immigrant parents can lead them to build different types of social capital, which in turn can affect the selection of their family engagement types.

\section{Theoretical Framework: Social Capital}


In the present study, I argue that social capital can play a mediating role between generational status and family engagement. This study distinguishes social capital within the family and social capital outside of the family (Coleman, 1988). Social capital within the family is created through parent-child interactions. During their interactions (e.g., helping with homework), parents can transfer not only academic knowledge but also their skills of problem-solving to their children (Coleman, 1988; Orellana et al., 2003). Social capital outside the family is shaped through networks with community or school members (Coleman, 1992). Parents can assist their children using information which they obtain from their social networks with teachers, co-workers, or other parents (Coleman, 1988; Lareau, 1987).

In this vein, I posit that immigrant generational status is an important factor in the formation of different types of social capital: social capital in the family or social capital outside the family. The longer someone is living in a new host country, the more likely they are to have more developed or different networks outside the family (Hill \& Taylor, 2004), and the more likely they will have developed more extensive knowledge within the family (Coll \& Pachter, 2002; Hill \& Taylor, 2004). In turn, different types of social capital may then determine immigrant parents' approach to engage in their children's education. In other words, immigrant families' social capital in the family or outside the family may have a significant influence on what types of family engagement they adopt.

\section{Research Question and Hypotheses}

Utilizing data from the Education Longitudinal Study of 2002 (ELS:2002), the national sample of US high school students, and using the structural equation modeling (SEM) approach, I examine the following research question: what are the relationships among generational status (first-, second-, and third-plus), social capital, 
and family engagement? In this case, generational status is classified by child's status: (a) first-generation immigrant students indicated that those who are born outside the United States, regardless of their mothers' birthplace; (b) second-generation immigrant students meant that one's born in the United States, but his/her mother is born outside the US territory; and (c) third-plus-generation immigrant students indicated that both the student and their mothers are born in the U.S. (Ingels et al., 2004). Based on the overarching research question, this study has three hypotheses:

Hypothesis 1: Parent's social capital differs significantly across immigrant generations. In particular, I hypothesize that relative to third-plus-generation families, first-and second-generation families are more likely to have social capital in the family (i.e., parent's expectations and parent-child communications). On the other hand, first- and second-generation families are less likely to have social capital outside the family compared to third-plus-generation families (i.e., parent's networks and intergenerational closure).

Hypothesis 2: Family engagement also differs significantly across immigrant generations. More specifically, I hypothesize that compared with third-plusgeneration families, first- and second-generation parents are more likely to engage in their child's education at home, rather than at school. In contrast, compared with third-plus-generation families, first- and second-generation families are less likely to engage in their child's education at school.

Hypothesis 3: The relationship between generational status and family engagement is mediated by social capital in and outside family. More specifically, I hypothesize that compared with third-plus-generation families, first- and secondgeneration families have a strength in building social capital in the family (i.e., higher parent's expectations and higher levels of parent-child communications), which, in 
turn, leads to a higher family engagement at home. Conversely, third-plus-generation families have greater social capital outside the family (i.e., higher parent's networks and higher levels of intergenerational closure) than first- and second-generation families, which relates to more engagement in their child's education at school.

\section{Significance of the Study}

As the US immigrant population becomes even more diverse, there is a growing need to examine the dynamics among immigrants and their children's local schools. This study seeks to explain how generational status and social capital of immigrant families may lead to different types of family engagements. The findings of such a study may prove useful to both schools and policymakers.

First, results from this study could inform school or district guidelines for enhancing immigrant family engagement to school. Although immigrant parents are willing to engage with their children's schools (Carreón et al., 2005; Guo, 2006), it remains challenging for many (Aguayo \& Dorner, 2017; Plunkett \& Bamaca-Gomez, 2003; Ruiz-de-Velasco et al., 2000). Schools and teachers have also suffered from the lack of information and knowledge regarding how to properly assist immigrant parents; they need more practical assistance for how to work effectively with immigrant parents from different cultural and language backgrounds (Guo, 2006; Griego Jones, 2003).

The current study aims to provide new guidelines for schools: if immigrant parents are likely to choose different types of family engagement depending on their generational status, schools would be able to offer more tailored opportunities or support for immigrant families based upon their generational status. For example, first-generation families benefit more from having assistance for building social networks with other parents. Schools may establish program centers for new 
immigrant families and help develop opportunities to relate to both U.S.-born and other immigrant parents. With regard to second-generation families, schools' encouragement to increase parent-child communications could substantially strengthen their family engagement. Those programs may help increase family engagement of immigrant families.

Second, this study aims to confirm that social capital is an important factor for explaining immigrant children's educational experiences (Kao \& Rutherford, 2007; Pong et al., 2005; White \& Glick, 2000; White \& Kaufman, 1997). By applying social capital as the theoretical framework, this study significantly expands the understanding of the role of contextual factors in the relationship between generational status and family engagement. Namely, throughout this framework, we can better grasp how generational status is related to the choice of family engagement types. For example, the results can account for why first-generation families engage less in their child's education at school than native-born families: first-generation families have lower levels of social capital outside the family (i.e., parent's networks and intergenerational closure), which dampens their engagement level at schools.

In this vein, this study has the ability to suggest that promoting social capital has a tangible effect in increasing family engagement of immigrant families. School practitioners or administrators may launch programs for new immigrant parents who want to build social capital. For example, schools would offer networking programs among parents such as mentoring, parent workshops, or support groups that promote the connectedness of immigrant parents (Oberoi, 2016; Sheldon, 2002). Additionally, schools would set up meetings for immigrant parents to have acquaintance with the parents of their children's friends. This could increase their level of intergenerational closure. These programs and meetings would significantly contribute to lowering 
barriers to family engagement of immigrant families. Throughout parent networks and intergenerational closure, not only do immigrant parents gain valuable information on their child's education, but also shape more positive attitudes towards family engagement within U.S. schooling.

Lastly, this research can inform policymaking. Since NCLB and ESSA were introduced, promoting family engagement has been an important goal of educational policies in the U.S. With the increased immigrant population in the U.S., policymakers have tried to reinforce immigrant family engagement, in particular for students who have new immigrant parents. Both NCLB and ESSA include provisions concerning new immigrant parents' engagement strategies, notification, and choice (US Department of Education, 2002, 2015). However, these strategies do not take diversity of immigrant families into account. Thus, the current policies have some limitations to support immigrant families who have diverse backgrounds. The findings of this research could provide new directions to policymakers, for instance, by providing more specific recommendations based on whether families are newly arrived or not.

\section{Definitions of Key Terms}

\section{Generational Status}

This study has categorized generation status into three types. First-generation immigrant students indicated that those who are born outside the United States, regardless of their mothers' birthplace; second-generation immigrant students meant that one's born in the United States, but his/her mother is born outside the US territory; and third-plus-generation immigrant students indicated that both the student and their mothers are born in the US (Ingels et al., 2004; Trevelyan et al., 2016).

\section{Immigrant Family}


Immigrants are generally defined as people living in a country other than their birth country (Bolter, 2019). In this study, first- and second- immigrant generation families are considered as immigrant families. Third-plus generation families are defined as native families (Rumbaut, 2004; Tienda \& Haskins, 2011).

\section{Family Engagement}

In the present study, family engagement refers to the participation of parents in the education of their children (Fan \& Williams, 2010; Fishel \& Ramirez, 2005; Hill \& Tyson, 2009; LaRocque et al., 2011; Sy et al., 2007; Jeynes, 2012). I classified family engagement by two types: home-based family engagement and school-based family engagement. Home-based family engagement is parent's assistance for schoolrelated tasks, monitoring, and supervising of their children (Hill \& Tyson, 2007; Pomerantz et al., 2009). School-based engagement represents that parents are volunteering for in-school activities, attending school meetings, and participating in school governance (Comer, 1995; Fan \& Williams, 2010; Pomerantz et al., 2009).

\section{Social Capital}

Social capital in this study refers to nontangible resources that are generated from the strength of social relationship (Bourdieu, 1986; Coleman, 1988). This relationship includes ones between adults and children as well as those between adults (Lin, 2001; Portes, 1998). In the current study, social capital is categorized into two

types: social capital in the family (relationships between parent and child) and 2) social capital outside the family (relationship with other parents)

\section{Conclusion}

Despite the sheer size and diversity of the U.S. immigrant student population, scant research attention has been paid to the family engagement of immigrants. This study argues that generational status and social capital are key determinants of family 
engagement types. Three hypotheses are proposed: (a) parent's social capital differ significantly across immigrant generations; (b) the structural compositions of family engagement differ significantly across immigrant generations; and (c) the relationship between generational status and family engagement is mediated by social capital in and outside the family. The Education Longitudinal Study of 2002 (ELS:2002) data set and structural equation modeling (SEM) are used for answering the research question. 


\section{Chapter 2. Literature Review and Theoretical Framework}

This chapter provides a literature review of family engagement in the United States and describes the theoretical framework, especially the concept of social capital, which guides this study. I begin with a discussion of the current literature on family engagement, especially its definitions, types, policies to promote it, and effects. Next, I review what we know about immigrant family engagement, in particular the motivations, barriers, and types of immigrant family engagement in the U.S. As a brief review, the current study centers on families' generational status which partly determines both strengths and weaknesses of family engagement for immigrants. Specifically, I posit that the generational status of immigrants is related to the selection of particular types of family engagement, home-based or schoolbased. This might expand the literature on the education of immigrant children which has overlooked the relationship between generational status and family engagement types.

In turn, I review and discuss social capital theory as the theoretical framework of this study, which can help fill this knowledge gap. Specifically, I focus on Coleman's (1988) social capital theory to explain how immigrant parents or caregivers engage in their children's education. This review suggests that whereas a large body of research asserted that immigrant backgrounds is related to family engagement (e.g., Sibley \& Dearing, 2014; Tang, 2015; Turney \& Kao 2009), this

study expanded previous research by showing that social capital (i.e., parent's expectations, parent-child communications, parent's networks, and parent's intergenerational closure) can play an important role in immigrant family's educational engagement.

\section{Family Engagement Research in General}


Over the last five decades, educational researchers have investigated the effects of family engagement on their children's education and the mechanisms through which such effects take place (Epstein, 1992; Ferrara, 2009; Gibson \& Jefferson, 2006; Jeynes, 2011; Mapp et al., 2008; Pomerantz et al., 2007). Family engagement can be generally defined as participation of parents in the education of their children (Fan \& Williams, 2010; Fishel \& Ramirez, 2005; Hill \& Tyson, 2009; LaRocque et al., 2011; Sy et al., 2007; Jeynes, 2012). However, there are various kinds of family engagement that include several different types of parental behaviors and involvement at home and in school (Epstein, 1995; Fan \& Chen, 2001; Jeynes, 2012). Therefore, instead of presenting a single definition, researchers have suggested diverging definitions for parent behaviors to better understand family engagement (Benner et al., 2016; Epstein, 1995; Fan \& Williams, 2010; Pomerantz et al., 2009; Sy et al., 2007).

\section{Frameworks for Family Engagement}

A number of researchers have agreed that family engagement is a multifaceted construction including parent's educational involvement not only in school but also at home and in the community (Benner et al., 2016; Fan \& Williams, 2010; Pomerantz et al., 2009; Sy et al., 2007). In this section, I will begin with describing the standard approach of traditional family engagement framework (Epstein, 1995; 2010) and in turn discuss somewhat newer or alternative approaches including the ecological approach (Barton et al., 2004) and the motivational approach (Hoover-Dempsey \& Sandler, 1995).

\section{Traditional Framework}

As provided in Table 2.1, Epstein's $(1995 ; 2010)$ framework of six types of involvement is most widely accepted in the existing frameworks about family 
involvement (Hill \& Tyson, 2009). In this framework, the main actors include not only parents but also teachers and community members. Epstein's framework emphasized that the six types of involvement can provide children with positive effects both in the short- and the long-term (Epstein, 2010). Epstein (2010) also insisted that most teachers and administrators would like to increase family engagement, but many do not know how to do so. Therefore, the main actors of Epstein's family involvement are not only parents or caregivers but also teachers, administrators, and community members.

The first type of involvement, parenting, indicates that families are central to establishing a supportive home environment for children's learning. Parents also give a basic level of care such as health, nutrition, and other services. Communicating is the second type

Table 2.1

Epstein's six types of parent involvement $(1995,2010)$

\begin{tabular}{|c|c|}
\hline $\begin{array}{c}\text { Type of } \\
\text { Involvement }\end{array}$ & Function \\
\hline Parenting & $\begin{array}{l}\text { Assisting families to establish a supportive home environment for } \\
\text { children's learning. }\end{array}$ \\
\hline Communicating & $\begin{array}{l}\text { Communicate with families about school programs and student's } \\
\text { progress by effective two-way (school to home and home to } \\
\text { school) communications. }\end{array}$ \\
\hline Volunteering & $\begin{array}{l}\text { Schools' efforts to recruit and organize parents' participation to } \\
\text { help and support school and student programs. }\end{array}$ \\
\hline Learning at Home & $\begin{array}{l}\text { Schools provide family with information or ideas on how to help } \\
\text { their children's homework or school projects. }\end{array}$ \\
\hline Decision making & Include families as participants in school decision processes. \\
\hline $\begin{array}{l}\text { Collaborating with } \\
\text { the Community }\end{array}$ & $\begin{array}{l}\text { Coordinate resources and services for facilitating the } \\
\text { improvement of school programs, family practices, and student } \\
\text { learning and development, and provide service to the community. }\end{array}$ \\
\hline
\end{tabular}


of involvement. The communications between school and home are important for children's educational progress, so Epstein and others (2018) recommend that both educators and family members should design effective ways to communicate with each other. For example, providing language translators to assist immigrant parents with limited English proficiency can help increase their attendance or comfort level, and thus opportunities to communicate with educators, at school events or conferences. The third type of engagement, volunteering, refers to schools' efforts to recruit and organize parents' participation to help and support their programs and events, which serves as an opportunity for them to work together with teachers. The fourth engagement type is learning at home. This type of engagement suggests that schools provide families with information or ideas on how to help their children's homework or school projects. Teachers can offer information on curricula, school activities, decisions, or planning, and parents can guide their children at home using this information. The fifth type of engagement, decision making, is parents' participation in school decision-making processes. Taking part in decision-making allows parents to share their ideas or opinions with teachers and administrators, which not only gives them voice but also enables them to better understand school programs or policies. The last type of involvement is collaborating with the community. Parents and schools can identify and integrate community resources and services for facilitating the improvement of school programs, family practices, and student learning and development (Epstein, 1995, 2010).

While these categories and this framework from Epstein are commonly cited, other researchers have presented fewer categories for the types of family engagement. Some of them have grouped family engagement into two types depending on the place: home-based versus school-based engagement (Kohl et al., 2000; Pomerantz et 
al., 2009; Seginer, 2006). At home, parents can provide assistance for school-related tasks (e.g. homework, school projects, course selections) (Cooper, 1989; Pomerantz et al., 2009), monitor and supervise their children (e.g. check to do homework, control watching television) (Fan \& Williams, 2010; Milne et al., 1986), and enhance and encourage their academic motivations by talking with their children about academic issues (e.g. choice of colleges, the value of good performance in school) (Hao \& Bonstead-Bruns, 1998; Hoover-Dempsey \& Sandler, 1995; Pomerantz et al., 2009). School-based involvement represents that parents are volunteering for in-school activities, attending school meetings, contacting teachers, and participating in school governance (Comer, 1995; Fan \& Williams, 2010; Pomerantz et al., 2009).

\section{Ecological Approaches to Family Engagement}

The Ecologies of Parental Engagement (EPE) theory (Barton et al., 2004) arose as an alternative approach to thinking about family engagement. According to the EPE theory, it is difficult to understand the whole system and environment of family engagement based on frameworks presented by existing studies, because they have neglected to understand that parental involvement is a social practice and dialogue in a social world. Therefore, schools and teachers should also consider how parents understand family engagement, why they become involved in their children's schooling, and how this engagement is related more broadly with parents' experiences and actions both inside and outside school communities (Barton et al., 2004). These ecological approaches stress that family engagement is not only parents' practice for their children's education but also collaborations among parents, teachers, children, and community members (Barton et al., 2004; Carreón et al., 2005).

\section{Motivation for Family Engagement}


Another line of research concentrates more on the motivation for family engagement (Hoover-Dempsey \& Sandler, 1995, 1997; Hoover-Dempsey et al., 2005; Tang, 2015). For example, Hoover-Dempsey and Sandler $(1995,1997)$ provided three accounts for family engagement. First, they focused on parents' motivational beliefs that they have to be involved in their children's education. Secondly, parent's motivation for family engagement is a crucial determinant whether parents feel they are invited to school activities by schools, teachers, and their children. Specifically, children can ask parents for help with homework and school projects or ask them to volunteer in school events. Invitations from children become more critical especially as they grow older (Green et al., 2007).

\section{Policies to Encourage Family Engagement}

Since many studies confirmed that family engagement has a positive impact on children's educational success (Fan \& Chen, 2001; Henderson \& Mapp, 2002; Hill \& Tyson, 2009; Jeynes, 2007), policymakers have contemplated effective measures to promote family engagement in children's education (Jeynes, 2011; Pomerantz et al., 2007). In the 1990s, family involvement was one of the primary goals of education reform (National Education Goals Panel, 1999; National Research Council, 1996). In the 2000s, the same tendency remained. The No Child Left Behind Act (NCLB, 2002), specifically for Title I schools and programs, strengthened the emphasis on family involvement (not called engagement at that time, as discussed below) and presented guidelines to encourage greater participation of parents. Under NCLB, schools receiving Title I funding were required to convene an annual meeting with parents to inform them of federal law's requirements for their right to be involved. Parents could also have information about school choice. NCLB stated that local schools should notify parents when the schools or teachers were identified as low-performing ones. 
This policy also demanded school districts and schools to have a written parental involvement policy. Such local parent involvement policies were required to stipulate how districts/schools would support parents to play an important role in their children's education. States were also required to explain how they would make effective parental involvement strategies in their state plans to the federal government (US Department of Education, 2002).

The current policy, Every Student Succeeds Act (ESSA, 2015), has also brought parental involvement to the forefront. Like NCLB, ESSA requires a written parent and family policy for schools that receive Title I funding. ESSA, however, made a few changes. First, ESSA focuses more on providing the same opportunity of family engagement to all parents. Under ESSA, school districts and schools should conduct outreach to all parents and family members and implement programs, activities, and procedures to involve all of them (US Department of Education, 2015). Second, ESSA emphasizes that they change the terminology: from parental/family involvement to parental/family engagement.

ESSA does not specify why they renamed it, but I speculate that this is in line with researchers who have started to replace the terminology parental involvement to family engagement (Aguayo \& Dorner, 2017; Barton et al, 2004; Carreón et al. 2005; Fenton et al. 2017; Reynolds \& Shalfer, 2010). While parental 'involvement' has been used to denote the tasks that parents can carry out specifically in schools (Barton et al., 2004; Reynolds \& Shalfer, 2010), the term, family 'engagement' includes parents' orientations to the world and the process through which those orientations were shaped (Barton et al., 2004). That is, family engagement notes that parents' cultural backgrounds, experiences, situations or beliefs can contribute to an individual's decision to participate in school events. As they also impact parents' educational 
philosophies, this line of studies stresses that researchers should take into account parents' orientations to understand their behaviors (Carreón et al., 2005).

Finally, ESSA also uses new words -- family members and caregivers -- in addition to parents (US Department of Education, 2015). This implies that the term family engagement should be expanded to other family members. And the word caregivers note the policy has tried to embrace non-traditional family structures, such as the single-parent family.

\section{Effects of Family Engagement on Children's Educational Success}

Research for over decades has demonstrated that family engagement has a generally positive impact on their children's academic success (Benner et al., 2016; Fan \& Chen, 2001; Grolnick \& Slowiaczek, 1994; Domina, 2005; Henderson \& Mapp, 2002; Hill \& Tyson, 2009; Jeynes, 2007), higher self-efficacy (Fan \& Williams, 2010; Kim, 2014), lower drop-out rate (McNeal, 2001; Teachman et al.,1996), and higher rate of college enrollment (Ryan \& Ream, 2016). In particular, the release of the nation-wide dataset named "National Educational Longitudinal Study" (NELS:88) in 1990, enabled researchers to more systematically examine linkages between family engagement and academic success (Carbonaro, 1996; Catsambis, 2001; Desimone, 1999; Fan, 2001; George \& Kaplan, 1998; Hao \& Bonstead-Bruns, 1998; Israel et al., 2001; McNeal, 1999; Morgan \& Sørensen, 1999; Pribesh \& Downey, 1999; Pong, 1998; Singh et al., 1995; Sui-Chu \& Willms, 1996; Sun, 1999; Yan, 1999). Because NELS:88 has a lot of survey questionnaires relevant to family engagement, researchers can conduct various analyses (Desforge \& Abouchaar, 2003). Examples include the effects of family engagement on academic achievement (George \& Kaplan, 1998; Sui-Chu \& Willms, 1996; Sun, 1999); the association between types of family engagement and academic achievement 
(Catsambis, 2001; Pong, 1998; Singh et al., 1995); the relationship among family backgrounds (e.g. social class or ethnicity), academic achievement, and family engagement (Desimone, 1999; Fan, 2001); the association between family engagement and social capital (Carbonaro, 1996; Yan, 1999); or immigrant family engagement's effects on educational success (Hao \& Bonstead-Bruns, 1998). Utilizing NELS:88, researchers have compiled extensive empirical evidence regarding the positive relationship between family engagement and children's academic success.

In detail, the relationship between a specific type of family engagement and students' academic achievement is the most widely investigated issue using NELS:88. For example, Sui-Chu and Willms (1996) explored the effect of different dimensions of family engagement on the achievement of $8^{\text {th }}$ graders. They identified four types of family engagement namely: discussing school activities with children at home, monitoring children's out-of-school activities, contacting other parents and school personnel, volunteering in school activities, and attending parent-teacher conferences or meetings. Their findings showed that discussions on school-related activities at home had the strongest relationship with academic achievements. Singh et al. (1995) also focused on the influence of different components of family engagement on children's academic achievement (e.g., parental aspirations, parent-child communication about school-related issues, home-structure, parental participation in school activities). Their findings indicated that parental aspiration was positively associated with children's academic achievement.

Researchers have also investigated the associations between family engagement and diverse family backgrounds such as ethnicity, social class, or language using this dataset (Desimone, 1999; Fan, 2001; Wong \& Hughes, 2006). For 
example, Desimone (1999) pointed out there are significant differences in the relationship between family engagement and student achievement across students' ethnicity (i.e., Asian, Black, Hispanic, and White) and family income. This study suggested that family engagement was a better predictor for the academic achievements of White, Asian, and middle-income students than those of Hispanic, Black, and low-income students (Desimone, 1999).

Meanwhile, several researchers have conducted works to prove the effects of family engagement using meta-analyses (Fan \& Chen, 2001; Jeynes, 2007; Jeynes, 2012; Wilder, 2013). These studies confirmed that in general a positive relationship exists between family engagement and students' academic achievements. After reviewing nine studies, Wilder (2013) concluded that the relationship between family engagement and academic achievement was positive, regardless of definitions of family engagement or measures of achievement. Fan and Chen (2001) analyzed twenty-five studies and pointed out family engagement has a medium-sized positive students' achievement.

However, the findings of existing studies are not consistent. Although a lot of studies confirmed that family engagement is a significant predictor of student's academic success, some researchers refuted this general finding. For example, while many previous works argued that home-based family engagement (e.g., assistance for homework or discussion of school-related issues) has a positive effect on student's academic success (McNeal, 1999; Pong, 1998; Sun, 1998, 1999), Hill and Tyson (2009) found that assisting children with homework did not have a significant impact. Regarding school-based involvement, several studies concluded that family engagement in school activities such as attending conferences or events has no influence on students' achievement (Domina, 2005; Singh et al., 1995). 
Even though there are fast-growing immigrant populations in the United States, there is little large-scale research like this about family engagement in immigrant families (Kao \& Rutherford, 2007; Nguyen et al., 2009). As shown in the following section, while we have some research on the impact of family engagement on immigrant students' achievement, even fewer studies investigate what parental factors shape immigrant family engagement. To understand immigrant family engagement, then, it is necessary to identify important components of immigrant family backgrounds and to reveal the process through which they shape family engagement behaviors. The following review supports the argument made in this dissertation to explore how immigrant generational status, in particular, may be related to family engagement at home and in schools.

\section{Immigrant Family Engagement}

In the current study, I contend that immigrant parents who have different generational status might have different types of family engagement. As the U.S. immigrant population becomes even more diverse, there is a growing need to examine dynamics among immigrants. The immigrant population in 2015 numbered more than 43.3 million which was approximately $13.5 \%$ of the total U.S. population (Zong et al., 2015). Specifically, the number of the foreign-born population has also steadily increased (Zong \& Batalova, 2017). This implies that immigrant groups in the U.S. have been further diversified particularly in their generational status. To fully account for family engagement behaviors of immigrant parents, it is required to incorporate their circumstances or environments in a new country. This section describes these circumstances of immigrant family engagement.

\section{Family Engagement of Immigrants: An Introduction}


As discussed earlier, family engagement has been shown to be positively related to children's educational performance (Barnard, 2004; Fan \& Chen, 2001; Lee \& Bowen, 2006; Jeynes, 2003; McWayne et al., 2004) and may mediate the effects of poverty, race, and social inequality of parents (Eamon, 2002; Schreiber, 2002). In particular, family engagement may be an essential factor for immigrant students to adapt to new school systems and curriculums. A large body of research has shown that many immigrant children have difficulties adapting to the US school environment because of language barriers and unfamiliar educational systems and culture (Lee, 2006; Toppelberg \& Collins, 2010).

For example, most studies have concluded that limited English proficiency and unfamiliar school systems can account for the relatively lower performance of immigrant children (Crawford, 2004; Duran, 2008; Lee, 2006; Menken, 2010). Students in the United States take classes in English, and instructions and tests are given in the English language. Moreover, English-language ability is essential at all stages of schooling, and it also facilitates the progress to the next stage of schooling (Bleakley \& Chin, 2004). Therefore, the language barrier is clearly an obstacle for immigrant students' academic performance (Crawford, 2004).

For these reasons, family engagement at home and school may be especially important for newly arrived students (Jung \& Zhou, 2016). Parents' engagements are likely to provide much needed emotional support to their children struggling in an unfamiliar environment as well as practical assistance for homework or school projects. This may lead to their children's educational success in a new country (Rong \& Preissle, 2008). However, family engagement varies depending on many factors, with research related to parents' varying ethnicities/races or countries of origin and generational status (Fan, 2001; Seginer, 2006). Each of these topics is explored 
further in the following sections, specifically, (a) barriers and strengths of immigrant family engagement, (b) types of immigrant family engagement, and (c) diversity of immigrant families per generational status. Then I explain how the theory of social capital will help explore the links among immigrant family engagement and generational status.

\section{Strengths and Barriers of Immigrant Families for Educational Engagement}

This section reviews strengths and barriers of immigrant families for educational engagement. First, I explain three challenges to immigrant family engagement: (a) lower level of educational attainment, (b) limited English proficiency, and (c) lack of time. Then, I review two strengths of immigrant families: higher expectations of their child' educational success and strong community cohesion.

\section{Immigrant Parent's Barriers}

First, immigrant parents' educational attainment can be a barrier for family engagement. In general, immigrant parents have a lower level of educational attainment compared to native-born parents, which can pose difficulties in engaging in their children's education (Hernandez, 1998; Shields \& Behrman, 2004). Researchers have concluded that high educational attainment of immigrant parents positively affects their children's academic achievement and provides them with educational motivations (Fuligni \& Fuligni, 2007; Kao, 2004). In contrast, lower educational attainment or little formal educational experience may hinder immigrant parents' engagement in their children's education (Plunkett \& Bamaca-Gomez, 2003). Extant research also has found that immigrant children under parents with lower educational attainment completed fewer years of schooling (Hernandez et al., 2007; 
Sewell et al., 1980), and have lower educational expectations (Hao \& BonsteadBruns, 1998).

Second, parents' English proficiency can also be a barrier to an immigrant family's engagement in their children (Kao \& Rutherford, 2007; Shin, 2009; Wang, 2008). Several studies have found that immigrant parents with limited English proficiency tend to be less active in their children's education (Guo, 2006; Sohn \& Wang, 2006). They may be more likely to feel that meetings with teachers are uncomfortable and schools do not welcome them (Guo, 2006), which can lead immigrant parents to be reluctant to participate in school activities or events for their children (Riches \& Curdt-Christiansen, 2010; Turney \& Kao, 2009).

Lastly, a lack of time can also be a barrier for immigrant family engagement. Many times, both parents of immigrant families are working, so they have limited time to engage in their children's schooling (Carreón et al., 2006; Zhou, 1997). These circumstances can make immigrant parents isolated from the school communities as well, which makes it more difficult for them to build social networks (Trueba, 1998). Moreover, the lack of time makes interactions with their children harder (Coleman, 1988). Many immigrant working parents have little time to physically engage in their children's education at home (Zhou, 1997). In sum, the time constraints immigrant parents face could lead to fewer opportunities to engage their children's education both in school and at home.

\section{Immigrant Parents' Strengths}

However, immigrant families also possess strengths in relation to their children's education. They generally have a strong willingness to improve the quality of their lives, which, some studies show, leads them to have higher expectations for their children's education than U.S-born families (Feliciano \& Lanuza, 2015; Shields 
\& Behrman, 2004). As such, immigrant children also hold high expectations for their education and future (Kao, 2004). Moreover, immigrant parents also put an emphasis on family obligations to their children (Zhou \& Bankston, 1998). This induces immigrant children to spend more time on doing homework at home and make more efforts in schools (Hernandez \& Charney, 1998).

Immigrants' strong community cohesion also has positive effects on families' engagement with schooling (Shields \& Behrman, 2004). Other immigrant families in the community with the same country origin can support newcomers, for instance, by assisting them to navigate new systems and institutions (e.g., children's schools) (Portes \& Rumbaut, 2001). In sum, although there exist barriers to immigrant family engagement in the U.S., it is important to note that immigrant families also have agency and strength in relation to their children's education.

\section{Types of Immigrant Family Engagement}

Earlier in this chapter, I reviewed the various types of family engagement and suggested that there are two main areas particularly important when considering immigrant family engagement: school-based activities and home-based activities. In this section, I provide in-depth reviews on these types of immigrant family engagement and account for immigrant parents' adoption of a specific type of family engagement.

Following literature, due to the barriers to family engagement, immigrant parents tend to engage more at home than at school (Coll \& Pachter, 2002; Sibley \& Dearing, 2014). For example, monitoring their children at home is one of the most preferred types of engagement for immigrant parents. They can monitor to keep their children focused on school-related works and stay away from unsafe neighborhoods and external influences (Plunket et al., 2009; Suárez-Orozco, 2001b). This is a 
relatively easier way to engage for immigrant parents who have trouble helping their children with homework or school projects. Similarly, prior research has shown that ethnic-minority parents in the U.S. (e.g., African, Asian, Hispanic) often are more involved in school-related activities at home than in school. Conversely, parents who are white, native-born and having higher educational attainment are more likely to be involved in school than at home (Eccles \& Harold, 1996; Shumow \& Lyutykh, 2014; Sibley \& Dearing, 2014). Because native-born parents have a greater knowledge of the U.S school system, they may provide more relevant guidance to their children (Valdes, 1996).

These tendencies suggest that the selection of family engagement types will carry a significant weight for immigrant families. Immigrant parents might adopt different types of family engagements depending on their backgrounds or the barriers they face. Also, understanding the process through which immigrant families select different types of educational engagement is of great importance, as it is likely to be distinct from that of non-immigrant families. However, existing studies have rarely explored the process of immigrant family engagement. Only a few studies examined the relationships between specific types of immigrant family backgrounds and family engagement (Turney \& Kao, 2009) or family engagement and students' academic achievement (Hill \& Taylor, 2004; Nguyen et al., 2009; Jung \& Zhang, 2016). Although these studies are well grounded in prior literature, their scope was limited only to the effects of family engagement on immigrant students' academic achievements. Furthermore, little is known about the mechanism through which the generational status is related to social capital, and ultimately to the selection of specific family engagement types. The next section reviews generational status which 
is a key independent variable of this study. I will explain the types of generational status, populations, and characteristics of each immigrant generational status.

\section{Generational Status}

The US Census Bureau categorizes generational status of immigrants into three groups according to their citizenship or birthplace (Trevelyan et al., 2016). Firstgeneration refers to anyone who is not a US citizen at birth including naturalized citizens, legal permanent residents, temporary migrants (e.g., foreign-born students), humanitarian migrants (e.g., refugees), and undocumented migrants. Second generation means US natives (born in the United States or territories) with at least one foreign-born parent, and third-plus generation stands for US natives (born in the United States or territories) with both parents native-born (Trevelyan et al., 2016). Scholars have used similar definitions: generational status is usually determined by immigrants' birthplace and classified into three types: first-, second-, or third-plusgeneration immigrant (Peguero, 2011; Portes \& Rumbaut, 2001, 2006).

The US Census Bureau also offers information about the immigrant population across generational status (See Table 2.2). Among the three generation groups, the third-plus-immigrant is the largest one with 235 million people, which is 75 percent of the total US population in 2013. The size of first-generation immigrants is 40 million and 13 percent of the total population, and the second-generation is about 36 million which is 12 percent (Trevelyan et al., 2016). The first-generation immigrant group, despite its smallest size, has shown the fastest growth rate since 1998. It has grown by 53 percent, from 26 million to 40 million. The secondgeneration group has increased by 23 percent, from 30 million to 36 million between 1998 and 2013. In the same period, the growth rate of the third-plus generation group has been only about 10 percent (Trevelyan et al., 2016). 


\section{Table 2.2}

Population by Generation Status between 1998 and 2013 in the US (Trevelyan et al., 2016)

\begin{tabular}{cccc}
\hline Generational Status & 1998 & 2013 & $\begin{array}{c}\text { Percentage } \\
\text { Population Growth }\end{array}$ \\
\hline First-Generation & 26 million (9.8\%) & 40.1 million $(12.9 \%)$ & $52.6 \%$ \\
Second-Generation & 30 million (11\%) & 36.3 million $(11.7 \%)$ & $23 \%$ \\
Third+-Generation & 213 million (79.2\%) & 234.7 million $(75.4 \%)$ & $10 \%$ \\
Total & 269 million & 311 million & $15.6 \%$ \\
\hline
\end{tabular}

A review of the literature suggests that the characteristics or lifestyles of immigrant people vary across their generational status (Bankston \& Zhou, 1995; Harker, 2001). The different generational status might lead immigrant families to have different backgrounds in their personal experience, educational attainment, social-economic status, or proficiency of host country languages (Trevelyan et al., 2016; Willgerodt \&Thompson, 2005). One conspicuous difference observed across immigrant generation groups is in their educational attainment. High school graduation rates were lower for the first-generation group in comparison to the second- and third-plus-generation groups. While only 70 percent of first-generation had a high school degree, over 90 percent of second- and third-plus-immigrants attained it. Economic standing is another notable difference. In terms of the median household income, first-generation households had lower income $(\$ 45,475)$ than second- $(\$ 51,291)$ or third-plus-generation $(\$ 51,853)$ households in 2012 (Trevelyan et al., 2016).

Past studies supported this phenomenon. Immigrants who live longer in host countries are more accustomed to their social norms and expectations consistent with social institutions (Alba \& Nee, 2003). On the other hand, new immigrants must take time to acclimate themselves to an entirely new society and culture (Harker, 2001; 
Watkins \& Melde, 2010). That is, first-generation immigrants may undergo more challenges for their social and economic advancement in new countries in comparison to later generations. For example, limited language proficiency and insufficient experience for host countries might give first-generation immigrants more difficulties in their daily lives (Bankston \& Zhou, 1995; Watkins \& Melde, 2010).

For children of immigrants, however, a large body of scholarship has pointed out that first-generation students have some advantages over second and third-plus generation students (Kao \& Tienda, 1995; Peguero \& Bondy, 2011; Portes \& Zhou, 1993; Portes \& Rumbaut, 2001 Zhou, 1997). Especially, first-generation youths tend to have strong relationships with their teachers and parents, which provide them with a better chance for success in school (Rong \& Preissle, 2008). Some researchers also find that first-generation youth are less likely to be involved in school violence and delinquency than those of second and third-plus generation (Chen \& Jiang, 2020; Peguero, 2011).

New immigrant parents are also willing to engage in their children's education (Carreón et al., 2005; Guo, 2006). In general, first-generation immigrant parents focus primarily on their educational process and adaptation to new environments (Carreón et al., 2005). Placing a high value on their children's education (Carreón et al., 2005; Delgado-Gaitan, 1991; Suarez-Orozco \& Suarez-Orozco, 2001; Trueba, 1999; Valdez, 1996), many attempts to engage at home through monitoring and assisting with school-related work, or giving educational advice (Behnke \& DeBord, 2006). Related research has found that new immigrant parents generally have higher educational expectations or aspirations toward their children than native-born counterparts (Feliciano \& Lanuza, 2015; Glick \& White, 2004; Hao \& BonsteadBruns, 1998; Mau, 1997; Zhou \& Kim, 2006). This can partly account for their 
stronger motivation to engage in children's schooling. Because most immigrants come to the US voluntarily with a hope of success, they tend to hold positive perspectives on the US society despite their low socio-economic status and language obstacles. In this vein, immigrant parents maintain optimistic outlooks that their children will be able to enter college and have a better life in the United States (Feliciano \& Rumbaut, 2005; Ogbu, 1978; Kao \& Tienda, 1995; Suarez-Orozco et al., 2009).

In the following section, I provide a brief review of research on family engagement and social capital before moving to a deeper description of this theory. When thinking about the relationship of generational status and types of family engagement, it follows that social capital may stimulate the effect of generational status to the selection of family engagement types. Each of these topics is explored further in the following sections, specifically, (a) definition of social capital, (b) social capital within the family/household, (c) social capital outside the family/household, (d) other determines of social capital, and (e) research about social capital and family engagement. Then, I introduce the conceptual framework of this study: how social capital mediated generational status and home- and school-based family engagement across immigrant families.

\section{Theoretical Framework}

The goal of the current study is to investigate the relationships between immigrants' generational status and the specific types of their family engagement in child education. In particular, this study spells out the underlying causal mechanism between generational status and engagement in child education, and I suggest that social capital plays a key role in this mechanism. This study categorizes family engagement into two types: home-based and school-based, following extant studies 
(Benner et al., 2018; Fantuzzo et al., 2014; Hill \& Tyson, 2007; Sui-Chu \& Willms, 1996). Home-based family engagement refers to parents' educational activities inside the home (Hill \& Tyson, 2007; Pomerantz et al., 2009), which includes parents assisting with school-related tasks, monitoring and supervising their children, and encouraging their academic motivations throughout conversations about academic issues. School-based engagement includes volunteering for in-school activities, attending school meetings, contacting teachers, and participating in the school governance (Comer, 1995; Fan \& Williams, 2010; Pomerantz et al., 2009). Based on this classification, I posit that social capital of the immigrant family can serve as a mechanism connecting attributes of immigrant families and their engagement at home and in school respectively.

\section{Social Capital}

Social capital is a commonly used sociological concept in many disciplines to understand how people create resources throughout relationships (Dika \& Singh, 2002; Tang, 2015). Social capital generally refers to nontangible resources that are generated from the strength of social relationship. This relationship includes ones between adults and children as well as those between adults (Bourdieu, 1986;

Coleman, 1988; Lin, 2001; Portes, 1998). The term "social capital" emerged in the 1920s, but more elaborated concepts were developed by Pierre Bourdieu and James Coleman in the 1980s (Dika \& Singh, 2002).

Bourdieu (1984, 1986), the first sociologist to systematically analyze the concept of social capital, noted that it refers to social relationships or networks which allow access to resources (Lareau, 2001). Especially he emphasized the importance of the amount of social capital. The amount of social capital possessed by individuals is partly determined by the size of their networks (Dika \& Singh, 2002). That is, the 
volume of social networks and relationships can lead to a disparity in social capital, which causes inequality of the amount and the quality of resources individuals have the access to (Bourdieu, 1986).

Like Bourdieu, Coleman $(1988,1990)$ proposed that social capital is embedded in social relations among actors. He concentrated on the functions of social capital and brought forward three crucial factors: (a) obligations, expectations, and trustworthiness of structures, (b) information channels, and (c) norms and effective sanctions. Particularly, Coleman emphasized that social capital can be generated among family members especially parents and children. This type of social capital is in general positively related to children's educational success (Coleman,1988).

Since the pioneering research of Bourdieu and Coleman, studies have paid substantial scholarly attention on the role of social capital (Dika \& Singh, 2002). Drawing from Bourdieu's work that had claimed individuals from different social locations are socialized differently, Lareau (2001) argued that the level of social class is related to the accessibility to knowledge and resources, and social capital plays a key role within this process. Putnam (2001) also presented the similar concept of social capital with Bourdieu: "social capital refers to connections among individuals social networks and the norms of reciprocity and trustworthiness that arise from them" (Putman, 2001, p.19). Like Bourdieu, Putnam augured that a gap of social capital exists among people. Yet, while Bourdieu had focused on inequality of social capital between individuals, Putnam's interest has been centered more on disparity of social capital across communities or regions. He believed that successful social capital is created by communities with well-functioning economic systems and a high level of political integration (Putnam, 1993). 
Coleman's work has a great influence on educational researchers because of his attempt to put social capital and education together. Following Coleman, social capital has been viewed as an essential factor for educational success of children such as high school graduation and college enrollment (Dika \& Singh, 2002). Therefore, Coleman's concept of social capital theory has long captured the attention of educational researchers and policymakers who aim at improving educational success for children, and how that may happen through relationships/social capital (Dika \& Singh, 2002; Kao, 2004; Kao \& Rutherford, 2007; Perna \& Titus, 2005; Ryan \& Ream, 2016).

Though individuals generally focus on social capital as something developed among adults, Coleman (1988) categorized social capital into two types: social capital in and outside the family. Social capital in the family is formed by interactions between parents and children. Social capital outside family, on the other hand, is shaped from networks with community members such as other parents or teachers. The current study employs Coleman's concepts for two reasons. First, this study seeks to examine the relationships among immigrant generational status, social capital in and outside family, and family engagement. In particular, I claim that social capital inside the family might have a stronger influence on home-based family engagement, and social capital outside the family facilitates school-based family engagement. Second, generational status might be related to social capital in and outside the family. For example, new immigrant parents tend to have lower social capital outside the family because of their unfamiliarity with the US culture and limited English proficiency (McNeal, 1999). These immigrant barriers hinder them from forming social networks with other parents or teachers. Generational status might also be related to social capital in the family. Past studies suggested that new immigrant 
parents generally have higher educational expectations to their children. The expectation to children constitutes Coleman's social capital inside the family (Coleman, 1988; Feliciano \& Lanuza, 2015).

\section{Social Capital Within Family/Household}

Social capital can be created by interactions among family members (Coleman, 1988; Oh \& Fuligni, 2010). In particular, Coleman (1988) posited parentchild interactions can shape social capital in the family. Based on past studies (Coleman,1988; Hao \& Bonstead-Bruns,1998; Sui-Chu \& Willms, 1996), this study introduces three conditions for shaping social capital in the family: (a) the frequency of parent-child communications, (b) parent's expectation for children's education, and (c) family structures.

The first, the frequency of parent-child communications, is one of the most widely used measures of family social capital (Dika \& Singh, 2002; McNeal, 2001; Nguyen et al., 2009; Perna \& Tutis, 2005; Stevens \& Patel, 2015; Sui-Chu \& Willms, 1996). Throughout communications, parents can have their children understand the importance of schooling and education (McNeal, 2001). Parents can also provide opportunities to review, organize, and interpret information. That is, such discussions provide children with extra learning opportunities for school-related issues (Nguyen et al., 2009).

Parent-child communications can also be a channel through which parents transfer human capital to their children (Coleman,1988; Perna \& Titus, 2005; Ryan \& Ream, 2016). Parents' human capital is generally measured by their educational attainment (Furstenberg \& Hughes, 1995; Ryan \& Ream, 2016; Teachman et al., 1997). Those with higher educational attainment are more inclined to have conversations with their children, and accordingly, have more opportunities to inherit 
their knowledge and skills (Fuligni \& Fuligni, 2007; Kao, 2004). As such, parentchild communications are positively associated with child's educational success such as academic achievement (Desimone, 1999; Eccles \& Harold, 1993; McNeal, 2001; Sui-Chu \& Willms, 1996), reduction for dropouts (Smith et al, 1992), and educational attainment (Perna \& Titus, 2005; Ryan \& Ream, 2016).

Second, social capital in the family is created by a parental expectation for children (Coleman, 1988; Furstenberg \& Hughes, 1995; Hao \& Bonstead-Bruns, 1998; Smith et al., 1992; Yan, 1999). In general, parental expectation is referred to as a belief parents hold in their children's future achievement (Carpenter II, 2014). Parents with higher academic expectations for their child tend to more actively help with homework and school projects and participate in school events (Asakawa, 2001; Sy \& Schulenberg, 2005). Furthermore, high parental expectation can lead children to hold greater expectations as well (Hao \& Bonstead-Bruns, 1998).

Family structure also shapes social capital in the family. In particular, family structure is highly related to the gap in social capital across families. According to Coleman (1988), two factors might cause a lack of social capital: (a) the absence of adults in the family, and (b) insufficient adult attention and support to the child. For this reason, children from single-parent family receive less attention from parents, and thus, they do not have the access to the same amount of social capital as those living with both natural parents (Astone \& McLanahan, 1991; Coleman, 1988; Smith et al., 1992; Yan, 1999). Similarly, the number of siblings is also an important factor explaining parent-child relationships and family structure (Coleman, 1988; Sui-Chu \& Willms, 1996). A child with many siblings has fewer learning opportunities (with parents) and weaker parent-child interactions (Blake, 1981). Like other conditions, family structure is related to a child's academic achievement. A child from a single- 
parent family or having a lot of siblings has been related to lower academic achievements compared with those from two-parent families or those with fewer siblings (Astone \& McLanahan, 1991; Israel et al., 2001).

\section{Social Capital Outside Family/Household}

Social capital is generated not only in the family but also outside the family. It can be created when a family is embedded in social relationships with other parents and social institutions (Coleman, 1988). To explain social capital outside the family, Coleman introduced the concept of "intergenerational closure" (Coleman, 1988, 1990). Intergenerational closure is defined as parents' relationship structure in which they recognize their children's friends and parents of those friends: "a child's friends and associates in school are sons and daughters of friends and associates of the child's parents" (Coleman, 1990, p. 318). Throughout this relationship, parents might be able to obtain information regarding their children's school life or activities (Coleman, 1988,1990; Kao \& Rutherford, 2007; Portes, 1998).

The intergenerational closure has been frequently used to denote social capital outside the family (Desimone, 1999; Kao \& Rutherford, 2007; McNeal, 1999; Morgan \& Todd, 2009; Ryan \& Ream, 2016). It is usually measured by the number of other parents with whom parents report that they regularly talk, names of their children's friends they remember, or the frequency of discussions with other parents (Dika \& Singh, 2002; Furstenberg \& Hughes, 1995; Perna \& Titus, 2005; Ryan \& Ream, 2016; Yan, 1999). Prior research found that intergenerational closure is positively related to children's academic achievements (Kao \& Rutherford, 2007; Yan, 1999) and educational attainment such as college enrollment (Perna \& Titus, 2005; Ryan \& Ream, 2016). 
Individuals who are the same community members of parents also shape their social capital outside the family (Furstenberg \& Hughes, 1995). For instance, if parents are members of a community with strong social ties and adherence to common norms, they would enjoy greater social capital, because the community members are willing to provide them with support and assistance (Furstenberg \& Hughes, 1995; Hao \& Bonstead-Bruns, 1998; Zhou \& Bankston, 1998).

\section{Other Determinants of Social Capital}

This section introduces important determinants for building social capital. First, family socio-economic status can cause a disparity in family social capital (Lareau, 1987; Sheldon, 2002; Aston \& McLanhan, 1991). Especially, social class is associated with differences in social networks and parenting patterns (Lareau, 1987, 1989; Hovart et al., 2003). While parents from middle-class families tend to socialize with other parents in their children's school communities, parents from working-class families typically socialize within their kinship groups or relatives, not with the school community members (Lareau, 1987). Therefore, middle-class parents can have denser and stronger social networks in their school communities than working-class counterparts and have more information regarding their children's activities in school (Lareau, 1987, 1989).

Bourdieu (1986) also pointed out that an individual's social and cultural context can contribute to the formation of social capital. Specifically, he used the terms habitus and field: habitus is "a system of dispositions" that results from social training and past experience (Brubaker, 2004; Lareau, 2001; Lee \& Bowen, 2006; Reed-Danahay, 2005), and field indicates "a structured system of social relations at a micro and macro level" (Grenfell \& James, 1998; Lareau \& Horvat, 1999; Lee \& Bowen, 2006). Applying the terms of habitus and field to family engagement, parents 
are using strategies based on their habitus when they participate in the field of their children's education (Grenfell \& James, 1998).

Bourdieu's concepts can account for the differences in the size of social capital and the degree of family engagement across immigrant families. Parents with different backgrounds may choose different types of family engagement because they differ in regard to habitus (Lee \& Bowen, 2006). Furthermore, if a parent's habitus is inconsistent with the field of education, they may experience difficulties in participating within the field (Lee \& Bowen, 2006; Shin, 2009). Many new immigrant parents are short of knowledge and experiences of the U.S school system, so they have trouble participating in school-based engagement. Indeed, immigrant parents prefer home-based engagement to school-based engagement because of their different habitus (Sibley \& Dearing, 2014).

Immigrants' proficiency in the host country's language can be related to social capital among immigrant families. The limited host language proficiency has a negative influence on building social norms and expectations consistent with social institutions (Bankston \& Zhou, 1995). Furthermore, because of limited English proficiency, new immigrant parents have difficulties in understanding their children's schooling, so they tend to have less school-related discussions with their children $(\mathrm{Oh}$ \& Fuligni, 2010). These hurdles also affect social capital outside the family, because limited English proficiency and unfamiliarity with school systems may render immigrant parents to hesitate attending school events due to the fear of not understanding school documents or different language environments (Guo, 2006). These circumstances may prevent them from building social relationships with school community members. 
However, new immigrant families also possess certain attributes conducive to building social capital (Zhou \& Bankston, 1998). In particular, first-and secondgeneration immigrant children can utilize unique forms of cultural resources existing in their families and communities such as knowledge of a non-English language, a high value placed on schooling, and high parental expectations (Feliciano \& Lanuza, 2015). In addition, cultural resources based on immigrant values can be a key factor for creating immigrant social capital. For example, knowledge of heritage language may give children access to ethnic communities and networks. Strong relationships with their peers and other parents in their own ethnic communities can help them to adapt to the US education system (Kao \& Rutherford, 2005; Zhou \& Bankston, 1998).

In the next section, I review the recent studies about family engagement and social capital. A large body of studies have used social capital to measure the level of family engagement (Hao \& Bonstead-Bruns, 1998; Dika \& Singh, 2002; McNeal, 1999). I investigate those studies first, and then introduce recent studies which attempted to distinguish social capital and family engagement (Li \& Fisher, 2017; Klugman et al., 2017). Lastly, I differentiate social capital and family engagement based on their core concepts presented by seminal works (Fan \& Williams, 2010; Hill \& Tyson, 2009; LaRocque et al., 2011).

\section{Social Capital and Family Engagement}

Research on the relationship between social capital and family engagement is relatively new. Prior research in general used social capital as an indicator of family engagement or the other way around (Hao \& Bonstead-Bruns, 1998; Dika \& Singh, 2002; McNeal, 1999; Parcel \& Dufur, 2001; Pong, 1999; Yan, 1999). For example, Ream and Palady (2008) categorized social capital into two types: informal and formal social capital. Their concept of informal social capital referred to how parents 
help their children with schoolwork, which is measured by the frequency of parentchild discussion. Formal social capital indicated school-related parental activities, which is similar to the concept of school-based engagement of this study.

Recent studies have also started to explicitly differentiate social capital and family engagement and attempted to reveal the relationship between these two factors (Bolívar \& Chrispeels, 2011; Li \& Fisher, 2017; Klugman et al., 2017; Mukar et al., 2017; Myers \& Myers, 2014; Von Otter \& Stenberg, 2015). For example, Von Otter and Stenberg (2015) documented that family social capital and parent-child relationships positively are related to school-related parental activities such as attending parent-teacher meetings. Parental networks such as relationships with other parents are also positively related to school-based engagement including participating in parent-teacher organization and volunteering at school (Sheldon, 2002; Li \& Fisher, 2017).

Yet, few studies have clearly explained why and how they differently conceptualize family engagement and social capital from what past studies had done. Therefore, in the current study, I differentiate social capital and family engagement based on their core concepts presented by seminal works (Coleman 1988; Epstein 1988; Yan, 1999). First, a number of studies about family engagement defined that family engagement is parents' participation in the education of their children (Fan \& Williams, 2010; Hill \& Tyson, 2009; LaRocque et al., 2011; Sy et al., 2007; Jeynes, 2012). For example, Epstein's framework of involvement (1988) focused on specific parental behaviors which provide children with positive effects both in the short- and the long-term. On the other hand, social capital is defined as nontangible resources that are generated from the strength of social relationships (Bourdieu, 1986; Coleman, 1988; Lin, 2001). Therefore, in the present study, I focus on parents' actions or 
behaviors of helping their children with educational success (e.g., helping with homework, participating school events) in order to examine family engagement. Also, I concentrate on the relationships between parents and children and between parents and other parents to study social capital, with a focus on immigrant families in particular.

\section{Conclusion}

A large body of studies found that family engagement is an important factor for children's educational success including academic achievement, lower drop-out rate, higher self-efficacy, or higher rate of college enrollment (Benner et al., 2016; Fan \& Chen, 2001; Domina, 2005; Hill \& Tyson, 2009; Jeynes, 2007; McNeal, 2001; Ryan \& Ream, 2016). Accordingly, parents, school, and policymakers have made an effort to elevate family engagement (Jeynes, 2011; Pomerantz et al., 2007). Immigrant parents are no exception: they have engaged in their children's education with strong motivations and positive expectations (Feliciano \& Lanuza, 2015; Shields \& Behrman, 2004). Yet, significant variations in family engagement have been observed within immigrant parents or between immigrant and native-born parents (Kao, 2001; Peguero et al., 2015).

Based on the literature review and theory, I hypothesize that different generational status (first-, second-, and third-plus-immigrant generational status) can shape immigrant family's social capital, and thereby, lead to adoption of specific types of family engagement (See Figure 2.1). In this causal mechanism, social capital can play a mediating role between 


\section{Figure 2.1}

Conceptual Framework of Generational Status, Social Capital, and Immigrant

Family Engagement.

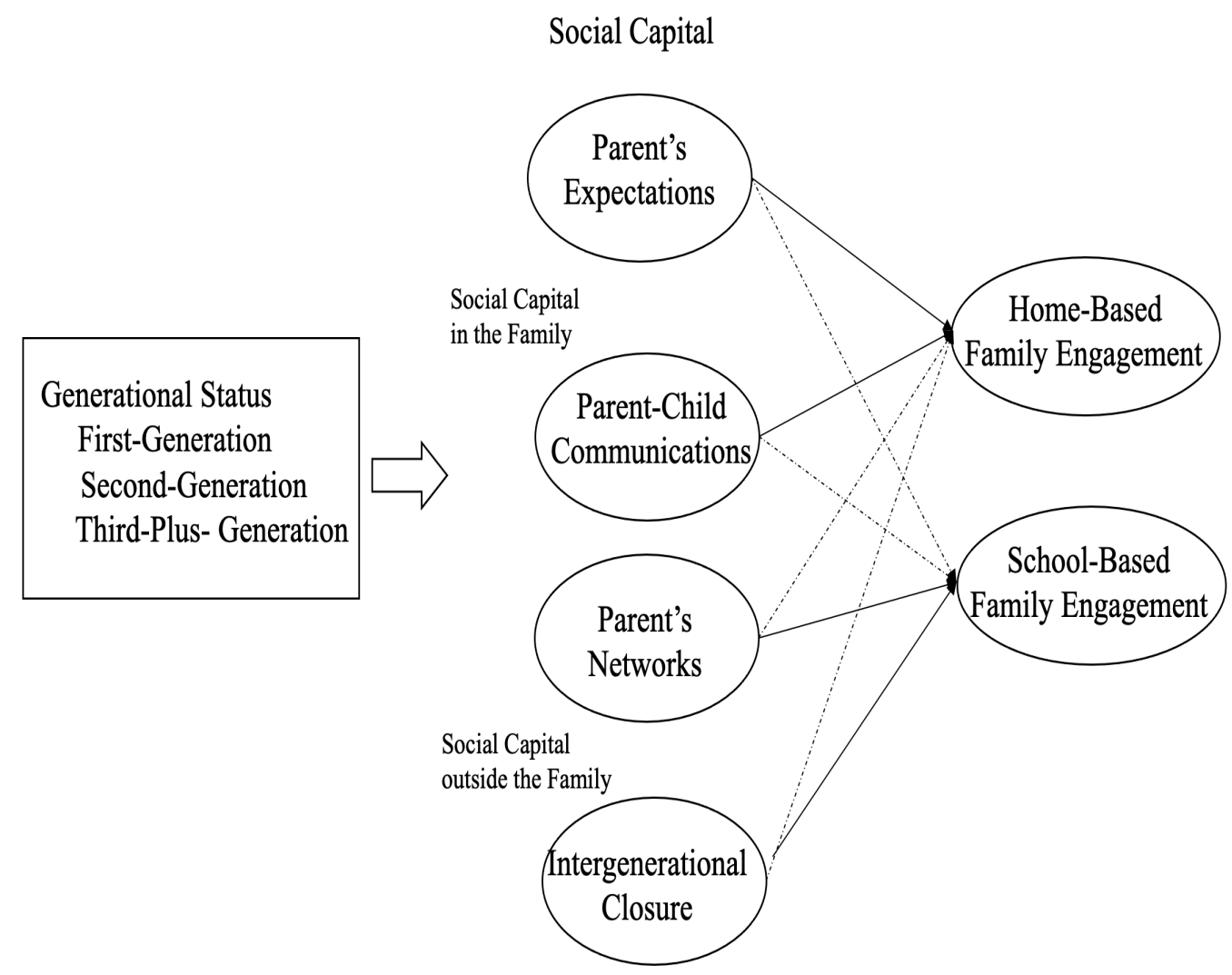

Note. Solid lines denote significant causal relationships, while dashed lines suggest insignificant causality.

generational status and family engagement. Drawing from the social capital theory, this study posits that based on immigrant families' generational status, they shape social capital either in or outside the family. This in turn is related to immigrant parents' efforts at either home-based or school-based family engagement. Social capital in the family might be positively related to immigrant parents' home-based family engagement activities. Conversely, school-based family engagement may be positively related to social capital outside the family.

In summary, only a limited number of studies have explored the processes that combine together to shape social capital and family engagement. Guided by the 
conceptual framework, this study examines the influences of immigrant generational status, social capital in and outside family, and types of family engagement. 


\section{Chapter 3. Methodology}

In this chapter, I discuss the methods employed for this study. In the first part of this chapter is provided the detailed description of the data. Then, I provide the information on each variable included in the analysis. The following part explains the analytical methods used to answer the research questions. As a review, my overarching research question was: What are the relationships among generational status (first-, second-, and third-plus), social capital (in and outside the family), and family engagement (home- and school-based)?

\section{Data and Sample}

The data for this study was gathered from the Education Longitudinal Study of 2002 (ELS:2002), the nationwide longitudinal survey data. The ELS:2002 is the fourth in a series of studies and is preceded by the National Study of the High School Class of 1972 (1972-1986), High School and Beyond (1980-1993), and the National Education Longitudinal Study of 1988 (1988-2000) from National Center for Education Statistics (NCES) (Ingels et al., 2014). The objective of the ELS:2002 is to monitor the transition of a national sample of young people as they proceed from high school into postsecondary education and the workplace (Ingels et al., 2004). The baseline survey of the ELS:2002 is completed for the $10^{\text {th }}$ graders in spring term 2002, and the follow-up surveys for them were completed in 2004, 2006, and 2012 (Ingels et al., 2014).

The data generating process of the ELS 2002 employed a two-stage sample selection process. Schools were the first-stage unit of the selection process, and it was with probability proportional to size (PPS). Overall, 1,221 eligible schools were selected from the population of approximately 27,000 schools containing $10^{\text {th }}$ graders. Among the eligible schools, 752 schools participated in the ELS:2002 survey. In the 
second stage, approximately twenty-six $10^{\text {th }}$ graders were randomly selected within each school. The initial sample size of the ELS:2002 was over 16,000 participants (Ingels et al., 2004).

The respondents of the ELS:2002 have included not only students, but also their parents, teachers, librarians, and school administrators. This study depended primarily on the surveys for $10^{\text {th }}$ graders and their parents in which survey questions were asked to one parent of each participating $10^{\text {th }}$ grader. The parent questionnaire was designed to examine parental expectations for their children, home educational support system, home background, and parental integrations with and opinions about the student's school. The parent questionnaire was provided both in English and in Spanish (Ingels et al., 2007).

\section{Data Rationale}

ELS:2002 is not the most recent data from NCES, because they released High School Longitudinal Study (HSLS:09) in 2009. However, ELS:2002 is more appropriate for this study than HSLS:09 for several reasons. First, it provides a broader coverage on diverse dimensions of family engagement than most previous studies. While the family engagement section consists of 6 main questions with 47 detailed items in the ELS:2002, HSLS:09 has only 13 questions (Ingels et al., 2004; Ingels et al., 2011). Specifically, for this research, it contains the level of parents' engagement in their children's academic performance. For example, $10^{\text {th }}$ graders were asked how often parents help with their homework or discuss grades, and parents were asked how often they attended school activities or contacted schools.

Second, the ELS:2002 contains questions to examine parents' social capital at home and in school. It provides more specific information on a source of parents' social capital: information about their children's close friends, their interactions with 
the parents of their children's friends, and the community in which they live. These are not covered in HSLS:09 (Ingels et al., 2004; Ingels et al., 2011). For example, one such question asks the extent to which parents interact with parents of the student's friends. This is the concept of intergenerational closure from Coleman (1988)'s social capital theory. Through these questions, researchers can learn about whether there exists a functional community that links families to schools and relationships between parents and adolescents (Ingels et al., 2007).

\section{Data Limitations}

The ELS:2002 is a longitudinal dataset, but the sample of this study took cross-sectional format because of the data restriction. The analytical sample of this study was $10^{\text {th }}$ graders and their parents, but parents participated only in the base year survey. Hence, this dataset had information on parents at a single time point. Thus, it was impossible to examine family engagement in a longitudinal manner using this dataset. In a cross-sectional design with a single-time point, it is more difficult to make a valid inference for causal relationships (Marsh, 2006; Maxwell et al., 2011; Wei et al., 2019). As such, the application of mediation models to cross-sectional data bears a risk of misrepresenting the results (Maxwell et al., 2011; Selig \& Preacher, 2009). Despite this methodological limit, this study still makes a substantial contribution by improving our understandings on the relationships among generational status, social capital, and family engagement.

\section{Analytical Sample and Weight}

The original data of this study included 13,488 first-, second-, and third-plusgeneration immigrant $10^{\text {th }}$ graders and their parents who participated in the base-year survey. I restricted the sample to those who provided complete information on the immigrant generational status (BYGNSTAT), which excluded 2,859 participants from 
the sample. I also excluded Native American students $(n=130)$ for their immigrant generational status. Therefore, total analytical sample number is 10,499 .

According to NCES (2007), the ELS:2002 is not a simple random sample of $10^{\text {th }}$ graders, but rather a stratified, two-stage random sample for this cohort of students. For this cohort, schools were selected at the first stage of sampling and students were randomly selected from those schools at the second stage. NCES recommends that weights must be used and be appropriately calculated to ensure accurate analysis of the ELS data (Ingles et al., 2007). This study used base-year data, so I applied base-year student weight (BYSTUWT) which is a cross-sectional weight as it pertains to only one round of data collection.

\section{Hypotheses of the Study}

The current study examines the relationship among generational status, social capital in and outside family and types of family engagement. I formulated following hypotheses based on the theoretical accounts suggested above:

Hypothesis 1: Parent's social capital differs significantly across immigrant generations. In particular, I hypothesize that relative to third-plus-generation families, first-and second-generation families are more likely to have social capital in the family (i.e., parent's expectations and parent-child communications). On the other hand, first- and second-generation families are less likely to have social capital outside the family compared to third-plus-generation families (i.e., parent's networks and intergenerational closure).

Hypothesis 2: Family engagement also differs significantly across immigrant generations. More specifically, I hypothesize that compared with third-plusgeneration families, first- and second-generation parents are more likely to engage in their child's education at home. In contrast, compared with third-plus-generation 
families, first- and second-generation families are less likely to engage in their child's education at school.

Hypothesis 3: The relationship between generational status and family engagement is mediated by social capital in and outside family. More specifically, I hypothesize that compared with third-plus-generation families, first- and secondgeneration families have a strength in building social capital in the family (i.e., higher parent's expectations and higher levels of parent-child communications), which, in turn, leads to a higher family engagement at home. Conversely, third-plus-generation families have greater social capital outside the family (i.e., higher parent's networks and higher levels of intergenerational closure) than first- and second-generation families, which makes them engage in their child's education more at school.

\section{Measures}

\section{Outcome Variables}

The key outcomes of this study are family engagement for adolescents at home and in schools. Based on the prior research (Benner et al., 2018; Fan \& Williams, 2010; Fantuzzo et al., 2014; Green at al., 2007; Hill \& Tyson, 2007; Sheldon, 2002Sui-Chu \& Willms,1996, Tang, 2015) and the students and parent questionnaire of ELS:2002, home-based family engagement in this study was consisted of two types of engagements: helping with homework or school projects and parent's monitoring at home. School-based family engagement included participation in school functions. To ensure the fit of the measurement model, I conducted confirmatory factor analysis (CFA) that accurately grouped the selected items for each factor, as follows. Table 3.1 showed the list of variables of this study.

\section{Home-Based Family Engagement}


To measure home-based family engagement, this study used parent's helping with homework and monitoring their children. Prior research suggested that helping with homework is an effective measure of home-based involvement in children's education (Gonida \& Cortina, 2014; Hill \& Tyson, 2009). Monitoring is an also widely used measure of home-based family engagement (Green et al., 2007; Hill \& Tyson, 2007; Toren, 2013). In particular, with the ELS:2002 data set, some researchers used monitoring or helping homework for measuring family engagement (Fan \& Williams, 2010; Ross, 2016). Measuring home-based family engagement was consisted of four items including: (a) parents check homework (BYS86A); (b) parents help homework (BYS85B); (c) special privileges given for good grades (BYS85C); and (d) limit the amount of time watching TV/playing video games (BYS85F). These four items were coded as: 1= "never", 2= "Rarely", 3= "Sometimes", and 4= "Frequently." CFA was conducted to combine these items and create the variable of home-based family engagement.

\section{School-Based Family Engagement}

Parent's participation in school functions is often used for measuring family engagement at school (Fan \& Williams, 2010; Hao \& Bonstead-Bruns, 1998; Israel et al., 2001; McNeal, 1999; You \& Sharkey, 2012). In the current study, the measure of parent's participation in school functions was assessed by three items. Sample items include 1) attend parent-teacher organization meetings (BYP54B); 2) act as a volunteer at the school (BYP54D); and 3) attend school activities with one's 10th grader (BYP57A). Because of the questionnaire format, these four items were coded as dichotomous variables (e.g., "Do you or your spouse/partner attend a parentteacher organization?”). I combined these items and created the variable of schoolbased family engagement using CFA. 


\section{Independent Variables}

\section{Generational Status}

Following prior research, generational status of this study was determined both by students and their parents' birthplace and classified into three types: first-, second-, or third-plus-generation immigrant (Peguero, 2011; Portes \& Rumbaut, 2001, 2006; Trevelyan et al, 2016). Three dummy variables were created for the generational status. First-generation immigrant students indicated that those who were born outside the United States, regardless of their mothers' birthplace ( 1 = firstgeneration, $0=$ else); second-generation immigrant students meant that one's born in the United States, but his/her mother was born outside the US territory $(1$ = secondgeneration, $0=$ else); and third-plus-generation immigrant students indicated that both the student and their mothers were born in the US $(1=$ third-plus-generation, $0=$ else). In the present study, following literature, I considered first- and secondgeneration groups are immigrant families, while third-plus-generation are considered as a part of the general non-immigrant population (Jiang \& Peterson, 2011; Singh et al., 2010; Trevelyan et al., 2016).

\section{Mediated Variables}

In the present study, I hypothesized that social capital plays a mediating role between generational status and family engagement. Based on Coleman (1988), I distinguished social capital in the family and outside the family. To ensure the fit of the measurement model, confirmatory factor analysis was conducted to check if the selected items for each factor were accurately grouped.

\section{Social Capital in the Family}

Social capital in the family was measured by two indicators: (a) parent-child communication; and (b) parental expectation for children's education. The first 
indicator, parent-child communication, was measured by eight items asking how frequently students spent time on communications with their parents. Following the prior literature (Fan \& Williams, 2010), I selected five items among them that address the communications between $10^{\text {th }}$ graders and parents from the ELS: 2002 base-year student questionnaire. The survey asked that how often students discuss about the following topics with their parents: school courses (BYS86A), school activities (BYS86B), things studied in class (BYS86C), grades (BYS86D), and preparation for ACT/SAT (BYS86F). These items are measured by 3-scale variables, ranging from "1 $=$ never," " $2=$ sometimes," and " $3=$ often." I combined these items and created the variable of parent-child communication using CFA.

Second, a number of studies suggested that parental expectations can be used to measure social capital within the family (Coleman, 1988; Hao \& Bonstead-Bruns, 1998; Muller \& Ellison 2001; Pong et al., 2005), because high parental expectations can lead more parent-child interactions in learning activities. Parental expectation is also related to trust which is the central concept of social capital (Coleman, 1988). Children who have a high degree of trustworthiness are more likely to have a sense of obligation to meet their parental expectation (Pong et al., 2005). In this study, parental expectation was measured by two parent questionnaires: "How far in school do you want your tenth grader to go (BYPARASP)?" and "How far in school parent expects 10th-grader will go?" (BYP81). On a seven-point scale with ' 1 ' representing the lowest level to ' 7 ' representing the highest level of parental expectation for child's education. Following is the detailed scale of this variable: $1=$ "Less than high school graduation", 2= "High school graduation or GED", 3 = "Attend or complete 2-year college/school", 4 = "Attend college, 4-year degree incomplete", 5 = "Graduate from 
college", 6 = "Obtain Master's degree or equivalent", 7 = "Obtain $\mathrm{PhD}, \mathrm{MD}$, or other advanced degree".

\section{Social Capital Outside the Family}

Social capital outside the family consisted of two factors: (a) intergenerational closure; and (b) parent's organization membership. Intergenerational closure refers to parents' relationship structure in which parents know their children's friends and their parents (Coleman, 1990). This is a commonly used measure of social capital outside the family (Kao \& Rutherford, 2007; Ryan \& Leam, 2016; Mogan \& Todd, 2009). Throughout intergenerational closure, parents can increase supervision and knowledge on their children's activities in and out of school. ELS:2002 asked parents to name their children's three closest friends and indicate whether they knew the parents (mother or father) of each friend (BYP59DA, BYP59DB, BYP59DC, BYP59EA, BYP59EB, BYP59EC). Kao and Rutherford (2007) totaled the answers to these questions, constructing a variable of intergenerational closure whose value ranges from 0 (knowing none of their child's friends' parents) to 6 (knowing parents of all six friends indicated). My intergenerational closure variable was created following Kao and Rutherford (2007).

Parent's networks was used as another indicator of social capital outside the family. A number of studies used parent's social networks to measure their social capital (Carbonaro, 1988; Coleman, 1988; Sheldon, 2002), because parents can build relationships with other parents throughout social networks. Further, this network can encourage the exchange of information, shape beliefs, and enforce norms of behavior which are main functions of social capital (Portes, 1998; Sheldon, 2002). In this study, parent's networks was measured by four items from the parent's questionnaire: (a) the number of times a parent of one of the student's friends gave the parent advice 
about the school's courses or teachers (BYP60A), (b) how often the parent has received a favor from a parent of one of the student's friends (BYP60B), (c) how often the parent has provided a favor to a parent of one of the student's friends (BYP60C), and 4) how often friend's parent supervised my tenth grader on an educational outing or field trip (BYP60D). CFA was conducted to combine these items and create the variable of parent's network.

\section{Background Variables}

Based on prior research on family engagement, this study includes six student related control variables and two school controls. Student covariates included parent's English proficiency, family structure, $10^{\text {th }}$ graders' test score, race, gender, and social economic status (SES). In addition, school controls included school size and school urbanicity.

Past studies explained that generational status affects the acquisition of English Language proficiency (Portes \& Hao, 1998; Rumbaut et al., 2006). The English proficiency of immigrant parents may stand for their capacities in understanding and communicating in English (Arias \& Morillo-Campbell, 2008). I followed the prior research (Jepsen, 2010; Jung \& Zhang, 2016), which concluded that the English proficiency should be measured by the ability to speak, listen, read or write in English. The ELS:2002 asked parents who did not identify English as their native language how well they do understanding spoken English (BYP 31a), speaking English (BYP31b), reading English (BYP 31c), and writing English (BYP 31d). 


\section{Table 3.1}

Variable list of the Study

\begin{tabular}{|c|c|c|}
\hline Variable & Description & ELS Label \\
\hline \multicolumn{3}{|l|}{ Outcome Variable } \\
\hline $\begin{array}{l}\text { Home-Based Family } \\
\text { Engagement }\end{array}$ & $\begin{array}{l}\text { How often do your parents check homework, help homework, special privileges given for } \\
\text { good grades, and limit the amount of time watching TV/playing video games? } \\
\text { (1= "never", } 2=\text { "seldom", } 3=\text { "usually", and } 4=\text { "always.") }\end{array}$ & $\begin{array}{l}\text { BYS85A } \\
\text { BYS85B } \\
\text { BYS85C } \\
\text { BYS85F }\end{array}$ \\
\hline $\begin{array}{c}\text { School-Based } \\
\text { Family Engagement }\end{array}$ & $\begin{array}{l}\text { Do you or your spouse/partner attend parent-teacher organization meetings, act as a } \\
\text { volunteer, attend activities with } 10^{\text {th }} \text { grader at the school? } \\
(0=\text { "No", } 1=\text { "Yes".) }\end{array}$ & $\begin{array}{l}\text { BYP54B } \\
\text { BYP54D } \\
\text { BYP57A }\end{array}$ \\
\hline \multicolumn{3}{|l|}{ Mediated Variable } \\
\hline $\begin{array}{l}\text { Social Capital in the } \\
\text { Family }\end{array}$ & $\begin{array}{l}\text { - Parental Expectation to their Child: } \\
\text { How far in school parent expects/wants 10th-grader will go? }(1=\text { "Less than high school } \\
\text { graduation", } 2=\text { "High school graduation or GED", } 3=\text { "Attend or complete } 2 \text {-year } \\
\text { college/school", } 4=\text { "Attend college, } 4 \text {-year degree incomplete", } 5=\text { "Graduate from } \\
\text { college", } 6=\text { "Obtain Master's degree or equivalent", } 7=\text { =Obtain PhD, MD, or other } \\
\text { advanced degree".) }\end{array}$ & $\begin{array}{l}\text { BYP81 } \\
\text { BYPARASP }\end{array}$ \\
\hline & $\begin{array}{l}\text { - Parent-Child Communication: } \\
\text { How often discussed school courses, school activities, things studied in class, grade, } \\
\text { preparation for ACT/SAT, college, and current events with parents? } \\
\text { (" } 1=\text { never," " } 2=\text { sometimes," and " } 3=\text { often.") }\end{array}$ & $\begin{array}{l}\text { BYS86A } \\
\text { BYS86B } \\
\text { BYS86C } \\
\text { BYS86D } \\
\text { BYS86F }\end{array}$ \\
\hline
\end{tabular}


Table 3.1 (Continued)

\begin{tabular}{|c|c|c|}
\hline Variable & Description & ELS Label \\
\hline \multirow[t]{2}{*}{ outside the Family } & $\begin{array}{l}\text { - Parent's Networks: } \\
\text { How many times did the parent of one of the student's friends gave the parent advice about } \\
\text { the school's courses or teachers, received a favor from the student's friend's parent, and } \\
\text { provided a favor to the student's friend's parent, and friend's parent supervised my tenth } \\
\text { grader on an educational outing or field trip? } \\
(1=\text { "none," } 2=\text { "once or twice," } 3=\text { "three or four times," and } 4=\text { "more than four } \\
\text { times.") }\end{array}$ & $\begin{array}{l}\text { BYP60A } \\
\text { BYP60B } \\
\text { BYP60C } \\
\text { BYP60D }\end{array}$ \\
\hline & $\begin{array}{l}\text { - Intergenerational Closure: } \\
\text { Do you know 10th grader's three closest friend's mother or father? } \\
(0=\text { "No", } 1=\text { "Yes".) }\end{array}$ & $\begin{array}{l}\text { BYP59DA } \\
\text { BYP59DB } \\
\text { BYP59DC } \\
\text { BYP59EA } \\
\text { BYP59EB } \\
\text { BYP59EC }\end{array}$ \\
\hline $\begin{array}{l}\text { Independent } \\
\text { Variable }\end{array}$ & & \\
\hline $\begin{array}{l}\text { Generational } \\
\text { Status }\end{array}$ & $\begin{array}{l}10^{\text {th }} \text { grader's immigrant generational status } \\
\text { (First-, Second-generations, and Third-plus-generational status) }\end{array}$ & BYGNSTAT \\
\hline \multicolumn{3}{|l|}{$\begin{array}{l}\text { Background } \\
\text { Variable }\end{array}$} \\
\hline Race & White, Black, Hispanics, or Asian & BYRACE \\
\hline $\begin{array}{l}\text { Parent's Socio- } \\
\text { Economic Status }\end{array}$ & $\begin{array}{l}\text { Parent's Socio-Economic Status } \\
\text { (Based on five equally weighted and standardized: Father's education attainment, Mother's } \\
\text { educational attainment, Family income, Father's occupation, and mother's occupation.) }\end{array}$ & BYSES1 \\
\hline
\end{tabular}


Table 3.1 (Continued)

\begin{tabular}{|c|c|c|}
\hline Variable & Description & ELS Label \\
\hline $\begin{array}{l}\text { Parent's English } \\
\text { Proficiency }\end{array}$ & $\begin{array}{l}\text { How well do you do understand, speak, read, and write English? } \\
\text { (1 = "not at all," } 2=\text { "not well," } 3=\text { "well," } 4 \text { = "very well", } 5 \text { = "English native speaker") }\end{array}$ & $\begin{array}{l}\text { BYP31A } \\
\text { BYP31D } \\
\text { BYP31C } \\
\text { BYP31D }\end{array}$ \\
\hline Family Structure & $10^{\text {th }}$ Grader Live with Mother and Father ( $0=$ "No", $1=$ "Yes".) & BYFCOMP \\
\hline Gender & $10^{\text {th }}$ grader's gender (male or female) & BYSEX \\
\hline School Urbanicity & Urban or not located urban & BYURBAN \\
\hline School Size & 10th grade enrollment of the school & BYG10EP \\
\hline
\end{tabular}


Each item is coded in a 4-point Likert scale from "not at all (4)" to "very well (1)." In this study, these four items are coded in the reverse order $(1=$ "not at all," 2 = "not well," 3 = "well," and 4 = "very well") so that a higher score represents higher proficiency in English. However, these items did not cover all the immigrant parents, especially the third- and plus generation immigrants who identified English as their native language. Therefore, I coded those parents 5, which was the highest level of English language proficiency. This is because the possibility for turning later-learnt languages into a native one is extremely low (Cook, 1994). Furthermore, even if adult non-native speakers may acquire a high degree of English proficiency, they may still have diverse issues in proficiency or expertise compared to native speakers (Davies, 1996, 2003; Rampton, 1990). In sum, immigrant parent's English language proficiency was measured by four items, the ability of understanding, reading, speaking, and listening, and they are recoded: $1=$ "not at all," $2=$ "not well," $3=$ "well," 4 = "very well", and 5 = "English native speaker". All of the four items were summed up to generate the total score on the parent's English proficiency measure (Shin, 2009; Jung \& Zhang, 2016). The internal consistency reliability (Cronbach's alpha) for the four-item scale of reported English proficiency was .99 .

Family structure was selected as another student level control variable, because it may be highly related to building social capital (Astone \& McLanahan, 1991). A child with less adult attention might have insufficient opportunities to shape social capital with their parents or caregivers. For example, children from single-parent families obtain less parent attention and limited access to social capital than those who live with both natural parents (Coleman, 1988). ELS:2002 provided the information on family (parents) composition from the parent questionnaire (BYFCOMP), and this item was coded: $1=$ " $10^{\text {th }}$ grader lives both their mother and 
father"; and $0=$ " $10^{\text {th }}$ grader does live both their mother and father" (child has singleparent or does not have parents).

The current standardized test score composite of $10^{\text {th }}$ graders variable was also included, because parents are more likely to engage in their children's education, when the children are accomplishing notable academic success (Turney \& Kao, 2009). Demographic factors of $10^{\text {th }}$ graders (i.e., gender and race) were also added to the models following previous studies (Turney \& Kao, 2009). Immigrants' characteristics, experiences, cultures, or lifestyles can vary depending on their racial features, hence I controlled for the race of immigrants (Pew Research Center, 2012). Immigrant families' socio-economic status were also added as a covariate. To measure family socio-economic status, this study employed the composite variable measuring SES (BYSES) in ELS:2002. This composite variable was constructed based on five equally weighted, standardized components: father's/caregiver's education, mother's/caregiver's education, family income, father's/caregiver's occupation, and mother's/caregiver's occupation (Ingels et al., 2004).

School covariates were school size and locations. First, the literature suggested that the level of family engagement can vary across school size (Crosnoe, 2001; Dee et al., 2006; Walsh, 2010). For example, Walsh (2010) showed that parents are 2 percentage points less likely to keep their contacts with schools, and 5 percentage points less likely to volunteer when the school size doubles. ELS:2002 provides the information on the $10^{\text {th }}$ grade enrollment of the school (BYG10EP). This variable was controlled for in the analysis as an indicator of school size. School locations are also related to family engagement (Prater et al, 1997). Compared to parents whose children attend suburban schools, those with children attending urban or rural schools are more likely to check their children's homework (Prater et al., 
1997). The dummy variable was created for school locations (BYURBAN: $1=$ urban, $0=$ else)

\section{Analytical Methods}

This analysis encompassed four main phases. First, the ELS:2002 data was downloaded from the National Center for Education Statistics (NCES) website. Stata 14 was used to clean and recode the variables, and it was also used to conduct descriptive analysis. Then, the data was converted to Mplus 8.3 (Muthén \& Muthén, 2017) for confirmatory factor analysis (CFA) and structural equation modeling (SEM). Second, using CFA, I tested two hypothesized social capital measurement models for finding a satisfying model to the data set. I also conducted CFA for confirming home-and school-based family engagement models. Lastly, I used structural equation modeling to evaluate the relationship between generational status, social capital, and family engagement.

\section{Confirmatory Factor Analysis}

After the data cleaning, confirmatory factor analysis (CFA) was conducted to analyze the measurement model specifying the associations between latent constructs and their corresponding indicator items (Bollen, 1989). CFA is regarded as a part of the structural equation modeling, and it usually plays an important role in evaluating the measurement model before a SEM is conducted (Byrne, 2013). CFA is performed to analyze the proposed measurement model explicitly specifying the associations between latent constructs and their corresponding observed indicators (Byrne, 2010; Wang \& Wang, 2012). If the model fits are not acceptable, the CFA measurement models should be modified (Kline, 2011).

\section{Measurement Model: Social Capital}


It is important to find appropriate measurement models for the dataset, hence many studies introduce how to conduct CFA (Byrne, 2005; Muller \& Hancock, 2007; Schumacker \& Lomax, 2010). Theory is the most important part of CFA models; accordingly, I have referred to the literature about social capital to establish the measurement models (Coleman 1988; McNeal, 1999; Ryan \& Leam, 2016). In the current study, there were two hypothesized measurement models of social capital. As described above, social capital is regarded to consist of four latent constructs which are parent-child communications, parent expectations, parent's networks, and intergenerational closure. Based on the hypothetical framework, this study compared two measurement models: first-order factor and second-order factor models.

A first-order factor model was designed to test the multidimensionality of a theoretical construct (Byrne, 2012). In the present study, the first-order factor model defined four correlated primary factors corresponding to the four theoretical dimensions. In other words, this application tests the hypothesis that social capital is a multidimensional construct composed of four factors- parent-child communications, parent expectations, parent's networks, and intergenerational closure (see Figure 3.1). The model also requires an assumption that the first-order factors are correlated. Yet, this model usually does not specify a priori the direction of the mutual association of these four factors by placing restrictions on these correlations (Brunner et al., 2011).

Some researchers also used first-order factor models for measuring social capital. For example, using ELS:2002 data set, Ryan and Ream (2016) examined the relationship among parent social capital, college-aligned actions, and four-year college enrollment. In this study, there were three latent constructs representing various forms of parent social capital such as college-relevant school social capital, college-relevant family social capital, and intergenerational closure. First-order factor 
model was used to examine the measurement model specifying the associations between these latent constructs and their corresponding observed items (Ryan \& Ream, 2016).

\section{Figure 3.1}

Social Capital Measurement Model 1: First-order Factor Model

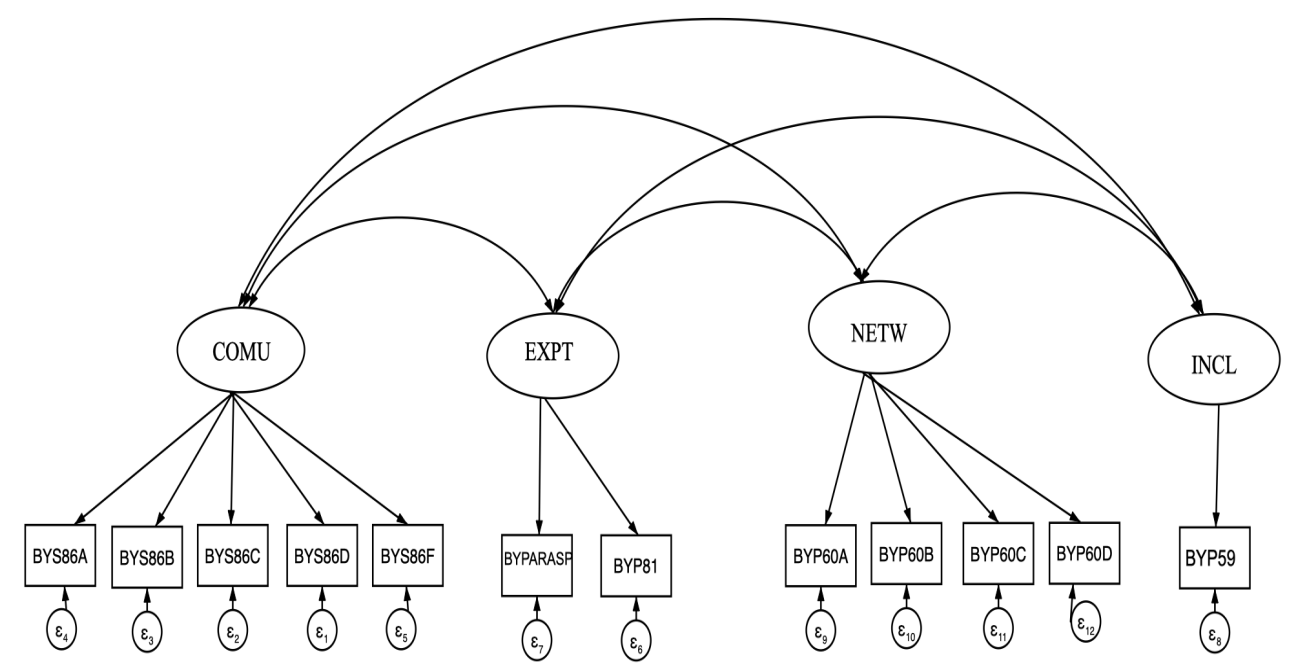

Note. EXPT $=$ parent's expectations, $\mathrm{COMU}=$ parent-child communications, NETW $=$ parent's networks, and INCL= parent's intergenerational closure

Social capital measurement model 2 was a second-order factor model (See Figure 3.2). A second-order factor model can be used when (a) first-order factors are substantially correlated with each other, and (b) there is a higher-order factor which is hypothesized to explain the relationship among first-order factors (Chen et al., 2006). Like a first-order factor model, theory plays an essential role in justifying a higherorder factor (Schumacker \& Lomax, 2010). In the current study, it consisted of four primary factors and one second-order factor (i.e., social capital) underlying the primary factors. 


\section{Figure 3.2}

Social Capital Measurement Model 2: Second-order Factor Model

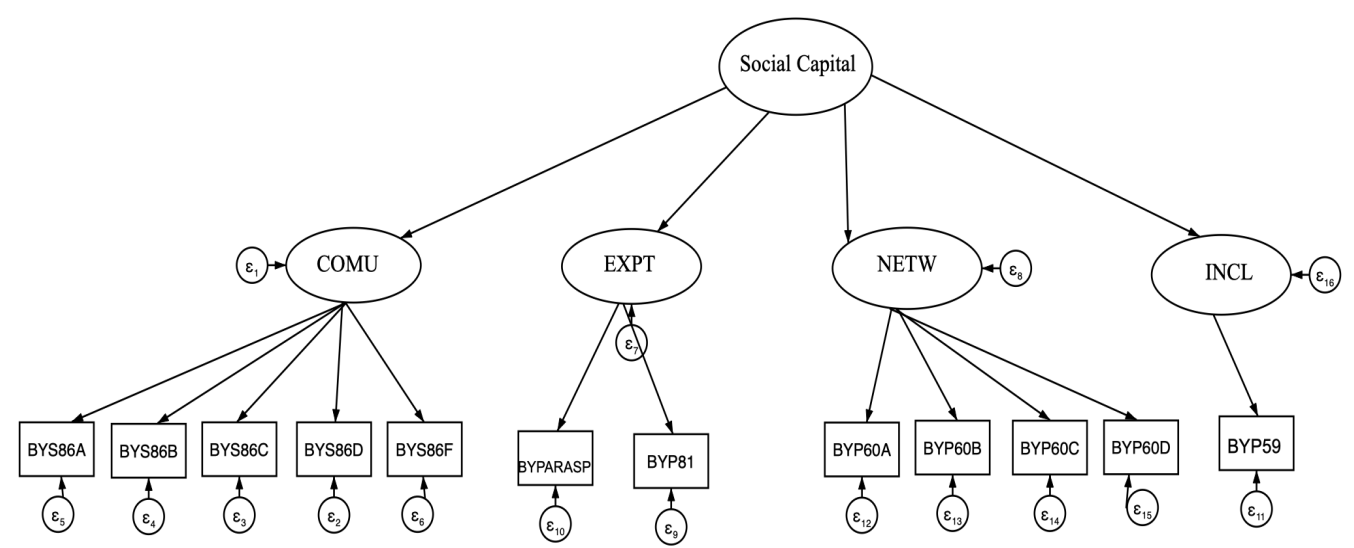

Note. EXPT $=$ parent's expectations, $\mathrm{COMU}=$ parent-child communications, NETW $=$ parent's networks, and INCL $=$ parent's intergenerational closure

\section{Measurement Model: Family Engagement}

The factor structure of home-and school-based family engagement was explored by testing one-factor confirmatory factor analyses respectively. Following past studies, home-based family engagement consisted of one primary factor with loadings on all four observed items including checking homework, helping homework, giving special privileges for good grades, and limiting the amount of time watching TV (Fan \& Williams, 2010; Ross, 2016). School-based family engagement also consisted of one primary factor with loadings on all three observed items. As it is a widely used primary factor for measuring family engagement at school, this study used parent's participation in school functions for measuring school-based engagement (Hao \& Bonstead-Bruns, 1998; Israel et al., 2001; McNeal, 1999). Three items including attending parent-teacher organization meetings, acting as a volunteer at the school, and attending school activities with 10th grader were used for measuring school-based family engagement.

\section{Model Goodness-of-Fit Statistics}


The model fits were assessed with the Comparative Fit Index (CFI), TuckerLewis Index (TLI), and the Root Mean Square Error of Approximation (RMSEA). The CFI compares the fit of the hypothesized model to the null model (Hooper et al., 2008). The CFI above 0.95 indicates a good fit to the data (Hu \& Bentler, 1999). The TLI, also known as the Non-Norm Fit index, assesses the model by comparing the chi-square values of the hypothesized and the null models. Like CFI, A value of 0.95 or higher is considered a good fit (Raykov \& Marcoulides, 2006). The RMSEA tells us "how well would the model, with unknown but optimally chosen parameter values, fit the population covariance matrix if it were available?" (Browne \& Cudeck, 1993, pp. 137). A RMSEA value of 0.06 or smaller to be indicative of good fit between the hypothesized model and the observed data (Hu \& Bentler, 1999).

\section{Analysis}

Following CFA, the proposed conceptual model was tested using structural equation modeling (SEM). SEM extends the possibility of relationships among the latent variables and includes two components: (a) a measurement model (the CFA) and (b) a structural model (Schreiber et al., 2006). SEM has several advantages for this study. First, the current study includes several latent constructs such as social capital and family engagement which are not directly observable. The measurement model of SEM displays the pattern of observed variables for those latent constructs in the proposed model (Schreiber et al., 2006). In other words, the structural model provides the interrelations among latent constructs and observable variables in the hypothesized model. Thus, SEM is an appropriate approach for this research. Second, this study seeks to examine mediating effects of social capital on the relationship between generational status and family engagement. As such, it requires to examine both direct and indirect effects. Using SEM, researchers simultaneously estimate the 
magnitude of both direct and indirect effects (Schneider et al., 2007). SEM is different from running regression models multiple times, since it conducts the CFA, the path analysis, and the mediating effects in the same model.

The final SEM model consisted of generational status, relevant social capital, and home- and school-based family engagement measurement models from CFA. To address the research questions of this study, I began by testing hypotheses about the direct associations between the generational status, social capital factors, and homeand school-based family engagement. Then, I conducted a path modeling in the form of multi-categorical mediation analyses (Hayes \& Preacher, 2014), because the predictor variable (generational status) of this study is categorical (first-, second-, and third-plus-generational status). This approach allows evaluating indirect effects of mediators with a categorical predictor (Deuling \& Burns, 2017). Like CFA, the SEM model fit was assessed by the Comparative Fit Index (CFI), Tucker-Lewis Index (TLI), and the root mean square error of approximation (RMSEA). CFI values and TLI values greater than 0.95 and RMSEA values smaller than 0.06 indicate good fit of the model (Hu \& Bentler, 1999).

The analyses were conducted using Mplus 8.3 (Muthén \& Muthén, 2017), a statistical software package. In particular, although the ELS:2002 has a nested structure with students nested within schools, my research questions are centered on a single level (i.e., $10^{\text {th }}$ graders and their parents). Therefore, I used “TYPE=COMPLEX” procedure of Mplus which produces correct parameters estimates, standard errors, and test statistics in the presence of interdependency (Muthén \& Muthén, 2015). In other words, using the command, the school where $10^{\text {th }}$ graders attended as the cluster variable, permits me to take the data dependency (i.e., students nested within schools) into account in a single-level analysis. Regarding 
mediated analysis, the indirect paths from social capital variables to family engagement are estimated and the associated indirect effects were calculated and tested for statistical significance using Mplus's MODEL INDIRECT command. The mediating variables are allowed to correlate with each other.

\section{Conclusion}

In summary, the present study examined the relationship between generational status, social capital, and types of family engagement in immigrant families using the national representative data, the ELS:2002. This dataset is appropriate for my research, because it provides questionnaires regarding various dimensions of family engagement, parental factors in immigrant families, and social capital in and outside the family. As for methodological approach, this study employed CFA and SEM. It has several advantages for this study. First, SEM works better to show the pattern of observed variables for those latent constructs in the hypothesized model (Schreiber et al., 2006). Second, this study examines mediating effects of social capital as well as direct effects of immigrant parents' background on family engagement. SEM enables researchers to more precisely estimate the magnitude of both direct and indirect effects (Schneider et al., 2007).

To ensure a satisfactory measurement model, I used CFA. There are two hypothesized measurement models of social capital: first-order and second-order factor models. One-factor CFA is used for home-and school-basement measurement models. The final SEM model consisted of generational status, appropriate social capital measurement model from CFA, and home-and school-based family engagement. The independent variable of this study is categorical (first-second-, and third-generational status), hence conducted path modeling in the form of multicategorical mediation analyses (Hayes \& Preacher, 2014). 


\section{Chapter 4. Results}

This study examined the associations among generational status, social capital (both in and outside the family) and home-and school-based family engagement. This chapter consists of three parts. The first discusses the results of CFA. Three latent constructs of social capital, home-based family engagement, and school-based family engagement were tested and evaluated for goodness of fit to the data. Second, I describe the average characteristics of the sample reflected by the variables and constructs of interest in this study. Lastly, I introduce and interpret the results from the final SEM model including the direct and the indirect path analyses.

\section{Results of Confirmatory Factor Analyses}

\section{Social Capital Measurement Model}

As discussed earlier, the factor structure of social capital was explored by testing two theoretical models with means of first- and second-order confirmatory factor analyses. The first-order factor model in this study defined four correlated primary factors corresponding to the theoretical dimension of parent-child communications, parent expectations, intergenerational closure and parent's networks. The second-order factor model defined the same four primary factors and one second-order factor (social capital) underlying the primary factors.

The results of the model fit indicated that the first-order model had a good fit to the data. The CFI value of 0.990 and the TLI value of 0.987 were both above the recommended threshold of 0.95 (Hu \& Bentler, 1999). The 90\% confidence intervals for RMSEA value from 0.034 to 0.037 were below 0.06 , indicating a good fit (Hu \& Bentler, 1999). The test statistics for the second-order model showed a good fit overall but was weaker than that of the first-order model. The CFI value of 0.983 and the TLI value of 0.978 showed a sign of a good fit. The upper bound of $90 \%$ 
confidence intervals $(0.061)$ slightly went above the recommended threshold of 0.06 , but the previous studies have treated this marginal deviation still an acceptable fit (see Browne \& Cudeck, 1993). Table 4.1 provides the results of two social capital measurement models.

\section{Table 4.1}

Social Capital Measurement Component Results (Standardized)

\begin{tabular}{lllll}
\hline & CFI & TLI & RMSEA & RMSEA90\%CI \\
\hline First-Order Factor Model & 0.990 & 0.987 & 0.035 & $0.034-0.037$ \\
Second-Order Factor Model & 0.983 & 0.978 & 0.058 & $0.057-0.061$ \\
\hline
\end{tabular}

These four indices suggested that the first-order factor model might have a better fit to the data than the second-order factor model (See Table 4.1). It also denoted that social capital is a multidimensional construct, hence I should use subfactors of social capital in the final model. As for correlations, social capital consists of four correlated primary factors with four corresponding items. The correlations between each of the four latent factors in the first-order factor model are significant and consistent with the theory of this study (See Table 4.2).

\section{Table 4.2}

Correlations Between the Four Dimensions of the Social Capital (First-Order Model)

\begin{tabular}{lllll}
\hline & EXPT & COMU & NETW & INCL \\
\hline EXPT & - & & & \\
COMU & 0.247 & - & & \\
NEWT & 0.087 & 0.100 & - & \\
INCL & 0.110 & 0.128 & 0.296 & - \\
\hline
\end{tabular}

Note. All correlations are significant at $\mathrm{p}<.001, \mathrm{EXPT}=$ parent's expectations, $\mathrm{COMU}=$ parent-child communications, $\mathrm{NEWT}=$ parent's networks, and INCL $=$ parent's intergenerational closure.

The CFA model also emphasized how and to what extent the observed variables are related to their underlying latent factors. In other words, it took into 
account the extent to which the observed variables are generated by the primary latent constructs. The strength of regression paths from factors to observed variable is called factor loading, and it is of the primary interest of factor analysis. (Byrne, 2013). Therefore, I tested factor loadings of the first-order social capital measurement model. The results showed that all the standardized factor loadings were above 0.4 and significant at $\mathrm{p}<0.001$, which implies a good convergent validity of the measurement model (Hair et al., 1998) (See Table 4.3). Furthermore, some researchers have already used a first-order factor model for measuring parent's social capital with the same dataset (Ryan \& Ream, 2016). Taken together, I concluded that the first-order factor model was an appropriate social capital measurement model for the present study.

\section{Table 4.3}

Factor Loading for All Latent Variables (Standardized)

\begin{tabular}{lcc}
\hline \multicolumn{1}{c}{ Latent Construct } & \multicolumn{2}{c}{ Factor Loadings } \\
\hline & $b$ & \\
Parent-Child Communications & & \\
Discussion about school courses & 0.830 & 0.005 \\
Discussion about school activities & 0.821 & 0.006 \\
Discussion about things studied in class & 0.811 & 0.006 \\
Discussion about grade & 0.729 & 0.008 \\
Discussion about preparation for ACT/SAT & 0.639 & 0.009 \\
Parent's Networks & & \\
Friends' parent gives advice & 0.591 & 0.011 \\
Friends' parent does favor & 0.953 & 0.005 \\
Friends' parent receives favor & 0.913 & 0.006 \\
Friends' parent supervises on field trip & 0.494 & 0.012 \\
Parents belong parent's organization & 0.448 & 0.014 \\
Parent's Expectations & & \\
Parent's expectation & 0.997 & 0.021 \\
Parent's aspirations & 0.734 & 0.016 \\
Home-Based Family Engagement & & \\
Check homework & 0.784 & 0.007 \\
Help homework & 0.801 & 0.007 \\
Special privileges given for good grades & 0.560 & 0.008 \\
Limit the amount of time watching TV & 0.433 & 0.009 \\
\hline
\end{tabular}




\begin{tabular}{lll}
\hline School-Based Family Engagement & & \\
Attend parent-teacher organization meetings & 0.752 & 0.012 \\
Take part in parent-teacher organization & 0.700 & 0.012 \\
Attend school activities with 10th grader & 0.935 & 0.010 \\
\hline
\end{tabular}

Note. All parameter estimates significant at $\mathrm{p}<.001$.

\section{Family Engagement Measurement Model}

CFA analyses were also conducted for the home-and school-based measurement models. The home-based family engagement had four observed variables: whether parents (a) check homework, (b) help homework, (c) place special privileges on good grades, and (d) limit the amount of the time watching TV. The school-based family engagement had three observed variables: whether parents (a) attend parent-teacher organization meetings, (b) act as a volunteer at schools, and (c) attend school activities with $10^{\text {th }}$ graders. For model goodness-of-fit statistics, both measurement models showed a good fit to the data overall.

For the home-based family engagement model, the CFI value of 0.995 and the TLI value of 0.984 were both well beyond the recommended threshold of 0.95 . The RMSEA value of 0.056 with the $90 \%$ confidence intervals from 0.049 to 0.059 was below 0.06, indicating a good fit (Hu \& Bentler, 1999). Regarding the school-based family engagement, the CFI value of 0.995 and the TLI value of 0.984 had a good fit to the data as well. RMSEA value of 0.056 with the $90 \%$ confidence intervals from 0.052 to 0.073 were also acceptable fit to the data (MacCallum et al., 1996). The model fits of each measurement analysis were presented in Table 4.4.

\section{Table 4.4}

Family Engagement Measurement Component Results (Standardized)

\begin{tabular}{lllll}
\hline & CFI & TLI & RMSEA & RMSEA $90 \%$ CI \\
\hline Home-Based Family Engagement & 0.995 & 0.984 & 0.056 & $0.049-.0059$ \\
School-Based Family Engagement & 0.995 & 0.984 & 0.040 & $0.030-0.051$ \\
\hline
\end{tabular}


Like the social capital measurement model, factor loadings of home- and school-based family engagement for each of the observed variables on their corresponding latent constructs were tested (See Table 4.3). The results indicated that the path coefficients of homework check, homework help, privileges to good grades, and limit on watching were respectively $0.784,0.801,0.560$, and 0.433 . For the school-based family engagement, participation in parent-teacher organization showed the best load at the highest at 0.935 , followed by belonging to parent-teacher organizations at 0.735 , attending parent-teacher organization meetings at 0.700 , and volunteering for schools at 0.652 . The results showed that all the standardized factor loadings are above 0.40 and significant at $\mathrm{p}<0.001$, which provided enough support for the validity of these variables to represent the latent constructs (Hair et al., 1998).

In summary, the results of the CFA analyses for home-and school-based family engagement indicated that both models had a good fit to the data. The direction of each factor loadings was consistent with the theory, and statistically significant. The findings offered reasonable evidence that the home- and school- based measurement models were adequate for the present study. In the following section, I will describe the average characteristics of the sample reflected by the variables of interest in this study.

\section{Descriptive Statistics}

Descriptive statistics are presented in Table 4.5 to provide a comprehensive picture of generational status, social capital, family engagement, and background characteristics. Without testing yet for significance (which I do in the next section on direct effects), the descriptive results showed some notable differences between thirdplus-generation families and first- and second-generation families in their access to social capital. For example, the third-plus-generation families scores on the parent 
expectation to their child ranged from 1 (less than high school graduation) to 7 (obtain advanced degree), with $M=4.84 ; S D=1.40$, while the scores of the first- and secondgenerations were $M=5.48 ; S D=1.32$ and $M=5.46 ; S D=1.29$, respectively. This suggested that third-plus parents, on average, had fewer expectations for their child's education than those of first-and second-generation, despite higher GPA of third-plus youths $(M=51.72 ; S D=9.74)$ than earlier generation youths (first: $M=48.09 ; S D=$ 10.38, second: $M=50.72 ; S D=10.08$ ). The scores on the membership to parents' networks also showed a significant difference between third-plus-generation and firstand second-generations. The result indicated that third-plus-parents, on average, were more connected to other parents. Likewise, the intergenerational closure of third-plusgeneration families is higher than first-and second-generation families. Specifically, third-plus-parents knew more parents of their child's friends $(M=4.95 ; S D=1.69)$ than those of the other generations (first: $M=4.07 ; S D=2.38$, second: $M=4.40$; $S D=2.11)$. However, the descriptive statistics showed no noteworthy in parent-child communications across three generation groups.

As for family engagement, third-plus-generation parents were even more engaged than those of the other generational groups in school-based activities (first-: $M=1.25 ; S D=0.67$, second-: $M=1.01 ; S D=0.67$; third-plus: $M=1.08 ; S D=$ 0.68). However, there was no noteworthy in home-based family engagement across three generation groups.

Table 4.5 also provides summary statistics of demographics in the sample. For firstgeneration families, Asian students represented $42 \%$ of the sample, followed by Hispanics (37\%), White (24\%), and Black students (6\%). Second-generation students in the sample consisted of Hispanics (39\%), Asians (38\%), White (17\%), and Black students $(7 \%)$. With regard to third-plus-generation families, the majority of students 
were Whites (75\%). Blacks and Hispanics were $15 \%$ and $8 \%$ of the sample, respectively. Asian students took a very small portion in the sample of the third-plusgeneration (1\%). As for the parent's English proficiency (1- not at all to 5-English native speaker), first-generation parents score is $M=3.16 ; S D=1.39$. The average scores of second-and third-plus generation were $M=3.65, S D=1.28$ and $M=4.97$; $S D=0.22$, respectively. The result indicated that first-and second-generation parents had a similar level of self-perceived English proficiency in understanding, listening, reading, and writing. It also denoted that almost every third-plus-parent reported English as their primary language. Parents' socio-economic status composite score ranged from -2.11 to 1.80 . The score of first-generation family is $M=-0.23, S D=$ 0.86 , which is substantially lower than those of second- $(M=-0.07 ; S D=0.84)$ and third-plus-generation families $(M=0.13 ; S D=0.70)$. In terms of family structure, a greater share of second-generation students reported to live in the same home with both biological parents $(M=0.66 ; S D=0.47)$, relative to the other groups (first-: $M=$ $0.62 ; S D=0.49$, third-plus: $M=0.59 ; S D=0.49$ ).

For school characteristics, third-plus-generation students enrolled to smaller size schools $(M=3.15 ; S D=1.73)$ than first- $(M=4.38 ; S D=1.84)$ and secondgeneration students $(M=4.39 ; S D=1.88)$. As for the school location, schools with more first- and second-generation students were located in urban areas (firstgeneration: $M=0.47 ; S D=0.50$ and second-generation $M=0.42 ; S D=0.49$ ) compared to schools with more third-plus-generation students $(M=0.29 ; S D=0.45)$. 


\section{Table 4.5.}

Descriptive Statistics on Primary Study Measures Among First-, Second-and Third-Plus-Generation Students

\begin{tabular}{lcccc}
\hline \multicolumn{1}{c}{ Variables } & First & Second & Third-Plus & Range \\
& $M(S D)$ & $M(S D)$ & $M(S D)$ & \\
\hline Parent Expectations & $5.48(1.32)$ & $5.46(1.29)$ & $4.84(1.40)$ & 1 (Less than high school grad) - \\
& & & & 7 (Obtain advanced degree) \\
Parent-Child Communications & $2.26(0.70)$ & $2.07(0.69)$ & $2.11(0.67)$ & 1 (never) - 3 (often) \\
Parent's Networks & $1.65(0.89)$ & $1.72(0.94)$ & $1.92(0.94)$ & 1 (never) - $4(5+$ times) \\
Intergenerational Closure & $4.07(2.38)$ & $4.40(2.11)$ & $4.95(1.69)$ & 0 (do not know) - 6 (know) \\
Home-Based Family Engagement & $2.57(1.02)$ & $2.58(1.02)$ & $2.60(1.12)$ & 1 (never) - 4 (often) \\
School-Based Family Engagement & $1.01(0.67)$ & $1.07(0.68)$ & $1.25(0.67)$ & 0 (no), 1 (yes) \\
10 ${ }^{\text {th }}$ Grader's Test Score & $48.09(10.38)$ & $50.72(10.08)$ & $51.72(9.74)$ & $20.91-81.04$ \\
Family Structure & $0.62(0.49)$ & $0.66(0.47)$ & $0.59(0.49)$ & 1 (Two-Parents Family), \\
& & & & 0 (Single-Parent Family) \\
Parent's Socio-Economic Status & $-0.23(0.86)$ & $-0.07(0.84)$ & $0.13(0.70)$ & $-2.11-1.82$ \\
Parent's English Proficiency & $3.16(1.39)$ & $3.65(1.28)$ & $4.97(0.22)$ & 1 (not at all) - \\
& & & & 5 (English native speaker) \\
White & $0.14(0.35)$ & $0.17(0.37)$ & $0.75(0.43)$ & 0 (no), 1 (yes) \\
Hispanic & $0.37(0.48)$ & $0.39(0.49)$ & $0.08(0.27)$ & 0 (no), 1 (yes) \\
Black & $0.06(0.25)$ & $0.07(0.25)$ & $0.15(0.36)$ & 0 (no), 1 (yes) \\
Asian & $0.42(0.49)$ & $0.38(0.48)$ & $0.01(0.11)$ & 0 (no), 1 (yes) \\
Female & $0.52(0.50)$ & $0.50(0.50)$ & $0.50(0.50)$ & 0 (no), 1 (yes) \\
School Urbanicity & $0.47(0.50)$ & $0.42(0.49)$ & $0.29(0.45)$ & 0 (non-Urban), 1 (Urban) \\
School Size & $4.38(1.84)$ & $4.39(1.88)$ & $3.15(1.73)$ & 1 (99 or less student) - \\
& & & & 7 (700 or more students) \\
\hline
\end{tabular}


In summary, first-and second- generation immigrant families had more characteristics in common and showed greater diversities in comparison to third-plusgeneration families. In the next sections, I will describe the results of the final SEM model. In the current study, SEM analyses were used to estimate the relationship among student generational status, family social capital, family engagement types. Following the results of CFA, I included the first-order social capital model, and the home- and the school-based family engagement models, which have shown good model fit, to my final SEM estimation.

\section{SEM Models}

Figures 4.1 and 4.2, and Table 4.6 present the results of the final SEM models. In the current study, I categorized generational status into three groups of first-, second-, and third-plus-generations. The third-plus-generation was omitted as the reference group in all the models. First, the overall model fits were good to the data. The CFI value of 0.946 , the TLI value of 0.930 , and the RMSEA value of 0.033 with the $90 \%$ confidence intervals from 0.032 to 0.034 .

For the sake of clarity of the final SEM model, I begin by describing the direct paths within the model. In these analyses, I examined the relationship between generational status and social capital factors which are parents' expectations, parentchild communications, parents' networks, and intergenerational closure. Next, the association between these four types of social capital and home-and school-based family engagements and then the results from mediation analyses are discussed. Additionally, it should be noted that this study estimates the single final SEM model, but it is broken down into different the results, tables, and figures for the reporting purposes.

\section{Testing Direct Paths between Generational Status and Social Capital}


Figures 4.1 and 4.2 show that generational status was significantly related to social capital shaped by immigrant families. In the present study, social capital was categorized into two types: social capital in the family (i.e., parent's expectations and parent-child communications) and social capital outside the family (i.e., parent's networks and intergenerational closure). Regarding social capital in the family, the results suggested that first-generational status had a positive correlation at a statistically significant level. More specifically, relative to third-plus generation, firstgenerational status was significantly associated with parent's expectation to their children $(b=0.338, S E=0.051)$ and parent-child communications $(b=0.138, S E=0.048)$,

\section{Figure 4.1}

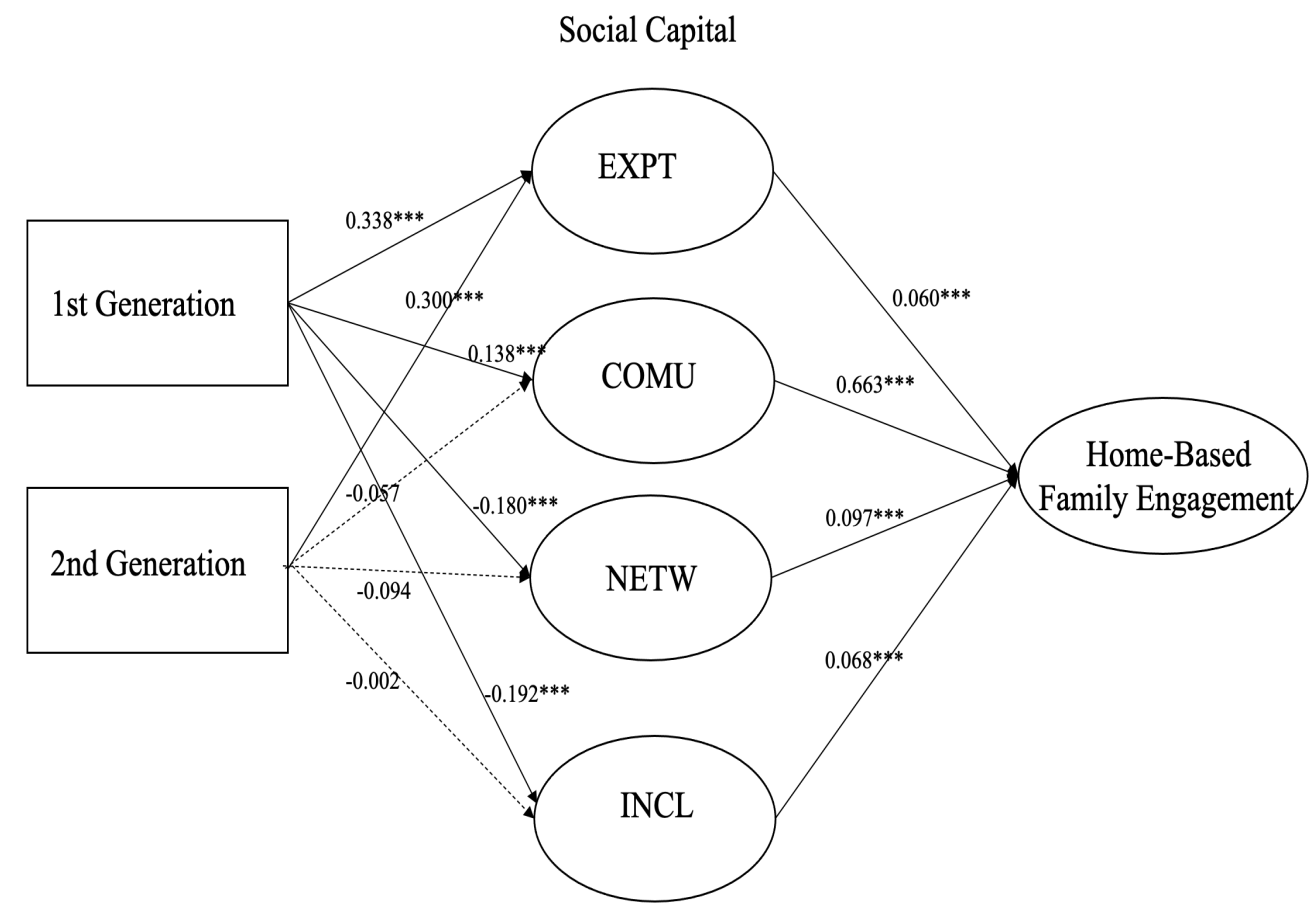

Note. ${ }^{*} \mathrm{p} \leq .05 .{ }^{* *} \mathrm{p} \leq .01 .{ }^{* * *} \mathrm{p} \leq .001 ., \mathrm{EXPT}=$ parent's expectations, COMU $=$ parent-child communications, NETW $=$ parent's networks, and INCL $=$ parent's intergenerational closure. Third-plus-generation status is the reference group. Dashed lines indicate insignificant causality. 
controlling for all the other relevant predictors in the final SEM model. These results suggested that first-generation immigrant parents were likely to have more positive expectations towards and a greater level of communication with their children than third-plus-generation families. Second-generation immigrant status was also positively associated with parent's expectation to their children $(b=0.300, S E=0.044)$ compared to third-plus-generations but did not reach the statistically significant level for parent-child communications.

As for social capital outside the family, the results showed that first-generation families had a negative and statistically significant correlations compared to thirdplus-generation families controlling for all the other predictors in final SEM model: parent's networks $(b=-0.0 .180, S E=0.062)$ and intergenerational closure $(b=-0.192$, $\mathrm{SE}=0.073$ ). The results suggested that relative to third-plus generation parents, parents of first-generation students were less likely to interact with other parents and make other parents' acquaintance. With regard to second-generation status, the result indicated that it was not statistically and significantly related to both parent's networks and intergenerational closure compared to third-plus-generation families.

Taken together, the results suggested that generational status was significantly related to social capital in and outside the family overall. In particular, depending on the types of social capital, social capital in or outside the family, the results of analyses notably varied. Specifically, while first-generation status was positively related to social capital in the family, it was negatively related to social capital outside the family. On the other hand, third-plus-generational status showed the opposite result: it was positively correlated with social capital outside the family, but negatively associated to social capital in the family. 


\section{Figure 4.2}

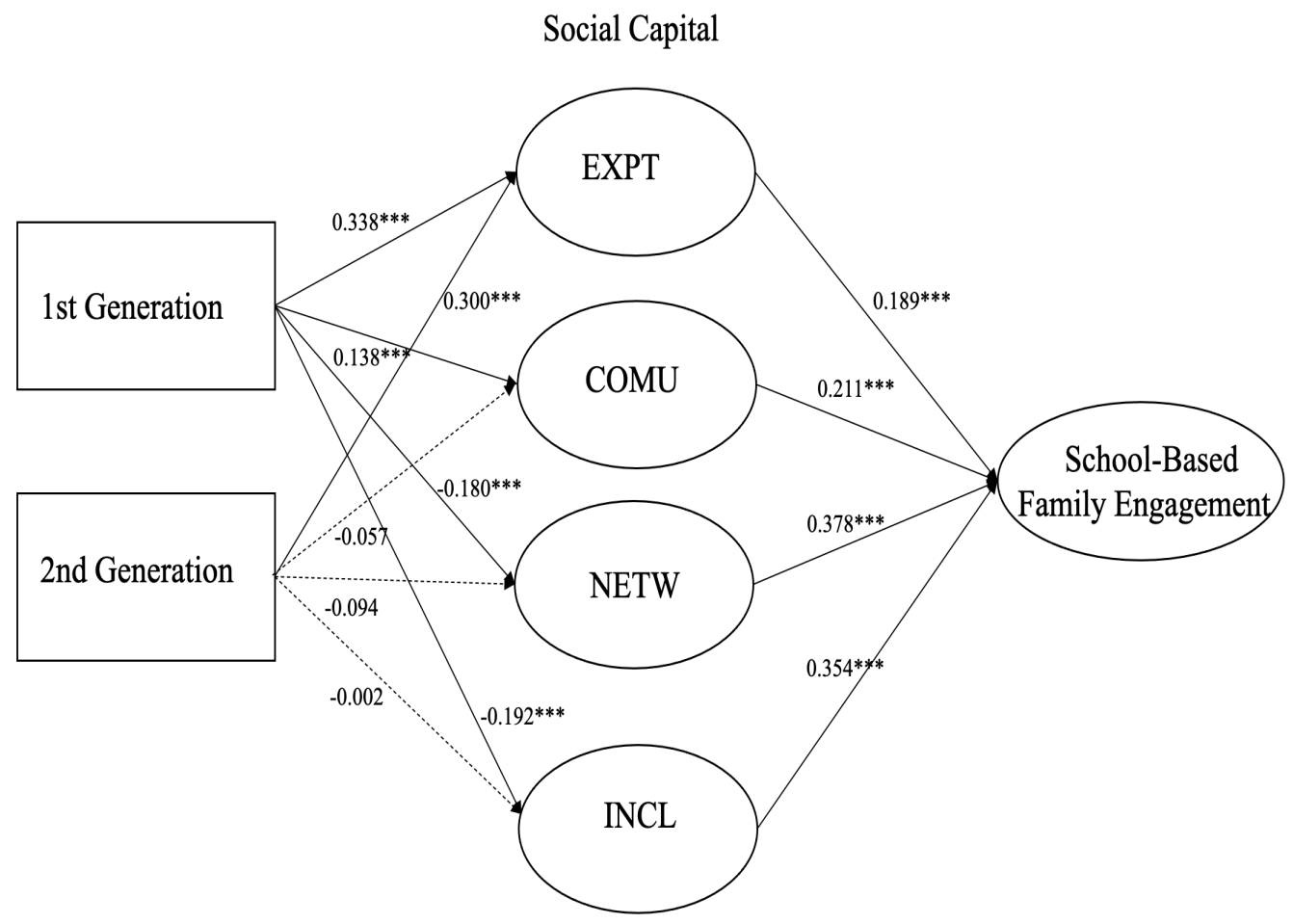

Note. ${ }^{*} \mathrm{p} \leq .05 .{ }^{* *} \mathrm{p} \leq .01 .{ }^{* * *} \mathrm{p} \leq .001 ., \mathrm{EXPT}=$ parent's expectations, COMU $=$ parent-child communications, NETW = parent's networks, and INCL= parent's intergenerational closure. Third-plus-generation status is the reference group. Dashed lines indicate insignificant causality.

\section{Testing Direct Paths between Social Capital and Home-and School-Family}

\section{Engagement}

The direct paths from the social capital variables to home- and school-based family engagement were estimated. The results indicated that all the social capital variables made significant contributions to both home- and school-based family engagement, controlling for all the other predictors in the final SEM model. First, parent's expectations (home-based engagement for $b=0.060, \mathrm{SE}=0.019$; school-based engagement for $b=0.189, \mathrm{SE}=0.018$ ) and parent-child communications (home-based engagement for $b=0.663, S E=0.012$; school-based engagement for $b=0.211$, $\mathrm{SE}=0.016$ ), factors of social capital in the family, were positively associated with family engagement. 
Table 4.6

Final SEM: Direct Relationships among Second-Generational Status, Social Capital, and Home-and School Family Engagement (Standardized).

\begin{tabular}{|c|c|c|c|c|c|c|}
\hline \multirow{2}{*}{ Variable } & \multicolumn{4}{|c|}{ Social Capital $\quad b(S E)$} & \multirow{2}{*}{$\begin{array}{c}\text { Home-Based } \\
\text { Family } \\
\text { Engagement }\end{array}$} & \multirow{2}{*}{$\begin{array}{c}\text { School-Based } \\
\text { Family } \\
\text { Engagement }\end{array}$} \\
\hline & EXPT & COMU & NETW & INCL & & \\
\hline 1st Generation & $\begin{array}{c}0.338 * * * \\
(0.051)\end{array}$ & $\begin{array}{l}0.138^{*} \\
(0.062)\end{array}$ & $\begin{array}{c}-0.180^{* *} \\
(0.061)\end{array}$ & $\begin{array}{c}-0.192 * * \\
(0.072)\end{array}$ & $\begin{array}{l}-0.024 \\
(0.064)\end{array}$ & $\begin{array}{c}-0.248^{* * *} \\
(0.064)\end{array}$ \\
\hline 2nd Generation & $\begin{array}{c}0.300 * * * \\
(0.044)\end{array}$ & $\begin{array}{l}-0.057 \\
(0.051)\end{array}$ & $\begin{array}{l}-0.094 \\
(0.061)\end{array}$ & $\begin{array}{l}-0.002 \\
(0.065)\end{array}$ & $\begin{array}{l}-0.030 \\
(0.053)\end{array}$ & $\begin{array}{c}-0.156^{* *} \\
(0.058)\end{array}$ \\
\hline EXPT & \multicolumn{4}{|c|}{$\rightarrow$} & $\begin{array}{c}0.060 * * * \\
(0.019)\end{array}$ & $\begin{array}{c}0.189 * * * \\
(0.018)\end{array}$ \\
\hline COMU & \multicolumn{4}{|c|}{$\rightarrow$} & $\begin{array}{c}0.663^{* * *} \\
(0.012)\end{array}$ & $\begin{array}{c}0.211^{* * *} \\
(0.015)\end{array}$ \\
\hline NETW & \multicolumn{4}{|c|}{$\rightarrow$} & $\begin{array}{c}0.097 * * * \\
(0.016)\end{array}$ & $\begin{array}{c}0.378 * * * \\
(0.013)\end{array}$ \\
\hline INCL & \multicolumn{4}{|c|}{$\rightarrow$} & $\begin{array}{c}0.068 * * * \\
(0.023)\end{array}$ & $\begin{array}{c}0.354 * * * \\
(0.020)\end{array}$ \\
\hline Female & $\begin{array}{c}0.275^{* * *} \\
(0.021)\end{array}$ & $\begin{array}{c}0.252 * * * \\
(0.020)\end{array}$ & $\begin{array}{c}0.087 * * * \\
(0.023)\end{array}$ & $\begin{array}{c}-0.042 \\
(0.030)\end{array}$ & $\begin{array}{c}-0.210^{* * *} \\
(0.027)\end{array}$ & $\begin{array}{l}-0.046 \\
(0.027)\end{array}$ \\
\hline \multicolumn{7}{|l|}{ Race (vs white) } \\
\hline Black & $\begin{array}{c}0.788 * * * \\
(0.030)\end{array}$ & $\begin{array}{c}0.265 * * * \\
(0.033)\end{array}$ & $\begin{array}{l}-0.090 \\
(0.054)\end{array}$ & $\begin{array}{c}-0.193 * * * \\
(0.049)\end{array}$ & $\begin{array}{c}-0.118 * * \\
(0.046)\end{array}$ & $\begin{array}{c}0.007 \\
(0.048)\end{array}$ \\
\hline Hispanic & $\begin{array}{c}0.286 * * * \\
(0.036)\end{array}$ & $\begin{array}{c}0.065 \\
(0.034)\end{array}$ & $\begin{array}{l}-0.088 \\
(0.063)\end{array}$ & $\begin{array}{l}-0.116 \\
(0.062)\end{array}$ & $\begin{array}{c}0.030 \\
(0.046)\end{array}$ & $\begin{array}{c}0.087 \\
(0.055)\end{array}$ \\
\hline Asian & $\begin{array}{c}0.201 * * * \\
(0.053)\end{array}$ & $\begin{array}{c}-0.177 * * \\
(0.062)\end{array}$ & $\begin{array}{c}-0.162 * * \\
(0.062)\end{array}$ & $\begin{array}{c}-0.182 * * \\
(0.069)\end{array}$ & $\begin{array}{l}-0.015 \\
(0.060)\end{array}$ & $\begin{array}{l}-0.007 \\
(0.067)\end{array}$ \\
\hline Test Score & $\begin{array}{c}0.043 * * * \\
(0.001)\end{array}$ & $\begin{array}{c}0.017 * * * \\
(0.001)\end{array}$ & $\begin{array}{c}0.008 * * * \\
(0.002)\end{array}$ & $\begin{array}{c}0.007 * * * \\
(0.001)\end{array}$ & $\begin{array}{c}-0.029 * * * \\
(0.002)\end{array}$ & $\begin{array}{c}-0.008 * * * \\
(0.002)\end{array}$ \\
\hline Family Structure & $\begin{array}{c}0.000 \\
(0.023)\end{array}$ & $\begin{array}{c}0.121 * * * \\
(0.025)\end{array}$ & $\begin{array}{c}0.180 * * * \\
(0.026)\end{array}$ & $\begin{array}{c}0.244 * * * \\
(0.033)\end{array}$ & $\begin{array}{c}0.090 * * * \\
(0.028)\end{array}$ & $\begin{array}{c}0.192 * * * \\
(0.029)\end{array}$ \\
\hline SES & $\begin{array}{c}0.329 * * * \\
(0.018)\end{array}$ & $\begin{array}{c}0.269 * * * \\
(0.021)\end{array}$ & $\begin{array}{c}0.220 * * * \\
(0.019)\end{array}$ & $\begin{array}{c}0.142 * * * \\
(0.020)\end{array}$ & $\begin{array}{l}-0.014 \\
(0.023)\end{array}$ & $\begin{array}{c}0.175 * * * \\
(0.025)\end{array}$ \\
\hline Parent's English & $\begin{array}{c}-0.165^{* * *} \\
(0.015)\end{array}$ & $\begin{array}{c}0.013 \\
(0.021)\end{array}$ & $\begin{array}{c}0.054 * * \\
(0.022)\end{array}$ & $\begin{array}{l}-0.035 \\
(0.029)\end{array}$ & $\begin{array}{c}0.042 * * \\
(0.019)\end{array}$ & $\begin{array}{c}0.083 * * * \\
(0.024)\end{array}$ \\
\hline School Urbanicity & $\begin{array}{c}0.085 * * \\
(0.025)\end{array}$ & $\begin{array}{l}0.054 * \\
(0.027)\end{array}$ & $\begin{array}{l}-0.008 \\
(0.030)\end{array}$ & $\begin{array}{c}-0.107^{*} \\
(0.039)\end{array}$ & $\begin{array}{l}-0.008 \\
(0.031)\end{array}$ & $\begin{array}{c}0.009 \\
(0.034)\end{array}$ \\
\hline School Size & $\begin{array}{c}0.005 \\
(0.007)\end{array}$ & $\begin{array}{c}0.014 \\
(0.008)\end{array}$ & $\begin{array}{c}-0.035 * * * \\
(0.007)\end{array}$ & $\begin{array}{c}-0.064 * * * \\
(0.009)\end{array}$ & $\begin{array}{c}0.010 \\
(0.008)\end{array}$ & $\begin{array}{c}-0.071 * * * \\
(0.008)\end{array}$ \\
\hline \multicolumn{7}{|l|}{ Fit Statics } \\
\hline CFI & \multicolumn{6}{|c|}{0.948} \\
\hline TLI & \multicolumn{6}{|c|}{0.935} \\
\hline RMESA/ CI $90 \%$ & \multicolumn{6}{|c|}{$0.031 / 0.030-0.032$} \\
\hline
\end{tabular}

Note. ${ }^{*} \mathrm{p} \leq .05 .{ }^{*} \mathrm{p} \leq .01 .{ }^{* * *} \mathrm{p} \leq .001 ., \mathrm{EXPT}=$ parent's expectations, $\mathrm{COMU}=$ parent- child communications, NETW = parent's networks, and INCL= parent's intergenerational closure. Third-plus-generation status is the reference group.

Likewise, parent's networks (home-based engagement for $b=0.097, \mathrm{SE}=0.016$;

school-based engagement for $b=0.378, S E=0.019)$ and intergenerational closure 
(home-based engagement for $b=0.068, \mathrm{SE}=0.022$; school-based engagement for $\mathrm{b}=0.354, \mathrm{SE}=0.048$ ), factors of social capital in the family outside the family were also positively related to family engagement.

Testing Direct Paths between Generational Status and Home- and School-based

\section{Family Engagement}

I also tested the direct paths from generational status to home- and schoolbased family engagement. After controlling for the background variables, the results indicated that none of the direct associations between generational status and homebased family engagement reached the statistically significant level. By contrast, there was evidence of direct paths from generational status to school-based family engagement. Relative to third-plus-generation families, first- $(b=-0.248, S E=0.064)$ and second- $(b=-0.156, S E=0.058)$ generation families were less likely to engage with their children's education at school.

\section{Indirect Relationships among Generational Status, Social Capital, and Home-}

\section{Based and School-Based Family Engagement}

Tables 4.7 and 4.8 present the indirect path coefficients for the final SEM model. First, there was a statistically significant indirect effect of generational status on home-based family engagement through social capital in the family. Specifically, relative to third-plus-generation families, those who were first-generation families had a 0.06 (parent's expectations) and 0.025 (parent-child communications) standard deviation increased in home-based family engagement respectively, which could be completely explained by the positive influence of generational status on social capital in the family. This means that, for first-generation families, all aspects of social capital in the family (parent's expectations and parent-child communications) may lead to home-based family engagement. 


\section{Table 4.7}

Final SEM: Indirect Relationships of Generational Status, Social Capital, and HomeBased Family Engagement (Standardized)

\begin{tabular}{lcccc}
\hline & \multicolumn{3}{c}{ Home-Based Family Engagement } \\
& \multicolumn{2}{c}{$1^{\text {st }}$ vs. } & \multicolumn{2}{c}{$2^{\text {nd }}$ vs. } \\
& $3^{\text {rd }}$-plus generation & \multicolumn{2}{c}{$3^{\text {rd }}$-plus generation } \\
& $b$ & $S E$ & $b$ & $S E$ \\
\hline Total effect & 0.031 & 0.018 & -0.011 & 0.018 \\
Total direct effect & 0.012 & 0.017 & -0.009 & 0.016 \\
Total indirect effect & 0.018 & 0.012 & -0.001 & 0.011 \\
Indirect effect through & & & & \\
EXPT & $0.006^{* * *}$ & 0.002 & $0.005^{* * *}$ & 0.002 \\
COMU & $0.025^{*}$ & 0.009 & -0.004 & 0.010 \\
NETW & $-0.005^{* *}$ & 0.002 & -0.003 & 0.002 \\
INCL & -0.004 & 0.002 & -0.001 & 0.002 \\
\hline
\end{tabular}

Note. ${ }^{*} \mathrm{p} \leq .05 .{ }^{*} \mathrm{p} \leq .01 .{ }^{* * *} \mathrm{p} \leq .001 ., \mathrm{EXPT}=$ parent's expectations, $\mathrm{COMU}=$ parent-child communications, NETW $=$ parent's networks, and INCL= parent's intergenerational closure.

With regard to social capital outside the family through parent's networks, the findings indicated that relative to third-plus-generational status, first-generation was indirectly and negatively related to home-based engagement $(b=-0.005, \mathrm{SE}=0.002)$. This implies that the weak social networks of first-generation families may inhibit their home-based family engagement. Yet, no significant indirect paths existed from first-generational status through intergenerational closure to home-based family engagement compared to third-plus generation families. As for second-generational status, there was no indirect effect of generational status on home-based family engagement through social capital except for parent's expectations $(b=0.005, \mathrm{SE}=$ $0.002)$.

Table 4.8 presents the results for the mediating analysis on the association between generational status and school-based family engagement through social capital The results showed discernible patterns between first-generation families and third-plus-generation families. The findings indicated that relative to third-plus- 
generational status, first-generational status indirectly and positively was associated with school-based family engagement through parent's expectations $(b=0.017, \mathrm{SE}=$ 0.003). The indirect effect of second-generational status on school-based engagement via parent's expectations was also positively significant $(b=0.016, \mathrm{SE}=0.003)$. Yet there was no indirect effect of first-generation families or second-generation families on school-based family engagement through parent-child communications.

\section{Table 4.8}

Final SEM: Indirect Relationships of Generational Status, Social Capital, and School-Based Family Engagement (Standardized)

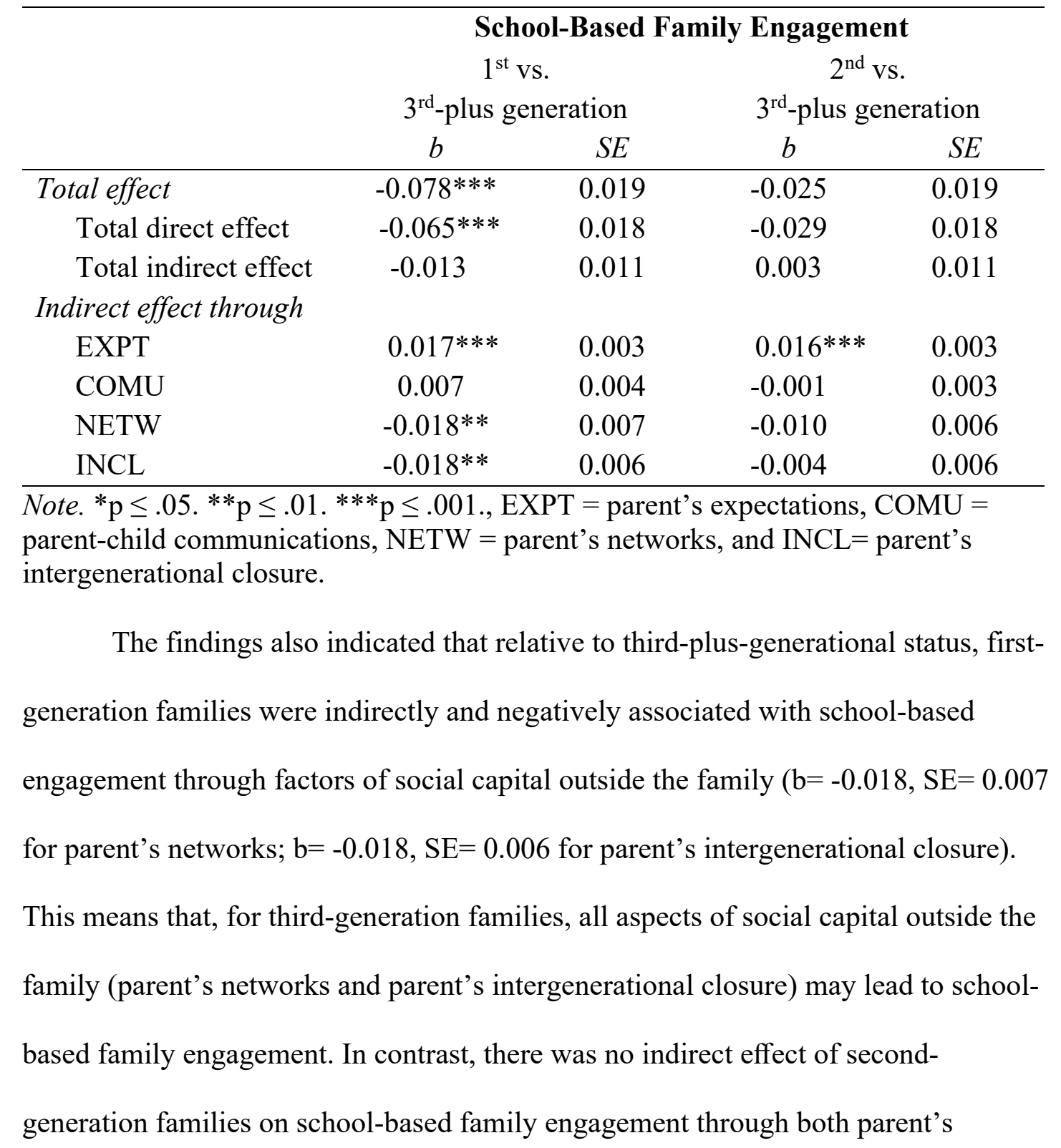


networks and parent's intergenerational closure compared to third-plus-generation families.

\section{Conclusion}

This chapter presented the results of CFA analyses, descriptive analyses, and the SEM models. The final SEM models consisted of the models that satisfied the CFA analyses: the first-order social capital measurement model and home- and school-based family engagement models. The results of the final SEM model demonstrated that generational status was a significantly related to social capital in and outside the family. Yet, its direct associations with home- and school-based family engagement were only marginal. Turning to the social capital factors, I found that they significantly contributed to shaping both home- and school-based family engagement. The mediating effects of social capital between generational status and family engagement were also tested in the final SEM model. The results indicated that social capital was a significant mediator between generational status and both homeand school-based family engagement. Social capital had a significant mediating effect between generational status and home-based family engagement. Yet, the mediating effects of social capital were ever greater between generational status and schoolbased family engagement. 


\section{Chapter 5. Discussion}

The purpose of this study was to expand our understanding about the relationship among immigrant generational status, social capital, and family engagement in the United States. Generational status, the key independent variable of the study, was categorized into first-, second-, and third-plus-generational status following Trevelyan et al. (2016). Social capital was expected to mediate the association between generational status and family engagement. This variable was classified into social capital in the family (i.e., parent's expectations and parent-child communications) and social capital outside the family (i.e., parent's network and intergenerational closure) (Coleman, 1988; Israel et al., 2001). The family engagement was categorized into home-based family engagement and school-based family engagement (Green at al., 2007; Sheldon, 2002; Tang, 2015). Utilizing data from ELS:2002, the national sample of US high school students and their parents, I tested three hypotheses with an SEM approach: (a) parent's social capital differs significantly across immigrant generations; (b) the structural compositions of family engagement differ significantly across immigrant generations; and (c) the relationship between generational status and family engagement is mediated by social capital in and outside the family.

This chapter interprets the empirical results reported in the previous chapter and relates these findings to prior research. Following are the limitations and the topics of further studies. Lastly, I discuss the implications of this research for policy innovations.

\section{Discussion of Research Findings}

The findings of the current study revealed that generational status is related to home- and school-based family engagement not only directly, but also indirectly 
through its impact on social capital. Families with different generational status developed a specific dimension of social capital. Specifically, first-generation immigrants are prone to build social capital in the family, while third-plusgenerational status was more significantly correlated to social capital outside the family. Those relationships systematically led them to engage more in home- or school-based family engagement.

In the following section, I begin by reviewing the findings about the relationship between generational status and social capital. Then, I account for the mediating role of social capital between generational status and family engagement. Figure 5.1 showed the final relationships among three aspects of this study.

\section{Generational Status and Social Capital}

The first hypothesis of this study was that parent's social capital is differently constituted across immigrant generations. Specifically, I hypothesized that compared to third-plus-generation families, first- and second- generation families will have less social capital outside the family (parent's network and intergenerational closure). Consistent to this hypothesis, the results showed that first-generation families had a significantly lower social capital outside the family compared to third-plus-generation families. This implied that first-generation families had fewer social interactions with other parents than U.S.-born families. This finding is also consistent with the results of earlier studies; for example, it has been widely recognized that new immigrant parents have limited opportunities to build relationships with other parents due to diverse barriers including lack of English proficiency and time (Kao \& Rutherford, 2007; Trueba, 1998; Wang, 2008), which isolate them from the networks of interparental exchange (Guo, 2006; Kao \& Rutherford, 2007; Rosenbaum \& Rochford, 2008; Wang, 2008). 
In the proposed model, I also expected that first- and second-generation families have more social capital in the family (parent's expectations and parent-child communications) than third-plus-generation families. The results provided supporting evidence to the hypothesis of this study. In particular, I found that in comparison with third-plus-generation families, first-immigrant parents have more positive expectations of their child's education and spend more time on communications with them. Again, this reflects prior findings; new immigrant families have some strengths such as higher expectations for their child's educational success (e.g., Feliciano \& Lanuza, 2015; Kao, 2004; Kao \& Tienda, 1995).

These results can be attributed to different characteristics or lifestyles of immigrants across their generational status. Prior research suggested that their generational status can lead immigrant families to shape different backgrounds in their personal experiences, social-economic status, or proficiency of host country languages (Trevelyan et al., 2016; Willgerodt \&Thompson, 2005).

Specifically, I supposed that immigrants' attitudes toward life have an influence on how they shape social capital in the family. Most first-generational immigrants come to the US voluntarily with a hope of success, and they are willing to change their life (Feliciano \& Rumbaut, 2005). That is, first-generation immigrant families tend to show a strong motivation to improve the quality of their lives, which leads them to have more optimistic attitudes (Glick \& White, 2004; Kao \& Tienda, 1995; Shields \& Behrman, 2004; Suárez-Orozco et al., 2009; Zhou \& Kim, 2006). Such attitudes are likely to make first-generation families have higher expectations towards their children's future and education and thus, spend more time on communications with their children than U.S-born families. This is because the higher level of parents' expectations and parent-child communications in immigrant 
families can exert a positive influence on their children's academic success (Weinstein, 2002).

Meanwhile, second-generational status showed no significant difference from third-plus-generation with regard to the types of social capital they have $e_{2}$ except for parents' expectation. These results implied that second-generation families' interparental relationships are constrained less by the immigrant barriers than firstgeneration families, and they still maintain the optimistic attitudes.

In sum, generational status does not simply mean the length of stay in the new county, but it encompasses the lifestyle or characteristics of immigrant people. Therefore, generational status of immigrants can be associated with shaping their social capital in and outside the family.

\section{Generational Status and Family Engagement}

This study also examined how the structure of family engagement differs significantly across immigrant generations. More specifically, I hypothesized that parents from first- and second-generation families will be less likely to engage in school-based family engagement compared to third-plus-generation families. Consistent with this hypothesis, first- and second-generation families engaged less in their children's education at school. The finding gives an additional support to the prior studies that new immigrant family parents are reluctant or unable to participate in school activities or events for their children, likely because of barriers such as unfamiliarity with the U.S school system, limited English proficiency, and a lack of time (Carreón et al., 2006; Guo, 2006; Riches \& Curdt-Christiansen, 2010; Turney \& Kao, 2009; Zhou, 1997).

On the contrary, I hypothesized that parents from first- and second-generation families are more likely to engage in home-based family engagement compared to 
those from third-plus-generation families. Yet, the results indicated that the difference in generational status was not associated with the level of home-based family engagement. This finding contradicted the claims of other studies that immigrant parents engage in their child's education more extensively at home (e.g., helping homework or monitoring) than native-born parents (Dyson, 2001; Sibley \& Dearing, 2014). This unexpected result may be attributed to age differences of children across the studies. Whereas the sample of past studies was parents of elementary students, the current study investigated parents of high school students (10th graders). In general, parents become less engaged in youth's education as they grow older (Cheung \& Pomerantz, 2015; Green et al., 2007; Matza et al., 2001; Wei et al., 2019).

One possible account for this lower level of engagement is that parents of secondary students had more difficulties helping their children with homework (Balli et al., 1998; Xu, 2004). Moreover, new immigrants tend to have a lower level of educational attainment: high school graduation rates were lower for the firstgeneration immigrants in comparison with the second- and third-plus-generation groups (Trevelyan et al., 2016). This rendered new immigrant parents to face greater difficulties to help their children's academic works, and thereby, may have hindered them from engaging with their children's education via traditional modes like helping with homework. Therefore, the generational difference of immigrant families in home-based family engagement might be blurred in the sample of secondary students' parents.

\section{Social Capital and Family Engagement}

I also tested the relationship between social capital in and outside the family and family engagement. Consistent with prior research (Myers \& Myers, 2014; Sheldon, 2002; Li \& Fisher, 2017; Tang, 2015; Von Otter \& Stenberg, 2015), the 
result for the direct effects indicated that social capital was clearly related to both home- and school-based family engagement. All the factors of social capital had a significant and positive direct link to home- and school-based family engagement controlling for the effects of generational status and background covariates. For example, parents who have higher expectations toward their child's education and have more conversations with their child were more likely to engage in both homeand school- based engagement. This finding supported that parents with higher academic expectations for their child tend to more actively help with homework and school projects and participate in school events (Asakawa, 2001; Fan \& Chen, 2001; Sy \& Schulenberg, 2005). Likewise, parents knowing their child's friends and interacting more with other parents were more likely to engage in both home- and school- based engagement (McNeal, 1999).

\section{Social Capital: Mediated Factor}

To better understand immigrant family engagement, I examined whether social capital mediated the associations between immigrant generational status and home- and school-based family engagement. The results provided the supporting evidence for the mediating effect of social capital. First, I hypothesized that compared to third-plus-generation families, first- and second-generation immigrant families were more likely to have social capital in the family, which led to foster home-based family engagement. The models gave empirical support to this hypothesis. Specifically, I found that parents in first-generation families have higher expectations and more conversations about education with their child (i.e., social capital in the family), which in turn was related to more engagement in their children's education at home. This suggests that social capital in the family might be one of the fundamental features for enhancing home-based family engagement. 
However, contrary to my expectation, social capital outside the family, especially parents' networks, also significantly mediated the relationship between generational status and home-based family engagement. The findings showed that third-plus-generation families interacted more with other parents than first-generation families, which in turn correlated with greater home-based engagement as well. This illuminated that parents' networks could also be an essential feature that enhances family engagement at home. This unanticipated result can be explained that parents with a dense network with other parents were likely to have a stronger feeling that they should be engaged in their child education (Sheldon, 2002). Furthermore, the networking provided parents with school-related information which could be used to help their engagement in children' education at home such as helping homework (Delgado-Gaitan, 1992; Sheldon, 2002).

As for school-based family engagement, I proposed that first-generation immigrants were likely to have weak social capital outside of the family compared to third-plus-generation families, which then led to less school-based engagement. Consistent with this hypothesis, first-generation families had less social capital outside the family (parent's networks and intergenerational closure) than third-plusgeneration families and this was related to lower levels of their educational engagement at school. This finding suggests that, compared to third-plus-generational status, first-generation families were involved less in the relationships with other parents and had lower intergenerational closure, which may have led to less engagement in school-based family engagement. This demonstrated that parents' networks and intergenerational closure were significant factors accounting for the immigrant generational disparity in school-based family engagement, particularly between first- and third-plus-generation families. 
I also expected that social capital in the family would have no significant mediating effect on school-based family engagement. However, the results denoted that positive expectation of their children' education, one component of social capital in the family that first- and second-generation immigrant families generated more than families who were third-plus-generation, was related to stronger school-based engagement. This implied that parents' expectations might also be a crucial factor for reinforcing family engagement at school. This can also explain why some immigrant parents were more extensively participating in their child's school activities than others (Antony-Newman, 2020).

In conjunction with prior research, the current study highlighted the importance of social capital in understanding the association between family engagement and immigrant generations. Whereas a large body of research asserted that immigrant backgrounds such as ethnicity, parent's English proficiency, or SES were related to family engagement (e.g., Sibley \& Dearing, 2014; Tang, 2015; Turney \& Kao, 2009), this study expanded previous research by showing that immigrant generational status was another key explanatory factor for their family engagement. Further, this study identified social capital as a specific pathway through which generational status is related to immigrant family engagement, building on existing studies exploring the effect of social capital (i.e., parent's expectations, parent-child communications, parent's networks, and parent's intergenerational closure) on family engagement (Von Otter \& Stenberg, 2015; Sheldon, 2002; Li \& Fisher, 2017).

In sum, the findings of the present study contributed in three key ways to the growing body of research that seeks to better understand the association among immigrant generational status, social capital, and types of family engagement. First, immigrant generational status was significantly related to families to shape which 
type of social capital. While first-generation families were likely to have a greater level of social capital in the family, third-plus generation families tended to extensively form social capital outside the family. These findings improved our understanding by revealing that generational status serves as an important ground for social capital. Second, both types of social capital in and outside the family were positively associated with both home- and school-based family engagement. This finding confirmed that social capital played a key role in enhancing both types of family engagement. Lastly, the findings suggested that social capital mediated the associations between immigrant generational status and home- and school-based family engagement overall. That is, the findings of specific pathways through social capital in and outside the family to home- and school-based family engagement might make a tangible contribution to understanding of family engagement and immigrant generations. This may expand the scholarly understanding of the family engagement process across immigrant generations.

\section{Limitations}

The contributions this study can make to the literature and its limitations should be considered as well. First, the design of this study was cross-sectional in nature because of the data restriction. The analytical sample of this study was composed of $10^{\text {th }}$ graders and their parents, but the parents participated only in the base year survey. Hence, this dataset had information on parents at a single time point. Thus, it was impossible to examine family engagement in a longitudinal manner using this dataset, which made it more difficult to make a valid inference for causal relationships (Marsh, 2006; Maxwell et al., 2011; Wei et al., 2019).

Second, although the items of family engagement have been widely used in the literature (Fan \& Williams, 2010; Hao \& Bonstead-Bruns, 1998; Israel et al., 
2001; McNeal, 1999; Ross, 2016; You \& Sharkey, 2012), the questionnaires used to construct the dataset may not fully take into account diverse characteristics of family engagement. In particular, the questionnaires for the data were made based on the perspectives of American parents, which might not adequately reflect immigrant parent's view on family engagement. In other words, the ELS:2002 might not include immigrant parent's unique approaches to help their child's educational success. For example, Asian immigrant parents tend to take family engagement differently including additional homework, workbooks, or private tutoring (Park et al, 2016; Sy, 2006). In addition, Korean immigrant parents have reported that they teach independent study skills such as searching for educational information, and they create supportive environments at home (Kim et al., 2016). Likewise, Hispanic immigrant parents emphasized encouraging their child to be more independent (McWayne et al., 2013). Above all, a lot of immigrant parents tend to spend time with their children sharing their own culture or tradition (McWayne et al., 2013; SoutoManning \& Swick, 2006), but the existing data fail to capture such behaviors of family engagement. Because of the data limitations, immigrant parents might be misunderstood as 'disinterested' in family engagement and their family engagement is likely to be underestimated. In sum, the present study might not be able to fully take into account the diversity of family engagement in immigrant families.

Third, the current study explored the quantity of social capital and behaviors of home- and school-based family engagement. Yet, the quantity does not equate to the quality, and the outcomes can vary depending on the quality of social capital (Bryman, 1988). For example, it might not be relevant to assume that the frequency of parent-child communications represents deeper relationships between them. 
Incorporating qualitative aspects of social capital may reveal more profound associations between social capital and family engagement.

Fourth, the present study included $10^{\text {th }}$ graders' racial feature as a background covariate, but it did not examine the effect of immigrant's unique racial features on the relationship between generational status and family engagement. Although immigrant families have similar characteristics distinguishable from native-born families, significant diversities exist across their ethnicities with regard to family engagement. In particular, immigrant parents have different definitions of family engagement by culture, ethnicity, or origin country (Dorner \& Aguayo, 2017; Kim et al, 2018). For example, Korean immigrant parents considered family engagement support to their children's nonacademic life at home such as teaching moral values, care, and kindness (Kim et al, 2018). Likewise, Hispanic immigrant parents think of family engagement as a way to assist the well-being of their children (Scribner et al., 1999). Furthermore, the racial feature can play an important role in selecting family engagement types, because immigrant parents have different characteristics, experiences, or lifestyles depending on their racial feature (Perna \& Titus, 2005).

Lastly, parents' engagement in their children's education is not the only determinant of immigrant family engagement, but collaborations among parents, teachers, peers, and community members can also have a significant influence (Barton et al., 2004; Carreón et al., 2005). Therefore, it is necessary to expand scholarly attention beyond generational status or social capital. Future studies should take into account characteristics of schools, communities, and neighborhoods for a more comprehensive understanding of immigrant family engagement.

\section{Future Research}


Based on this study, as well as the limitations, this section presents several directions for future research. First, researchers should construct new measures for social capital or family engagement which can more effectively reflect unique attributes of immigrants. As I discussed earlier, a lot of immigrant parents have their own behaviors of family engagement (Park et al, 2016; McWayne et al., 2013; Sy, 2006). Also, immigrant parents believe that teaching their own culture is an important aspect for their children's education and make an effort to share their culture with their children (McWayne et al., 2013; Souto-Manning \& Swick, 2006). Future studies may develop survey questions more effectively capturing the diversity in immigrant family engagement such as “I teach my child about my family's country's traditions, food, and music" or "I teach my child to understand my own cultures."

Second, it is necessary for future research to incorporate longitudinal approaches. A longitudinal design will allow more precisely examining the associations among generational status, social capital, and immigrant family engagement over time. This will improve the validity of inference for causal relationships among these factors (Marsh, 2006; Maxwell et al., 2011; Wei et al., 2019). Thus, future research might advance the present study by reevaluating the proposed chain of links with a longitudinal dataset.

Third, additional qualitative research would provide more in-depth pictures of generational status, social capital, and immigrant family engagement. For example, close interviews to parents and children would enable researchers to catch a delicate nuance or a completely new aspect in their relationships which large $\mathrm{N}$ data might not be able to show. Furthermore, qualitative approaches help researchers to directly observe their hypothesized causal effects indeed take place.

\section{Policy Implications}


As I discussed earlier, the current policy of the U.S. federal government, Every Student Succeeds Act of 2015 (ESSA), requires that states and school districts engage parents and families in the work of ensuring positive outcomes for all students (US Department of Education, 2015). Particularly, ESSA states that schools and districts that receive Title I funding should hold regular meetings for parents of English learners. That is, policymakers have tried to embrace immigrant families into family engagement programs. However, this policy overlooked the differences of immigrant differences attributed to the intersections of social capital and generational status. The findings of this research suggest that policymakers or practitioners need to better understand the nuanced relationship among generational status, social capital, and immigrant family engagement. Below are some policy suggestions for immigrant family engagement based on the findings of this study.

First, policymakers and school administrators should seek to accurately capture differences in family engagement across generational status. Consistent with literature, the results of the present study suggested that first- and second-generation families were less likely to engage in school-based family engagement than third-plus generation families (Lee, 2006; Toppelberg \& Collins, 2010). Barriers to immigrants such as limited English proficiency, unfamiliar school system, or unwelcoming environment make immigrant parents participate in school activities less than nativeborn parents (Gao, 2006).

Therefore, school practitioners should recognize the difficulties of first- and second-generation immigrant families and make an effort to understand those challenges. For example, schools can establish parent centers for first- and secondimmigrant families, which can play a significant role in engaging and supporting immigrant families. Such centers would provide information about the school and the 
community, translation service, orientations or sample classes (Sobel \& Kugler, 2007; U.S. Department of Education, 2017; Lindeman, 2001). Specifically, they might be more helpful to first-generation immigrant parents who suffer more from immigrant barriers (e.g., limited English proficiency, unfamiliarity with the U.S. school system, or a sense of isolation and disadvantage).

Second, this study contended that social capital is an important factor for promoting family engagement. In detail, the results showed that generational status was significantly related to the formation of social capital, and it was ultimately associated with the level of home- and school-based family engagement. In particular, first-generation families had lower social capital outside the family than third-plusgeneration families, and thus they engaged less in both home- and school-based family engagement. Namely, new immigrant parents interacted much less with other parents than native-born parents, which was negatively related to the level of their family engagement. These findings implied that social capital outside the family was an essential factor to elevate family engagement of immigrant families and enhancing it could foster new immigrant parents' engagement at home and school.

To build up social capital outside the family, schools would offer policies and programs which connect immigrant parents to other parents. Networking programs among parents such as mentoring, parent workshops, or support groups might promote the connectedness of immigrant parents (Oberoi, 2016; Sheldon, 2002). With regard to intergenerational closure, schools might consider offering immigrant parents opportunities to meet parents of their children's friends. The increased level of intergenerational closure by these meetings will advance immigrant parents' access to educational information for their children as well as reduce their immigrant barriers of family engagement. 
Lastly, the results of this study suggested that schools and policymakers should extend their viewpoints of family engagement. In general, the U.S. policymakers have focused only on school-based family engagement. This narrow focus, coupled with a relatively lower level of school-based family engagement, has misled the policymakers to consider that immigrant parents are less interested in their children's education than native-born parents (US Department of Education, 2015). However, this study showed that immigrant parents extensively engage in their children's education at home using their social capital inside the family. This implies that schools and policymakers should revisit their view that immigrant parents do not pay attention to or engage in their children's education.

In this vein, schools and policymakers should recognize that immigrant parents may have their own perspectives on family engagement and come up with new policies or practices effectively reflecting the views of immigrants. Specifically, new policies need to encourage family engagement not only at school but also at home. The limited focus on school-based engagement might not be the optimal way to increase immigrant family engagement. If it is true that many immigrant parents prefer home-based family engagement to school-based family engagement, policymakers should be able to craft policies to support their engagement at home. In this line, schools may provide information or materials for immigrant parents to use to help their children at home, which can later bridge home- and school-based family engagement for immigrants.

\section{Conclusion}

This study highlighted the importance of social capital in understanding the disparity in family engagement across immigrant generations. A large body of research showed that immigrant barriers contributed to the generational difference in 
family engagement (Carreón et al., 2006; Guo, 2006; Riches \& Curdt-Christiansen, 2010; Turney \& Kao, 2009; Zhou, 1997). This study expanded previous research by incorporating the mediating effect of social capital on the association between immigrant generations and family engagement. The social capital (i.e., parent's expectations, parent-child communications, parent's networks, and intergenerational closure) played an important role in immigrant family engagement. The findings of specific pathways through social capital in and outside the family to home- and school-based family engagement might make a tangible contribution to understanding of family engagement and immigrant generations. Further, the present research suggested that immigrant families were not only constrained from participating in their children's education, but also had their own strength for family engagement such as positive expectations for and extensive communications with their children. 


\section{References}

Aguayo, D., \& Dorner, L. M. (2017). Assessing Spanish-speaking immigrant parents' perceptions of climate at a New Language Immersion School: A critical analysis using "Thinking with Theory". education policy analysis archives, 25, 112.

Alba, R., \& Nee, V. (2003). Remaking the American mainstream: Assimilation and contemporary immigration. Cambridge, MA: Harvard University Press.

Antony-Newman, M. (2020). Parental involvement of Eastern European immigrant parents in Canada: whose involvement has capital?. British Journal of Sociology of Education, 41(1), 111-126.

Asakawa, K. (2001). Family socialization practices and their effects on the internalization of educational values for Asian and White American adolescents. Applied Developmental Science, 5(3), 184-194.

Balli, S. J., Demo, D. H., \& Wedman, J. F. (1998). Family involvement with children's homework: An intervention in the middle grades. Family Relations, 47, 149-157.

Bang, H. J., Suárez-Orozco, C., \& O’Connor, E. (2011). Immigrant students’ homework: Ecological perspective on facilitators and impediments to task completion. American Journal of Education, 118(1), 25-55.

Barton, A. C., Drake, C., Perez, J. G., St. Louis, K., \& George, M. (2004). Ecologies of parental engagement in urban education. Educational Researcher, 33(4), 312.

Batalova, J., \& Hanna, M. \& Levesque, C. (2021). Frequently requested statistics on immigrants and immigration in the United States. Migration information source 
Beaulieu, L. J. (1992). Effects of human capital and social capital on dropping out of high school in the South. Journal of Research in Rural Education, 8(1), 75-87.

Benner, A. D., Boyle, A. E., \& Sadler, S. (2016). Parental involvement and adolescents' educational success: The roles of prior achievement and socioeconomic status. Journal of youth and adolescence, 45(6), 1053-1064.

Bolívar, J. M., \& Chrispeels, J. H. (2011). Enhancing parent leadership through building social and intellectual capital. American Educational Research Journal, 48(1), 4-38.

Bollen, K. A. (1989). A New Incremental Fit Index for General Structural Equation Models. Sociological Methods \& Research, 17(3), 303-316.

Borjas, G. J. (2011). Poverty and program participation among immigrant children. The Future of Children, 247-266.

Bronfenbrenner, U. (1986). Ecology of the family as a context for human development: Research perspectives. Developmental psychology, 22(6), 723.

Browne, M. W., \& Cudeck, R. (1993). Alternative ways of assessing model fit In Bollen KA \& Long JS (Eds.), Testing structural equation models (pp. 136162).

Brunner, M., Nagy, G., \& Wilhelm, O. (2012). A tutorial on hierarchically structured constructs. Journal of personality, 80(4), 796-846.

Byrne, B. M. (2005). Factor analytic models: Viewing the structure of an assessment instrument from three perspectives. Journal of personality assessment, $85(1), 17-32$.

Byrne, B. M. (2013). Structural equation modeling with Mplus: Basic concepts, applications, and programming. routledge. 
Carbonaro, W. J. (1998). A little help from my friend's parents: Intergenerational closure and educational outcomes. Sociology of education, 71(4), 295.

Carreón, G. P., Drake, C., \& Barton, A. C. (2005). The importance of presence: Immigrant parents' school engagement experiences. American Educational Research Journal, 42(3), 465-498.

Catsambis, S. (2001). Expanding knowledge of parental involvement in children's secondary education: Connections with high school seniors' academic success. Social psychology of education, 5(2), 149-177.

Chen, F. F., West, S. G., \& Sousa, K. H. (2006). A comparison of bifactor and second-order models of quality of life. Multivariate Behavioral Research, 41, $189-225$.

Chen, X., \& Jiang, X. (2020). Children's immigrant generational status and delinquency: The mediating effects of friendship networks. Social science research, 90, 102-124.

Coll, C. G., \& Pachter, L. M. (2002). Ethnic and minority parenting. Handbook of parenting: Social conditions and applied parenting, 4, 1-20.

Comer, J. P. (2005). The rewards of parent participation. Educational leadership, 62(6).

Cook, V. (1999). Going beyond the native speaker in language teaching. TESOL quarterly, 33(2), 185-209.

Cooper, H. (1989). Synthesis of research on homework. Educational leadership, 47(3), 85-91.

Crosnoe, R. (2001). Parental involvement in education: The influence of school and neighborhood. Sociological Focus, 34(4), 417-434.

Gonida, E. N., \& Cortina, K. S. (2014). Parental involvement in homework: Relations 
with parent and student achievement-related motivational beliefs and achievement. British Journal of Educational Psychology, 84(3), 376-396.

Delgado-Gaitan, C. (1991). Involving parents in the schools: A process of empowerment. American journal of Education, 100(1), 20-46.

Desforges, C., \& Abouchaar, A. (2003). The impact of parental involvement, parental support and family education on pupil achievement and adjustment: A literature review (Vol. 433): DfES London.

Desimone, L. (1999). Linking parent involvement with student achievement: Do race and income matter? The Journal of Educational Research, 93(1), 11-30.

Deuling, J. K., \& Burns, L. (2017). Perfectionism and work-family conflict: Selfesteem and self-efficacy as mediator.Personality and Individual Differences, 116, 326-330.

Domina, T. (2005). Leveling the home advantage: Assessing the effectiveness of parental involvement in elementary school. Sociology of education, 78(3), 233-249.

Dorner, L. M., Orellana, M. F., \& Jiménez, R. (2008). "It's one of those things that you do to help the family" language brokering and the development of immigrant adolescents. Journal of Adolescent Research, 23(5), 515-543.

Epstein, J. L. (1995). School/family/community partnerships. Phi delta kappan, 76(9), $701-712$

Epstein, J. L. (2010). School/family/community partnerships: Caring for the children we share. Phi delta kappan, 92(3), 81-96.

Epstein, J. L., Sanders, M. G., Sheldon, S. B., Simon, B. S., Salinas, K. C., Jansorn, N. R., ... \& Williams, K. J. (2018). School, family, and community partnerships: Your handbook for action. Corwin Press. 
Fan, X., \& Chen, M. (2001). Parental involvement and students' academic achievement: A meta-analysis. Educational psychology review, 13(1), 1-22.

Fan, W., \& Williams, C. M. (2010). The effects of parental involvement on students' academic self-efficacy, engagement and intrinsic motivation. Educational psychology, 30(1), 53-74.

Feliciano, C., \& Lanuza, Y. R. (2016). The immigrant advantage in adolescent educational expectations. International Migration Review, 50(3), 758-792.

Fenton, P., Ocasio-Stoutenburg, L., \& Harry, B. (2017). The power of parent engagement: Sociocultural considerations in the quest for equity. Theory into Practice, 56(3), 214-225.

Ferrara, M. M. (2009). Broadening the Myopic Vision of Parent Involvement. School Community Journal, 19(2), 123-142.

Fishel, M., \& Ramirez, L. (2005). Evidence-based parent involvement interventions with school-aged children. School psychology quarterly, 20(4), 371.

Fuligni, A. J. (1997). The academic achievement of adolescents from immigrant families: The role of family background, attitudes, and behavior. Child development, 68(2), 351-363.

Furstenberg Jr, F. F., \& Hughes, M. E. (1995). Social capital and successful development among at-risk youth. Journal of Marriage and the Family, 580592.

George, R., \& Kaplan, D. (1998). A structural model of parent and teacher influences on science attitudes of eighth graders: Evidence from NELS: 88. Science Education, 82(1), 93-109.

Gibson, D. M., \& Jefferson, R. N. . (2006). The effect of perceived parental involvement and the use of growth-fostering relationships on self-concept in 
adolescents participating in gear up. Family Therapy: The Journal of the California Graduate School of Family Psychology, 33(1), 29-43.

Glick, J. E., \& White, M. (2004). Parental aspirations and post-secondary school participation among immigrant and native youth in the United States. Social Science Research, 33, 272-299.

Glick, J. E., Bates, L., \& Yabiku, S. T. (2009). Mother's age at arrival in the United States and early cognitive development. Early Childhood Research Quarterly, 24(4), 367-380.

Glick, J. E., \& Hohmann-Marriott, B. (2007). Academic performance of young children in immigrant families: The significance of race, ethnicity, and national origins. International Migration Review, 41(2), 371-402.

Green, C. L., Walker, J. M., Hoover-Dempsey, K. V., \& Sandler, H. M. (2007). Parents' motivations for involvement in children's education: An empirical test of a theoretical model of parental involvement. Journal of educational psychology, 99(3), 532.

Grolnick, W. S., \& Slowiaczek, M. L. (1994). Parents' involvement in children's schooling: A multidimensional conceptualization and motivational model. Child development, 65(1), 237-252.

Hair, J. F., Anderson, R. E., Tatham, R. L., \& William, C. (1998). Black (1998), Multivariate data analysis.

Hancock, G. R., \& Mueller, R. O. (2001). Rethinking construct reliability within latent variable systems. In R. Cudeck, S. du Toit, \& D. So r̈bom (Eds.), Structural equation modeling: Present and future-A Festschrift in honor of Karl Jo r̈eskog (pp. 195-216). Lincolnwood, IL: Scientific Software International. 
Hao, L., \& Bonstead-Bruns, M. (1998). Parent-child differences in educational expectations and the academic achievement of immigrant and native students. Sociology of education, 175-198.

Hao, L., \& Woo, H. S. (2012). Distinct trajectories in the transition to adulthood: Are children of immigrants advantaged?. Child Development, 83(5), 1623-1639.

Hayes, A. F., \& Preacher, K., J. (2014). Statistical mediation analysis with a multicategorical independent variable. British Journal of Mathematical and Statistical Psychology, 67, 451-470.

Henderson, A. T., \& Mapp, K. L. (2002). A New Wave of Evidence: The Impact of School, Family, and Community Connections on Student Achievement. Annual Synthesis, 2002.

Hernandez, D.J., and Charney, E., eds.(1998). From generation to generation: The health and well-being of children in immigrant families. Washington, DC: National Academy Press

Hernandez, D. J., Denton, N. A., \& Macartney, S. E. (2008). Children in Immigrant Families: Looking to America's Future. Social Policy Report. Volume 22, Number 3. Society for Research in Child Development.

Hill, N. E., \& Taylor, L. C. (2004). Parental school involvement and children's academic achievement: Pragmatics and issues. Current directions in psychological science, 13(4), 161-164.

Hill, N. E., \& Tyson, D. F. (2009). Parental involvement in middle school: a metaanalytic assessment of the strategies that promote achievement. Developmental psychology, 45(3), 740. 
Hoover-Dempsey, K. V., Battiato, A. C., Walker, J. M., Reed, R. P., DeJong, J. M., \& Jones, K. P. (2001). Parental involvement in homework. Educational psychologist, 36(3), 195-209.

Hoover-Dempsey, K. V., \& Sandler, H. M. (1995). Parental involvement in children's education: Why does it make a difference? Teachers college record.

Hoover-Dempsey, K. V., Walker, J. M., Sandler, H. M., Whetsel, D., Green, C. L., Wilkins, A. S., \& Closson, K. (2005). Why do parents become involved? Research findings and implications. The elementary school journal, 106(2), 105-130.

Hu, L., \& Bentler, P. M. (1999). Cutoff criteria for fit indexes in covariance structure analysis: Conventional criteria versus new alternatives. Structural Equation Modeling, 6(1), 1-55.

Israel, G. D., Beaulieu, L. J., \& Hartless, G. (2001). The influence of family and community social capital on educational achievement. Rural sociology, 66(1), 43-68.

Jeynes, W. (2012). A meta-analysis of the efficacy of different types of parental involvement programs for urban students. Urban education, 47(4), 706-742.

Jung, E., \& Zhang, Y. (2016). Parental involvement, children's aspirations, and achievement in new immigrant families. The Journal of Educational Research, 109(4), 333-350.

Kao, G. (1995). Asian Americans as model minorities? A look at their academic performance. American journal of Education, 103(2), 121-159.

Kao, G. (2004). Parental influences on the educational outcomes of immigrant youth. International Migration Review, 38(2), 427-449.

Kao, G., \& Rutherford, L. T. (2007). Does Social Capital Still Matter? Immigrant 
Minority Disadvantage in School-Specific Social Capital and its Effects on Academic

Achievement. Sociological Perspectives, 50(1), 27-52.

Kao, G., \& Tienda, M. (1995). Optimism and achievement: The educational performance of immigrant youth. Social science quarterly, 1-19.

Kim, M. (2014). Family background, students' academic self-efficacy, and students' career and life success expectations. International Journal for the Advancement of Counselling, 36(4), 395-407.

Kline, R. B. (2011). Principles and practice of structural equation modeling (3rd ed.). New York, NY: Guilford Press.

Klugman, J., Lee, J. C., \& Nelson, S. L. (2012). School co-ethnicity and Hispanic parental involvement. Social science research, 41(5), 1320-1337.

Kohl, G. O., Lengua, L. J., \& McMahon, R. J. (2000). Parent involvement in school conceptualizing multiple dimensions and their relations with family and demographic risk factors. Journal of school psychology, 38(6), 501-523.

LaRocque, M., Kleiman, I., \& Darling, S. M. (2011). Parental involvement: The missing link in school achievement. Preventing School Failure, 55(3), 115122.

Li, A., \& Fischer, M. J. (2017). Advantaged/disadvantaged school neighborhoods, parental networks, and parental involvement at elementary school. Sociology of Education, 90(4), 355-377.

MacCallum, R. C., Browne, M. W., \& Sugawara, H. M. (1996). Power analysis and determination of sample size for covariance structure modeling. Psychological methods, l(2), 130 .

Mapp, K. L., Johnson, V. R., Strickland, C. S., \& Meza, C. (2008). High school 
family centers: Transformative spaces linking schools and families in support of student learning. Marriage \& Family Review, 43(3-4), 338-368.

McNeal Jr, R. B. (1999). Parental involvement as social capital: Differential effectiveness on science achievement, truancy, and dropping out. Social forces, $78(1), 117-144$.

Milne, A. M., Myers, D. E., Rosenthal, A. S., \& Ginsburg, A. (1986). Single parent, working mothers, and the educational achievement of school children. Sociology of education.

Morgan, S. L., \& Sørensen, A. B. (1999). Parental networks, social closure, and mathematics learning: A test of Coleman's social capital explanation of school effects. American Sociological Review, 661-681.

Muktar, B., Jali, M. R. B. M., \& Razak, N. A. A. (2017). Does family’s Social Capital Affects Parental Involvement in the Schooling of Left-behind Children? Empirical Evidence from Niger State, Nigeria. Journal of Economics, 5(2), $57-67$.

Muller, C., \& Ellison, C. G. (2001). Religious involvement, social capital, and adolescents' academic progress: Evidence from the National Education Longitudinal Study of 1988. Sociological Focus, 34(2), 155-183.

Muthén, L. K., \& Muthén, B. O. (2015). Mplus user's guide. Los Angeles, CA: Muthén \& Muthén.

Myers, S. M., \& Myers, C. B. (2015). Family structure and school-based parental involvement: A family resource perspective. Journal of Family and Economic Issues, 36(1), 114-131.

Nguyen, J. T., You, S., \& Ho, H.-Z. (2009). The process of Asian American parental involvement and its relationship to students' academic achievement. New 
perspectives on Asian American parents and students and teacher recruitment, 25-49.

Oberoi, A. (2016). Mentoring for first-generation immigrant and refugee youth. National Mentoring Resource Center. $<$ http://nationalmentoringresourcecenter. org/images/PDF/ImmigrantRefugeeYouth_Population_Review.pdf.

O'Hare, W. P. (2004). Trends in the well-being of America's children. New York, NY: Russell Sage Foundation.

Orellana, M. F., Dorner, L., \& Pulido, L. (2003). Accessing assets: Immigrant youth's work as family translators or para-phrasers. Social problems, 50(4), 505-524.

Peguero, A. A., \& Bondy, J. M. (2011). Immigration and students' relationship with teachers. Education and Urban Society, 43(2), 165-183.

Perreira, K. M., Chapman, M. V., \& Stein, G. L. (2006). Becoming an American parent: Overcoming challenges and finding strength in a new immigrant Latino community. Journal of Family Issues, 27(10), 1383-1414.

Pew Research Center (2012, June 19). The rise of Asian American. [Report]. https://www.pewresearch.org/social-trends/2012/06/19/the-rise-of-asianamericans/.

Pomerantz, E. M., Moorman, E. A., \& Litwack, S. D. (2007). The how, whom, and why of parents' involvement in children's academic lives: More is not always better. Review of educational research, 77(3), 373-410.

Pong, S.1. (1998). The school compositional effect of single parenthood on 10th-grade achievement. Sociology of education, 23-42. 
Portes, A., \& Fernández-Kelly, P. (2008). No margin for error: Educational and occupational achievement among disadvantaged children of immigrants. The annals of the American academy of political and social science, 620(1), 12-36.

Portes, A., \& Hao, L. (1998). E pluribus unum: Bilingualism and loss of language in the second generation. Sociology of education, 269-294.

Portes, A., \& Rumbaut, R.G. (2001). Legacies: The story of the immigrant second generation. Berkeley and Los Angeles, CA: University of California Press.

Plunkett, S. W., \& Bamaca-Gomez, M. Y. (2003). The relationship between parenting, acculturation, and adolescent academics in Mexican-origin immigrant families in Los Angeles. Hispanic Journal of Behavioral Sciences, 25(2), 222-239.

Putnam, R. D. (2000). Bowling Alone. New York: Simon \& Schuster.

Pribesh, S., \& Downey, D. B. (1999). Why are residential and school moves associated with poor school performance? Demography, 36(4), 521-534.

Raleigh, E., \& Kao, G. (2010). Do immigrant minority parents have more consistent college aspirations for their children? Social science quarterly, 91(4), 10831102.

Rampton, M. B. H. (1990). Displacing the "native speaker": Expertise, affiliation and inheritance. ELT Journal, 44, 338-343.

Raykov, T., \& Marcoulides, G. A. (2006). On multilevel model reliability estimation from the perspective of structural equation modeling. Structural Equation Modeling, 13(1), 130-141.

Ream, R. K., \& Palardy, G. J. (2008). Reexamining social class differences in the availability and the educational utility of parental social capital. American Educational Research Journal, 45(2), 238-273. 
Reynolds, A. J., \& Shalfer, R. J. (2010). Parent involvement in early education Handbook of school-family partnerships (pp. 176-192): Routledge.

Rong, X., \& Preissle, J. (2008). Educating immigrant students in the 21st century: What we need to know to meet the challenges. Thousand Oaks, CA: Corwin Press.

Rosenbaum, E., \& Rochford, J. A. (2008). Generational patterns in academic performance:The variable effects of attitudes and social capital. Social Science Research, 37(1),350-372.

Ruiz-de-Velasco, J., Fix, M., \& Clewell, B. C. (2000). Overlooked\& Underserved. Immigrant students in US secondary schools. Washington, DC: Urban Institute.

Rumbaut, R. G., Massey, D. S., \& Bean, F. D. (2006). Linguistic life expectancies: Immigrant language retention in Southern California. Population and development review, 447-460.

Schreiber, J. B., Nora, A., Stage, F. K., Barlow, E. A., \& King, J. (2006). Reporting structural equation modeling and confirmatory factor analysis results: A review. The Journal of educational research, 99(6), 323-338.

Schneider, B. Carnoy, M. Kilpatrick, J., Schmidt, W.H. and Shavelson, R.J. (2007). Estimating causal effects using experimental designs and observational designs. Washington D.C. American Education Research Association.

Schumacker, R. E., \& Lomax, R. G. (2004). A beginner's guide to structural equation modeling. psychology press.

Seginer, R. (2006). Parents' educational involvement: A developmental ecology perspective. Parenting: Science and practice, 6(1), 1-48.

Shin, H. (2009). Parental involvement of Asian American immigrant mothers: 
Investigating social capital, English proficiency, length of U.S. esidency, and social class. Unpublished doctoral dissertation, University of Maryland, College Park.

Shumow, L., \& Lyutykh, E. (2014). Looking at Literacy from the Family-School Frame of Reference. Language-Based Approaches to Support Reading Comprehension, 67.

Sibley, E., \& Dearing, E. (2014). Family educational involvement and child achievement in early elementary school for American-born and immigrant families. Psychology in the Schools, 51(8), 814-831.

Singh, K., Bickley, P. G., Trivette, P., \& Keith, T. Z. (1995). The effects of four components of parental involvement on eighth-grade student achievement: Structural analysis of NELS-88 data. School psychology review.

Smith, M. H., Beaulieu, L. J., \& Israel, G. D. (1992). Effects of human capital and social capital on dropping out of high school in the South. Journal of Research in Rural Education, 8(1), 75-87.

Spring, J. (2013). The American school, a global context: From the Puritans to the Obama administration: McGraw-Hill Higher Education.

Suárez-Orozco, C., \& Suárez-Orozco, M. M. (2009). Children of immigration. Cambridge, MA: Harvard University Press.

Suárez-Orozco, C. (2011). Understanding diverse immigrant students'trajectories in american schools1. Canadian Issues, 78.

Suárez-Orozco, C., \& Suárez-Orozco, M. M. (1995). Transformations: Immigration, family life, and achievement motivation among Latino adolescents. Stanford University Press. 
Suárez-Orozco, C., Suárez-Orozco, M. M., \& Todorova, I. (2009). Learning a new land. Cambridge, MA: Harvard University Press.

Sui-Chu, E. H., \& Willms, J. D. (1996). Effects of parental involvement on eighthgrade achievement. Sociology of education, 126-141.

Sun, Y. (1999). The contextual effects of community social capital on academic performance. Social Science Research, 28(4), 403-426.

Sy, S. R., Rowley, S. J., \& Schulenberg, J. E. (2007). Predictors of parent involvement across contexts in Asian American and European American families. Journal of Comparative Family Studies, 38(1), 1a-28.

Sy, S. R., \& Schulenberg, J. E. (2005). Parent beliefs and children's achievement trajectories during the transition to school in Asian American and European American families. International Journal of Behavioral Development, 29(6), $505-515$.

Tang, S. (2015). Social capital and determinants of immigrant family educational involvement. The Journal of Educational Research, 108(1), 22-34.

Teachman, J. D., Paasch, K., \& Carver, K. (1996). Social capital and dropping out of school early. Journal of Marriage and the Family, 773-783.

Toppelberg, C. O., \& Collins, B. A. (2010). Language, culture, and adaptation in immigrant children. Child and Adolescent Psychiatric Clinics, 19(4), 697-717.

Trevelyan, E. N., Gambino, C., Gryn, T., Larsen, L., Acosta, Y., Grieco, E. M., ... \& Walter, N. (2016). Characteristics of the US Population by Generational Status, 2013. US Department of Commerce, Economic and Statistics Administration, US Census Bureau.

Trueba, E. T. (1999). Latinos unidos: From cultural diversity to the politics of solidarity. Rowman \& Littlefield. 
Turney, K., \& Kao, G. (2009). Barriers to school involvement: Are immigrant parents disadvantaged? The Journal of Educational Research, 102(4), 257-271.

U.S. Department of Education 2017. "Newcomer Toolkit Retrieved" Accessed 29 Marc2021.https://www2.ed.gov/about/offices/list/oela/newcomerstoolkit/ncomertoolkit.pdf

Von Otter, C., \& Stenberg, S. Å. (2015). Social capital, human capital and parentchild relation quality: interacting for children's educational achievement?. British Journal of Sociology of Education, 36(7), 996-1016.

Walsh, P. (2010). Is parental involvement lower at larger schools?. Economics of education review, 29(6), 959-970.

Wang, J., \& Wang, X. (2019). Structural equation modeling: Applications using Mplus. John Wiley \& Sons.

Watkins, A. M., \& Melde, C. (2010). Latino and Asian students' perceptions of the quality of their educators: The role of generational status and language proficiency. Youth \& Society, 42(1), 3-32.

Wei, J., Pomerantz, E. M., Ng, F. F. Y., Yu, Y., Wang, M., \& Wang, Q. (2019). Why does parents' involvement in youth's learning vary across elementary, middle, and high school?. Contemporary Educational Psychology, 56, 262-274.

Weinstein, R. S. (2002). Reaching higher: The power of expectations in schooling. Cambridge, MA: Harvard university Press.

Wilder, S. (2014). Effects of parental involvement on academic achievement: A metasynthesis. Educational Review, 66(3), 377-397.

$\mathrm{Xu}$, J. (2004). Family help and homework management in urban and rural secondary schools. Teachers College Record, 106(9), 1786-1803. 
Yan, W. (1999). Successful African American students: The role of parental involvement. Journal of Negro Education, 5-22.

Yu, S. M., \& Singh, G. K. (2012). High parenting aggravation among US immigrant families. American Journal of Public Health, 102(11), 2102-2108.

Zhou, M. (1997). Growing up American: The challenge confronting immigrant children and children of immigrants. Annual review of sociology, 23(1), 63-95.

Zhou, M., \& Bankston, C. (1998). Growing up American: How Vietnamese children adapt to life in the United States: Russell Sage Foundation.

Zong, J., Batalova, J., \& Hallock, J. (2015). Frequently requested statistics on immigrants and immigration in the United States. Migration Policy Institute, 26, 1-18. 


\section{VITA}

Jinmyung Choi is a doctoral candidate in Educational Leadership and Policy Analysis at the University of Missouri-Columbia. She completed a bachelor's degree in psychology at Chung-Ang University, and a master's degree in area studies at Yonsei University, Seoul, South Korea. Her research interests focus on educational policy for immigrant students, immigrant family engagement, language issues such as educational policy for English language learners (ELL) and bilingual language programs. 